\title{
The Wide-Area Energy Storage and Management System - Battery Storage Evaluation
}

\author{
$\mathrm{NLu}$ \\ MR Weimar \\ YV Makarov \\ $\mathrm{J} \mathrm{Ma}$ \\ VV Viswanathan
}

July 2009

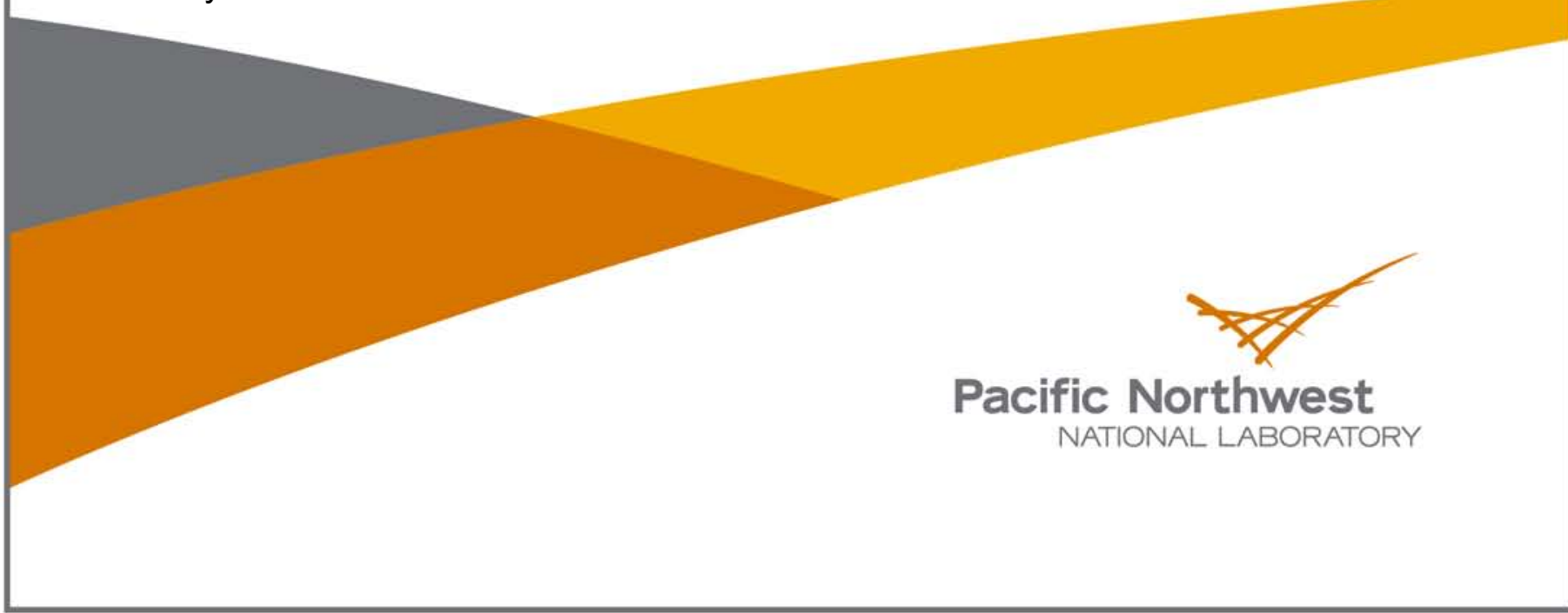





\title{
DISCLAIMER
}

United States Government. Neither the United States Government nor any agency thereof, nor Battelle Memorial Institute, nor any of their employees, makes any warranty, express or implied, or assumes any legal liability or responsibility for the accuracy, completeness, or usefulness of any information, apparatus, product, or process disclosed, or represents that its use would not infringe privately owned rights. Reference herein to any specific commercial product, process, or service by trade name, trademark, manufacturer, or otherwise does not necessarily constitute or imply its endorsement, recommendation, or favoring by the United States Government or any agency thereof, or Battelle Memorial Institute. The views and opinions of authors expressed herein do not necessarily state or reflect those of the United States Government or any agency thereof.

\author{
PACIFIC NORTHWEST NATIONAL LABORATORY \\ operated by \\ BATTELLE \\ for the \\ UNITED STATES DEPARTMENT OF ENERGY \\ under Contract DE-AC05-76RL01830 \\ Printed in the United States of America \\ Available to DOE and DOE contractors from the \\ Office of Scientific and Technical Information, \\ P.O. Box 62, Oak Ridge, TN 37831-0062; \\ ph: (865) 576-8401, fax: (865) 576-5728 \\ email: reports@adonis.osti.gov \\ Available to the public from the National Technical Information Service, \\ U.S. Department of Commerce, 5285 Port Royal Rd., Springfield, VA 22161 \\ ph: (800) 553-6847, fax: (703) 605-6900 \\ email: orders@ntis.fedworld.gov \\ online ordering: http://www.ntis.gov/ordering.htm
}

This document was printed on recycled paper.

$(8 / 00)$ 

PNNL-18679

\section{The Wide-Area Energy Storage and Management System - Battery Storage Evaluation}

N Lu, Ph.D.: Senior Engineer, Project Manager MR Weimar, Ph.D.: Chief Economist, Task Lead YV Makarov, Ph.D.: Chief Scientist - Power Systems, Principal Investigator J Ma, Ph.D.: Research Engineer

VV Viswanathan, Ph.D., Senior Research Engineer

July 2009

Prepared for California Institute for Energy and Environment and the California Energy Commission under Contract DE-AC05-76RL01830 Related Services

Pacific Northwest National Laboratory

Richland, Washington 99352 



\section{Abstract}

This report presents the modeling a pproach, methodologies, and results of the sodium sulfur (NaS) battery e valuation s tudy, which w as c onducted by the Pacific N orthwest N ational L aboratory (PNNL) operated for the U.S. department of Energy by Battelle Memorial Institute for the California Institute for Energy and Environment (CIEE) and California Energy Commission (CEC).

The goal of this research is to investigate technical characteristics and economics of the NaS battery energy st orage us ed for regulation and real-time di spatch (also called load following) ser vices in the electricity market operated by the California Independent System Operator (CAISO). This report is part of the deliverables for Phase II of the Wide Area Energy Storage and Management System (WAEMS) project.

The tasks addressed in Phase II are as follow:

- Study the value of the ancillary services that can be provided by the NaS battery for the following two wind energy penetration scenarios: (1) a hypothetical scenario without wind energy resource and (2) a scenario with $20 \%$ of CAISO's energy supply being provided by renewable resources including the wind energy resource. Scenario (1) was analyzed to compare the i ncremental effects of wind power production.

- Evaluate technical and economical characteristics of the $\mathrm{NaS}$ battery when it is used to provide regulation and real-time dispatch services.

- Consider di fferent op erational $\mathrm{c}$ onditions, $\mathrm{f}$ ind limitations, a nd recommend a dditional opportunities for the $\mathrm{NaS}$ battery arising in the California energy market.

- Suggest de sign improvements for the following $\mathrm{NaS}$ battery phy sical characteristics helping to increase the value and expand market opportunities in California: energy capacity, power output, and lifetime.

The results and conclusions of the study are summarized as follows:

- If an NaS battery is operated for 20 years at its rated output $4 \mathrm{MW}$, operating it at a lower depth of discharge (DOD) results in less cost with the now lifecycle-DOD curve. If manufacturers can improve the NaS battery lifecycles at high DODs, the breakeven prices will drop significantly for high DOD cases.

- Under the pay-by-energy scheme for regulation and real-time dispatch services, for a $4 \mathrm{MW}, 28$ MWh NaS b attery to p rovide regulation and real-time di spatch services, breakeven prices are above 100 \$MWh, making the operation not economical in the California market.

- Under the pay-by-capacity scheme for r egulation services, the battery has a 1 onger 1 ife and a lower cost when it runs at lower DOD. With current technology, the battery rated power output is $4 \mathrm{MW}$. The results indicate that if the $4 \mathrm{MW}$ battery provides one-directional regulation service, the high-end cost will be $26 \$ / \mathrm{MW}$ a nd the low-end cost will be $16 \$ / \mathrm{MW}$. In the California market, this means the $\mathrm{NaS}$ battery may become marginally profitable.

- If the battery rated power can be increased, the breakeven price will drop significantly because the battery is able to handle a broader range of signals. However, after $12 \mathrm{MW}$, the price drop is not significant, but the battery life is shortened dramatically. Therefore, based on the current 
lifecycle-DOD curve, it is beneficial for the battery manufacturer to increase the battery rated power output up to 8 or $12 \mathrm{MW}$, which will result in a breakeven price drop of $1 / 2$ to $1 / 3$.

- At higher-rated power, there is a tradeoff between the DOD and battery life. At $4 \mathrm{MW}$, the DOD does not result in a shortened battery life because the 28 MWh NaS battery is underused when providing the regulation. At $20 \mathrm{MW}$, however, the battery lives are significantly shorter at higher DODs.

- The NaS battery provides almost the same amount of regulation or real-time dispatch services for the "with $20 \%$ renewables" and "without wind" cases. Thus, the breakeven prices were similar. More batteries contribute greater ancillary service capacity and therefore, allow more intermittent generation resources to connect to the power grid. However, the amount of regulation and realtime dispatch services that an individual battery provides depends mainly on its power rating. For the "with $20 \%$ r enewables" and "without wind" cas es, signals sent to the NaS battery are all within its rated power output $\pm 4 \mathrm{MW}$. For example, although $193 \mathrm{MW}$ are needed for regulation without wind, and $248 \mathrm{MW}$ are needed for regulation with $20 \%$ renewable, for the $4 \mathrm{M} \mathrm{W} \mathrm{NaS}$ battery, it provides s ervices within $\pm 4 \mathrm{MW}$ in both cases; therefore, the a mounts of e nergy provided in both cases are similar.

- The NaS battery provides economical and reliable regulation and real-time dispatch services if it responds to a one-directional signal with small variations and close to the battery $r$ ated power output. For r egulation signals ou tside the ba ttery's capability, it is r ecommended that st orage devices with high power outputs but less energy storage capacity such as flywheels provide the regulation service. 


\section{Executive Summary}

This report presents the modeling a pproach, methodologies, and results of the sodium sulfur (NaS) battery e valuation s tudy, which w as c onducted by the Pacific N orthwest N ational L aboratory (PNNL) operated for the U.S. department of Energy by Battelle Memorial Institute for the California Institute for Energy and Environment (CIEE) and California Energy Commission (CEC).

\section{Background}

California has set the goal of reaching 20\% renewable energy by 2012. Moving quickly towards this goal, $\mathrm{t}$ he $\mathrm{C}$ alifornia I ndependent $\mathrm{S}$ ystem $\mathrm{O}$ perator ( CAISO) ne eds $\mathrm{t} \mathrm{o}$ find $\mathrm{w}$ ays $\mathrm{t} \mathrm{o}$ mitigate $\mathrm{t}$ he intermittence and fast-ramp that occurs at higher penetration levels of intermittent resources, the majority of w hich a re w ind and s olar pow er. P umped-hydro pow er pl ants, ba tteries, f lywheels, distributed generation resources, and de mand side $\mathrm{m}$ anagement are $\mathrm{f}$ lexible ene rgy st orage opt ions that cou ld potentially prov ide $t$ he ne eded fast $r$ esponsive anc illary ser vice $r$ esources. Pacific $G$ as and Electric (PG\&E) is planning to build a $4 \mathrm{MW}, 28 \mathrm{MWh}$ NaS battery storage. To evaluate operational, market, and regulatory opportunities and limitations concerning the use of the PG\&E Battery Storage Facility, PNNL proposed this research to CIEE and CEC.

Ford M otor Company pioneered the NaS battery in the 1960s to pow er e arly-model el ectric ca rs; NGK and Tokyo Electric refined it for the power grid. The benefits of the NaS battery are its high energy density, efficiency, and long-term durability [1][2]. For example, its energy density is approximately three times larger than lead-acid batteries. Furthermore, the battery can be charged and discharged over periods of 7 hours or stored indefinitely if the temperature is maintained at 600 degrees Fahrenheit. The cycle life of $\mathrm{NaS}$ batteries is based on depth of discharge and environmental factors. However, when a battery is providing regulation or real-time dispatch services, the battery capacity may not be fully used, resulting in a low ut ilization factor. Whether or not the services are eco nomical is unk nown. We expect that this research will lay a solid foundation for an extensive energy storage evaluation study, which will include the economics of all energy storage options for both the energy and ancillary services.

\section{Objectives}

The goal of this research is to investigate technical characteristics and economics of the NaS battery energy st orage us ed for regulation and real-time di spatch (also called load following) ser vices in the electricity market operated by the California Independent System Operator (CAISO). This report is part of the deliverables for Phase II of the Wide Area Energy Storage and Management System (WAEMS) project.

The tasks addressed in Phase I are as follow:

- Evaluate and compare av ailable energy st orage options. Review the w orld experience. Identify the top three technologies that can meet the needs of this project.

- Design and evaluate con figurations and integration schemes of the en ergy st orage, generation resources, their combinations, and other options. Identify the most promising configurations and their benefits. 
- Analyze the technical and market c ompatibility of the proposed integration s chemes with the existing regulation and load following systems at Bonneville Power Administration (BPA) and CAISO.

- Collect data needed for experiments at BPA and CAISO.

- Develop algorithms $\mathrm{f}$ or the en ergy $\mathrm{s}$ torage a nd generation $\mathrm{c}$ ontrol. I mplement $\mathrm{t}$ hem a $\mathrm{s}$ MATLAB ${ }^{\mathrm{TM}}$ codes.

- Conduct experiments using the MATLAB ${ }^{\mathrm{TM}}$ model and collected data.

- Carry out the cost benefit analyses based on simulation results.

- Provide a summary of results and recommendations for possible continuation of the project.

The tasks addressed in Phase II are as follow:

- Study the value of the ancillary services that can be provided by the NaS battery for the following two wind energy penetration scenarios: (1) a hypothetical scenario without wind energy resource and (2) a scenario with $20 \%$ of CAISO's energy supply being provided by renewable resources including the wind energy $r$ esource. Scenario (1) was analyzed to compare the i ncremental effects of wind power production.

- Evaluate technical and economical characteristics of the $\mathrm{NaS}$ battery when it is us ed to provide regulation and real-time dispatch services.

- Consider di fferent op erational conditions, $f$ ind limitations, a nd recommend additional opportunities for the $\mathrm{NaS}$ battery arising in the California energy market.

- Suggest de sign improvements for the following $\mathrm{NaS}$ battery phy sical characteristics helping to increase the value and expand market opportunities in California: energy capacity, power output, and lifetime.

\section{Approach}

The modeling framework is shown in Figure 1. The regulation and real-time dispatch signals were simulated us ing $2006 \mathrm{C}$ AISO hi storical da ta s ets. The ba ttery model w as developed based on battery depth of discharge characteristics. The methodology us ed in P hase I of this project was improved by considering the physical characteristics of the $\mathrm{NaS}$ battery storage so that the number of battery lifecycles and annual energy provided are realistic. The battery performance was simulated by feeding the simulated minute-to-minute $r$ egulation a nd real-time di spatch signals i nto t he ba ttery model. To ev aluate $t$ he efficacy of the $\mathrm{NaS}$ ba ttery s torage i $\mathrm{n} \mathrm{m}$ itigating the i ntermittence br ought by the higher levels of penetration of renewable energy, a scenario was studied with $20 \%$ of the CAISO load being supplied by renewable energy resources including wind generation, and compared it against a scenario with zero wind generation.

To provide regulation or real-time dispatch service, an $\mathrm{NaS}$ battery can run at either the bi-directional or one -directional m ode. I $\mathrm{n}$ he b i-directional m ode, the ba ttery $\mathrm{r}$ esponds to both " up" a nd " down" signals. In the one-directional mode, the battery responds to the "up" signal when it is discharging and the "down" signal when charging. The one-directional operation scheme was selected and modeled in detail in this study because the one-directional operation allows the NaS battery to have a longer service life and is easier to implement compared to bi-directional operation schemes. 
In the benefit study, the economics of the four services in terms of breakeven ${ }^{1}$ costs were evaluated and compared for different device performance characteristics and operation mechanisms to find the best options. Net present value (NPV) ${ }^{2}$ was not calculated because the service's breakeven costs were not low enough to provide a positive N PV g iven a ssumed CAISO market pr ices for regulation a nd r eal-time dispatch services. There were two sets of breakeven prices considered: the high-end cost and the low-end cost. The high-end cost was obtained by applying pessimistic estimations of input variables, and the lowend cost was obtained by applying the optimistic ones.

Two payment methods were studied for the regulation service: pay-by-capacity and pay-by-energy ${ }^{3}$. For the real-time dispatch service, only the pay-by-energy method was considered.

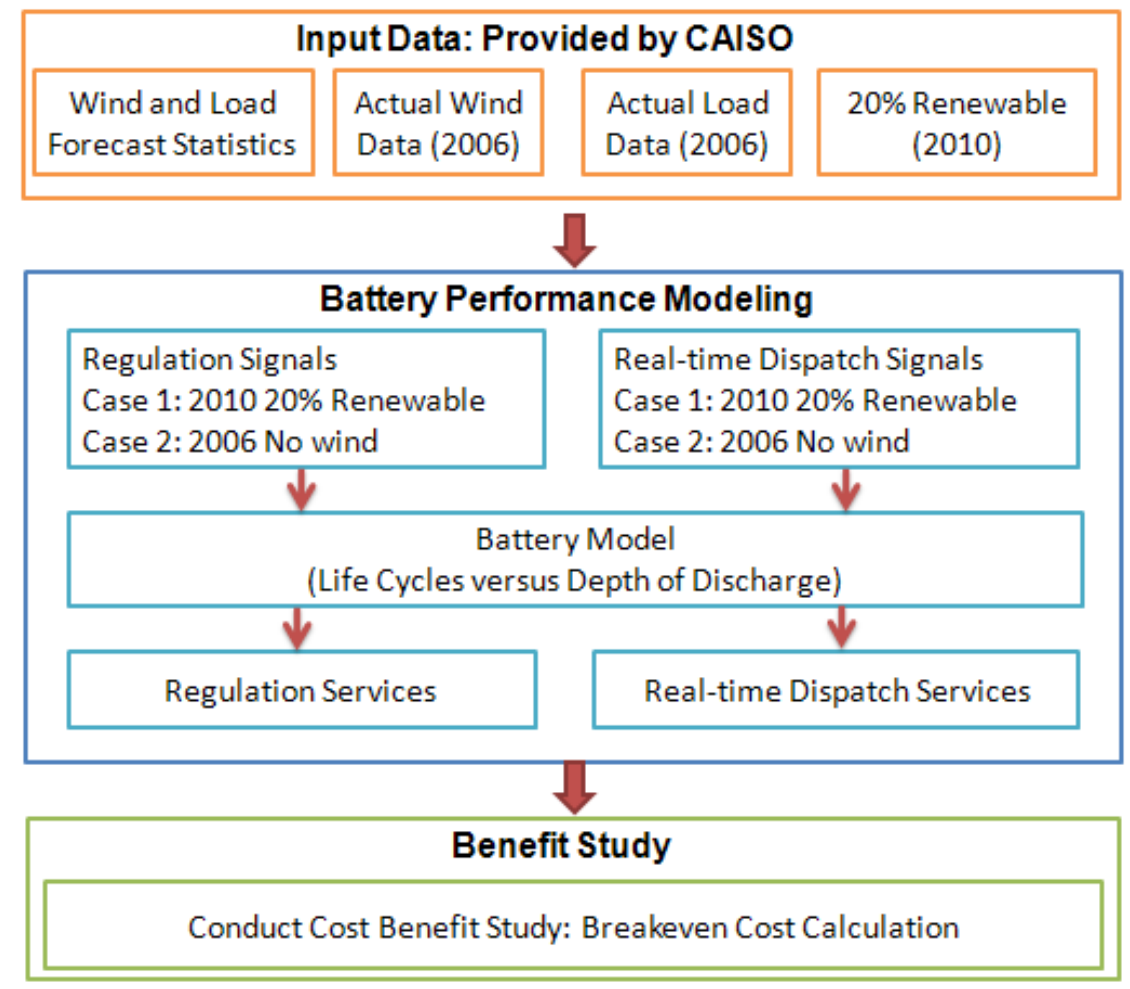

Figure 1: The modeling framework

\section{Results and Conclusions}

The modeling $\mathrm{r}$ esults a re summarized in Table 1 to Table 3 , which a re $\mathrm{c}$ olor $\mathrm{s}$ caled $\mathrm{f}$ or be tter visualization. The greener the color, the better the value. The results and conclusions of the study a re summarized as follows:

- Improved lifecycles: If an Na S battery is ope rated for 20 y ears at its $r$ ated out put, $4 \mathrm{M} \mathrm{W}$, operating it at a lower depth of discharge (DOD) results in less cost with the current lifecycle-

\footnotetext{
${ }^{1}$ The break-even [3] point for a product is the point where total revenue received equals the total costs associated with the sale of the product.

${ }^{2}$ Net present value (NPV) or net present worth (NPW) [4] is defined as the total present value (PV) of a time series of revenues - costs.

${ }^{3}$ Pay-by-capacity means that a unit is paid by the capacity that it bids into the market regardless of the actual energy that it provides to the grid. Pay-by-energy means that a unit is paid by the actual energy that it provides to the grid.
} 
DOD curve, as shown by the blue line in Figure 2. However, if manufacturers can improve the $\mathrm{NaS}$ ba ttery's number of lifecycles at high DODs, as shown by the $r$ ed $l$ ine in Figure 2, the breakeven prices will drop significantly for high DOD cases. The results are compared in Figure 3 and Table 1.

- As s hown in Table 2, unde $\mathrm{r}$ the pay-by-energy scheme for $\mathrm{r}$ egulation and real-time di spatch services, for a $4 \mathrm{MW}, 28 \mathrm{MWh} \mathrm{NaS}$ battery to provide regulation and real-time dispatch services, breakeven prices a re above $\$ 100 / \mathrm{MWh}$, making the operation not e conomical in the California market.

- As shown in Table 3, under the pay-by-capacity scheme for regulation services, the battery has a longer life and a lower cost when it runs at lower DOD. W ith current technology, the battery rated power output is $4 \mathrm{M} \mathrm{W}$. T he $\mathrm{r}$ esults i ndicate that i $\mathrm{ft}$ he $4 \mathrm{MW}$ battery provides on edirectional regulation service, the high-end cost will be $\$ 26 / \mathrm{MW}$ and the low-end cost will be $\$ 16 / \mathrm{MW}$. In the California market, this means the NaS battery may become marginally profitable.

Table 1: The breakeven prices of two lifecycle-DOD curves

\begin{tabular}{|c|c|c|c|c|c|c|}
\hline \multicolumn{3}{|c|}{$\begin{array}{l}\text { Base Case } \\
\text { With current technology }\end{array}$} & \multicolumn{2}{|c|}{$\begin{array}{l}\text { High End Breakeven Price } \\
\text { (\$/MWh) }\end{array}$} & \multicolumn{2}{|c|}{$\begin{array}{l}\text { Low End Breakeven } \\
\text { Price (\$/MWh) }\end{array}$} \\
\hline Life & DOD & Life (cycle) & 0\% Profit & 8\% Profit & 0\% Profit & 7\% Profit \\
\hline 20 & $5 \%$ & 379208 & 15.22 & 23.12 & 7.61 & 11.84 \\
\hline 20 & $10 \%$ & 125092 & 23.08 & 35.04 & 11.54 & 17.94 \\
\hline 20 & $20 \%$ & 41265 & 34.98 & 53.11 & 17.49 & 27.19 \\
\hline 20 & $30 \%$ & 21569 & 44.61 & 67.74 & 22.31 & 34.68 \\
\hline 20 & $40 \%$ & 13612 & 53.02 & 80.51 & 26.51 & 41.22 \\
\hline 20 & $50 \%$ & 9525 & 60.61 & 92.04 & 30.31 & 47.12 \\
\hline 20 & $60 \%$ & 7115 & 67.62 & 102.68 & 33.81 & 52.57 \\
\hline 20 & $70 \%$ & 5560 & 74.17 & 112.63 & 37.08 & 57.66 \\
\hline 20 & $80 \%$ & 4490 & 80.36 & 122.03 & 40.18 & 62.48 \\
\hline 20 & $90 \%$ & 3719 & 86.24 & 130.96 & 43.12 & 67.05 \\
\hline 20 & $100 \%$ & 3142 & 91.87 & 139.51 & 45.94 & 71.43 \\
\hline \multicolumn{3}{|c|}{$\begin{array}{l}\text { Technology Improvement } \\
\text { Prolonged Lifecycles at Higher DODs }\end{array}$} & \multicolumn{2}{|c|}{$\begin{array}{l}\text { High End Breakeven Price } \\
\text { (\$/MWh) }\end{array}$} & \multicolumn{2}{|c|}{$\begin{array}{l}\text { Low End Breakeven } \\
\text { Price (\$/MWh) }\end{array}$} \\
\hline Life & DOD & Life (cycle) & 0\% Profit & 8\% Profit & 0\% Profit & 7\% Profit \\
\hline 20 & $5 \%$ & 379208 & 15.22 & 23.12 & 7.61 & 11.84 \\
\hline 20 & $10 \%$ & 125092 & 23.08 & 35.04 & 11.54 & 17.94 \\
\hline 20 & $20 \%$ & 53645 & 26.91 & 40.86 & 13.45 & 20.92 \\
\hline 20 & $30 \%$ & 32354 & 29.74 & 45.16 & 14.87 & 23.12 \\
\hline 20 & $40 \%$ & 27224 & 26.51 & 40.25 & 13.25 & 20.61 \\
\hline 20 & $50 \%$ & 23813 & 24.24 & 36.82 & 12.12 & 18.85 \\
\hline 20 & $60 \%$ & 21345 & 22.54 & 34.23 & 11.27 & 17.52 \\
\hline 20 & $70 \%$ & 19460 & 21.19 & 32.18 & 10.60 & 16.48 \\
\hline 20 & $80 \%$ & 17960 & 20.09 & 30.51 & 10.05 & 15.62 \\
\hline 20 & $90 \%$ & 16736 & 19.17 & 29.10 & 9.58 & 14.90 \\
\hline 20 & $100 \%$ & 15710 & 18.37 & 27.90 & 9.19 & 14.29 \\
\hline
\end{tabular}


Table 2: The breakeven prices, utilization rates, and battery lifetimes (Pay-by-energy)

\begin{tabular}{|c|c|c|c|c|c|c|c|c|c|c|c|c|c|c|c|c|}
\hline \multicolumn{7}{|c|}{ Breakeven Price (8\% Profit) (\$MWh) } & \multirow{2}{*}{\multicolumn{5}{|c|}{$\begin{array}{c}\text { Utilization Rate }\left(\mathrm{P}_{\text {ave }} / \mathrm{P}_{\text {rated }}\right) \\
\text { DOD }\end{array}$}} & \multicolumn{5}{|c|}{ Adjusted LifeTime (Year) } \\
\hline & \multirow{2}{*}{$\begin{array}{l}\mathbf{P}_{\text {rated }} \\
\text { (MW) }\end{array}$} & \multicolumn{5}{|c|}{ DOD } & & & & & & \multicolumn{5}{|c|}{ DOD } \\
\hline & & 1 & 0.8 & 0.6 & 0.4 & 0.2 & 1 & 0.8 & 0.6 & 0.4 & 0.2 & 1 & 0.8 & 0.6 & 0.4 & 0.2 \\
\hline \multirow{5}{*}{$\begin{array}{l}\text { Regulation } \\
20 \% \\
\text { Renewables }\end{array}$} & 4 & 197 & 206 & 204 & 198 & 238 & 0.18 & 0.17 & 0.17 & 0.18 & 0.15 & 20 & 20 & 20 & 20 & 20 \\
\hline & 8 & 112 & 106 & 103 & 119 & 124 & 0.18 & 0.18 & 0.17 & 0.15 & 0.14 & 14 & 16 & 20 & 20 & 20 \\
\hline & 12 & 89 & 89 & 86 & 80 & 87 & 0.18 & 0.16 & 0.15 & 0.15 & 0.13 & 10 & 12 & 15 & 20 & 20 \\
\hline & 16 & 84 & 79 & 73 & 67 & 68 & 0.15 & 0.15 & 0.15 & 0.14 & 0.13 & 8 & 10 & 12 & 15 & 20 \\
\hline & 20 & 77 & 71 & 65 & 60 & 57 & 0.15 & 0.15 & 0.15 & 0.14 & 0.12 & 7 & 8 & 9 & 13 & 20 \\
\hline \multirow{5}{*}{$\begin{array}{c}\text { Real-time } \\
\text { Dispatch } \\
\\
20 \% \\
\text { Renewables }\end{array}$} & 4 & 164 & 169 & 183 & 203 & 270 & 0.15 & 0.15 & 0.14 & 0.12 & 0.09 & 20 & 20 & 20 & 20 & 20 \\
\hline & 8 & 97 & 101 & 114 & 135 & 189 & 0.13 & 0.12 & 0.11 & 0.09 & 0.07 & 19 & 20 & 20 & 20 & 20 \\
\hline & 12 & 82 & 83 & 90 & 108 & 148 & 0.11 & 0.10 & 0.09 & 0.08 & 0.06 & 15 & 19 & 20 & 20 & 20 \\
\hline & 16 & 74 & 73 & 77 & 95 & 125 & 0.10 & 0.09 & 0.08 & 0.07 & 0.05 & 13 & 16 & 20 & 20 & 20 \\
\hline & 20 & 68 & 68 & 70 & 83 & 110 & 0.09 & 0.08 & 0.07 & 0.06 & 0.05 & 11 & 14 & 19 & 20 & 20 \\
\hline \multirow{5}{*}{$\begin{array}{l}\text { Regulation } \\
\text { No-wind }\end{array}$} & 4 & 135 & 137 & 137 & 135 & 144 & 0.18 & 0.18 & 0.18 & 0.18 & 0.17 & 20 & 20 & 20 & 20 & 20 \\
\hline & 8 & 77 & 73 & 71 & 72 & 79 & 0.18 & 0.18 & 0.18 & 0.17 & 0.16 & 14 & 16 & 19 & 20 & 20 \\
\hline & 12 & 63 & 60 & 55 & 52 & 55 & 0.18 & 0.17 & 0.17 & 0.16 & 0.15 & 9 & 11 & 13 & 18 & 20 \\
\hline & 16 & 56 & 52 & 48 & 45 & 43 & 0.17 & 0.17 & 0.17 & 0.16 & 0.14 & 7 & 8 & 10 & 14 & 20 \\
\hline & 20 & 52 & 48 & 44 & 40 & 37 & 0.17 & 0.17 & 0.16 & 0.16 & 0.14 & 6 & 7 & 8 & 11 & 19 \\
\hline \multirow{5}{*}{$\begin{array}{l}\text { Real-time } \\
\text { Dispatch } \\
\text { No-wind }\end{array}$} & 4 & 177 & 179 & 201 & 229 & 303 & 0.14 & 0.14 & 0.12 & 0.11 & 0.08 & 20 & 20 & 20 & 20 & 20 \\
\hline & 8 & 108 & 115 & 128 & 151 & 219 & 0.12 & 0.11 & 0.10 & 0.08 & 0.06 & 20 & 20 & 20 & 20 & 20 \\
\hline & 12 & 86 & 90 & 101 & 121 & 172 & 0.10 & 0.09 & 0.08 & 0.07 & 0.05 & 16 & 20 & 20 & 20 & 20 \\
\hline & 16 & 77 & 79 & 87 & 109 & 147 & 0.09 & 0.08 & 0.07 & 0.06 & 0.04 & 14 & 17 & 20 & 20 & 20 \\
\hline & 20 & 72 & 74 & 78 & 96 & 129 & 0.08 & 0.07 & 0.06 & 0.05 & 0.04 & 12 & 16 & 20 & 20 & 20 \\
\hline
\end{tabular}


Table 3: The breakeven price comparison between pay-by-energy and pay-by-capacity

\begin{tabular}{|c|c|c|c|c|c|c|c|c|c|c|c|c|c|c|c|c|}
\hline & & \multirow{2}{*}{\multicolumn{5}{|c|}{$\begin{array}{l}\text { High-end Pay-by-Capacity } \\
\text { (\$/MW) } \\
\text { DOD }\end{array}$}} & \multirow{2}{*}{\multicolumn{5}{|c|}{$\begin{array}{l}\text { Low-end Pay-by-Capacity } \\
\text { (\$/MW) } \\
\text { DOD }\end{array}$}} & \multicolumn{5}{|c|}{ Adjusted Life Time (Year) } \\
\hline & \multirow{2}{*}{$\begin{array}{c}\mathbf{P}_{\text {rated }} \\
(\mathrm{MW}) \\
\end{array}$} & & & & & & & & & & & & & DOD & & \\
\hline & & 1 & 0.8 & 0.6 & 0.4 & 0.2 & 1 & 0.8 & 0.6 & 0.4 & 0.2 & 1 & 0.8 & 0.6 & 0.4 & 0.2 \\
\hline \multirow[t]{2}{*}{ Regulation } & 4 & 26 & 26 & 26 & 26 & 26 & 16 & 16 & 16 & 16 & 16 & 20 & 20 & 20 & 20 & 20 \\
\hline & 8 & 15 & 14 & 13 & 13 & 13 & 9 & 9 & 8 & 8 & 8 & 14 & 16 & 20 & 20 & 20 \\
\hline \multirow{3}{*}{$\begin{array}{c}20 \% \\
\text { Renew ables }\end{array}$} & 12 & 12 & 10 & 10 & 9 & 9 & 8 & 7 & 6 & 5 & 5 & 10 & 12 & 15 & 20 & 20 \\
\hline & 16 & 10 & 9 & 8 & 7 & 7 & 6 & 6 & 5 & 4 & 4 & 8 & 10 & 12 & 15 & 20 \\
\hline & 20 & 9 & 8 & 7 & 6 & 5 & 6 & 5 & 5 & 4 & 3 & 7 & 8 & 9 & 13 & 20 \\
\hline \multirow{8}{*}{$\begin{array}{l}\text { Regulation } \\
\text { No-w ind }\end{array}$} & 4 & 26 & 26 & 26 & 26 & 26 & 16 & 16 & 16 & 16 & 16 & 20 & 20 & 20 & 20 & 20 \\
\hline & 8 & 15 & 14 & 13 & 13 & 13 & 9 & 9 & 8 & 8 & 8 & 14 & 16 & 19 & 20 & 20 \\
\hline & 12 & 12 & 11 & 10 & 9 & 9 & 8 & 7 & 6 & 6 & 5 & 9 & 11 & 13 & 18 & 20 \\
\hline & 16 & 10 & 10 & 9 & 7 & 7 & 7 & 6 & 6 & 5 & 4 & 7 & 8 & 10 & 14 & 20 \\
\hline & 20 & 9 & 9 & 8 & 7 & 5 & 6 & 6 & 5 & 4 & 3 & 6 & 7 & 8 & 11 & 19 \\
\hline & & \multicolumn{5}{|c|}{$\begin{array}{l}\text { High-end Pay-by-Energy } \\
\text { (\$/MWh) }\end{array}$} & \multicolumn{5}{|c|}{$\begin{array}{l}\text { Low-end Pay-by-Energy } \\
\text { (\$/MWh) }\end{array}$} & \multicolumn{5}{|c|}{ Adjusted Life Time (Year) } \\
\hline & $\mathbf{P}_{\text {rated }}$ & \multicolumn{5}{|c|}{ DOD } & \multicolumn{5}{|c|}{ DOD } & \multicolumn{5}{|c|}{ DOD } \\
\hline & (MW) & 1 & 0.8 & 0.6 & 0.4 & 0.2 & 1 & 0.8 & 0.6 & 0.4 & 0.2 & 1 & 0.8 & 0.6 & 0.4 & 0.2 \\
\hline \multirow[t]{2}{*}{ Regulation } & 4 & 197 & 206 & 204 & 198 & 238 & 86 & 90 & 89 & 86 & 104 & 20 & 20 & 20 & 20 & 20 \\
\hline & 8 & 112 & 106 & 103 & 119 & 124 & 50 & 47 & 45 & 52 & 54 & 14 & 16 & 20 & 20 & 20 \\
\hline \multirow{3}{*}{$\begin{array}{c}20 \% \\
\text { Renew ables }\end{array}$} & 12 & 89 & 89 & 86 & 80 & 87 & 41 & 40 & 38 & 35 & 38 & 10 & 12 & 15 & 20 & 20 \\
\hline & 16 & 84 & 79 & 73 & 67 & 68 & 39 & 37 & 33 & 30 & 30 & 8 & 10 & 12 & 15 & 20 \\
\hline & 20 & 77 & 71 & 65 & 60 & 57 & 37 & 33 & 30 & 27 & 25 & 7 & 8 & 9 & 13 & 20 \\
\hline \multirow{5}{*}{$\begin{array}{l}\text { Regulation } \\
\text { No-w ind }\end{array}$} & 4 & 135 & 137 & 137 & 135 & 144 & 83 & 84 & 84 & 83 & 88 & 20 & 20 & 20 & 20 & 20 \\
\hline & 8 & 77 & 73 & 71 & 72 & 79 & 49 & 46 & 44 & 44 & 48 & 14 & 16 & 19 & 20 & 20 \\
\hline & 12 & 63 & 60 & 55 & 52 & 55 & 41 & 39 & 35 & 32 & 34 & 9 & 11 & 13 & 18 & 20 \\
\hline & 16 & 56 & 52 & 48 & 45 & 43 & 37 & 34 & 31 & 28 & 27 & 7 & 8 & 10 & 14 & 20 \\
\hline & 20 & 52 & 48 & 44 & 40 & 37 & 35 & 32 & 29 & 25 & 23 & 6 & 7 & 8 & 11 & 19 \\
\hline
\end{tabular}




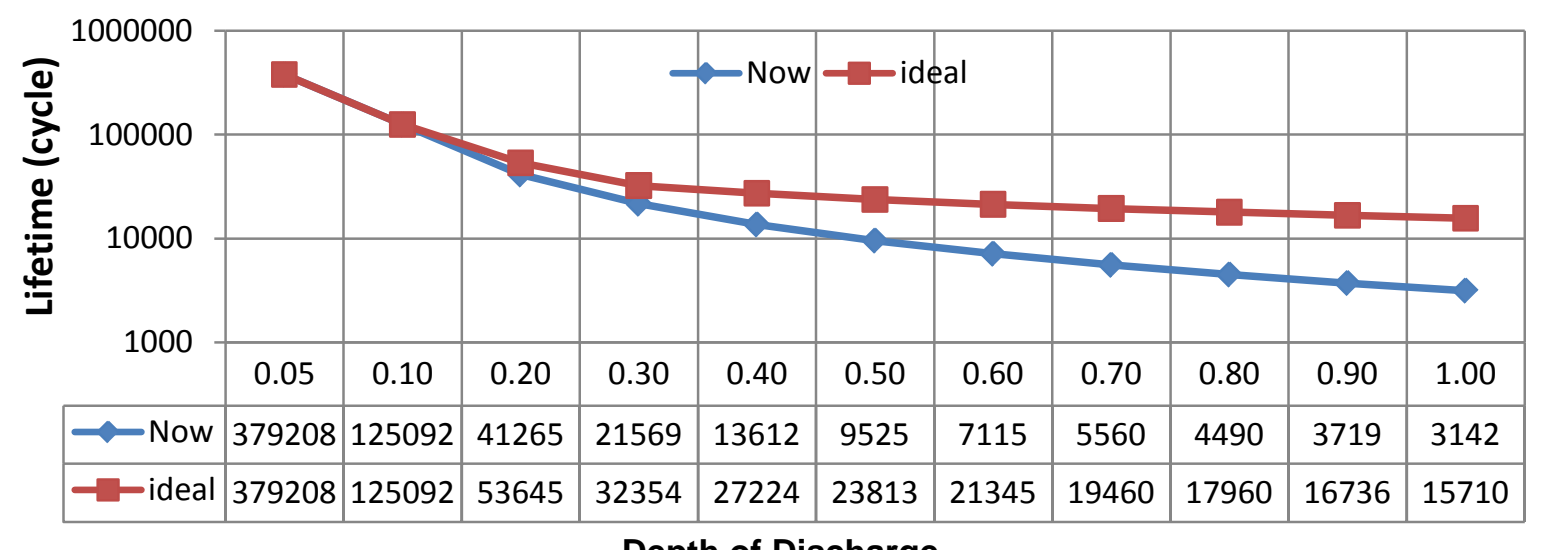

Depth of Discharge

Figure 2: The battery lifetime with respect to the depth of discharge

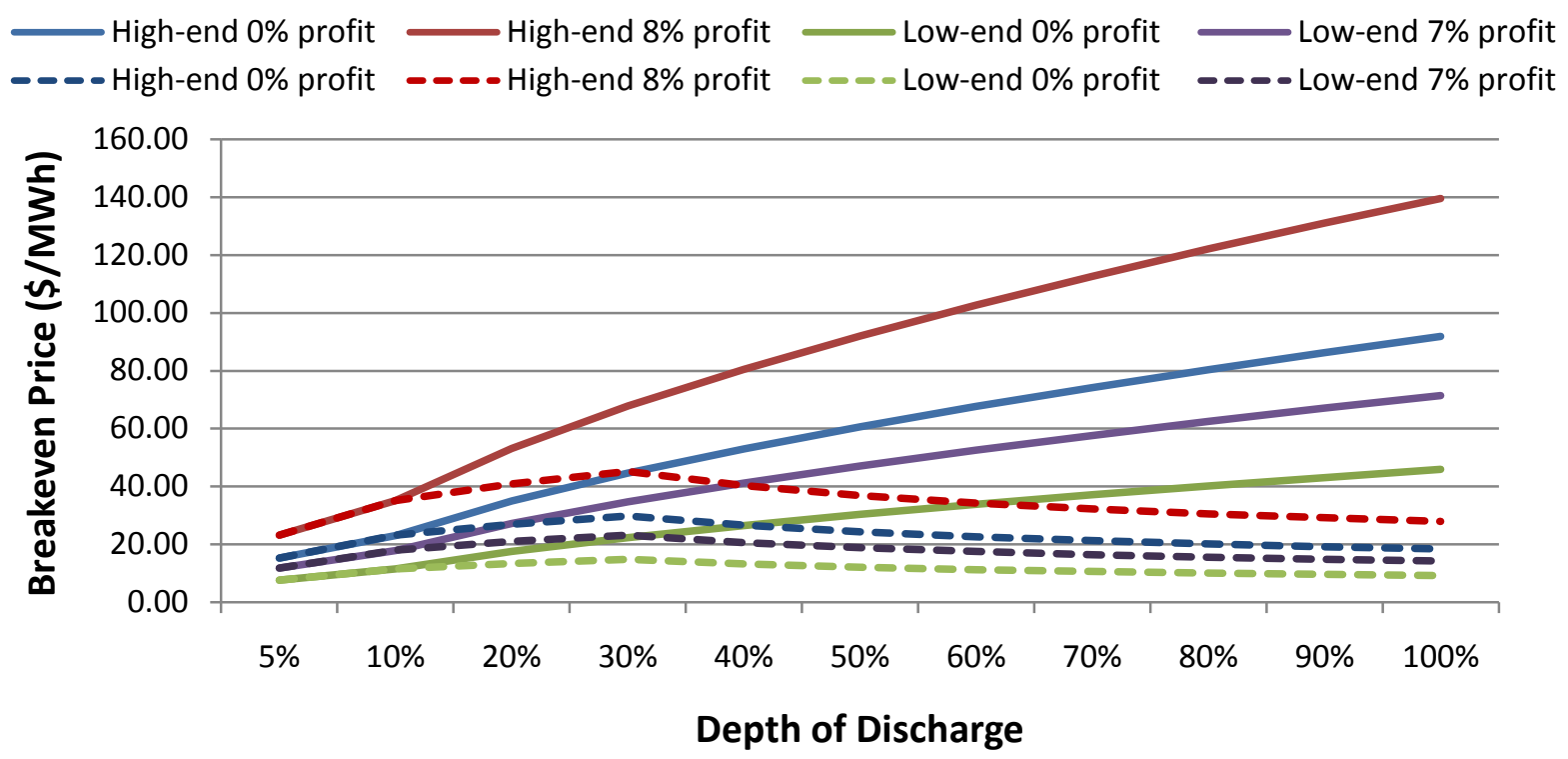

Figure 3: A comparison of high-end and low-end breakeven prices of the improved battery lifecycle case (dash-lines) and the base case (solid lines)

- As shown in Table 2 and Table 3, if the battery rated power can be increased (as shown in Figure 4), the breakeven price will drop significantly because the battery is able to handle a broader range of signals. However, a fter $12 \mathrm{MW}$, the price drop is not significant, but the battery life is shortened dramatically. Therefore, based on the current lifecycle-DOD curve, it is beneficial for the battery manufacturer to increase the battery rated power output up to 8 or $12 \mathrm{MW}$, which will result in a breakeven price drop of $1 / 2$ to $1 / 3$. 


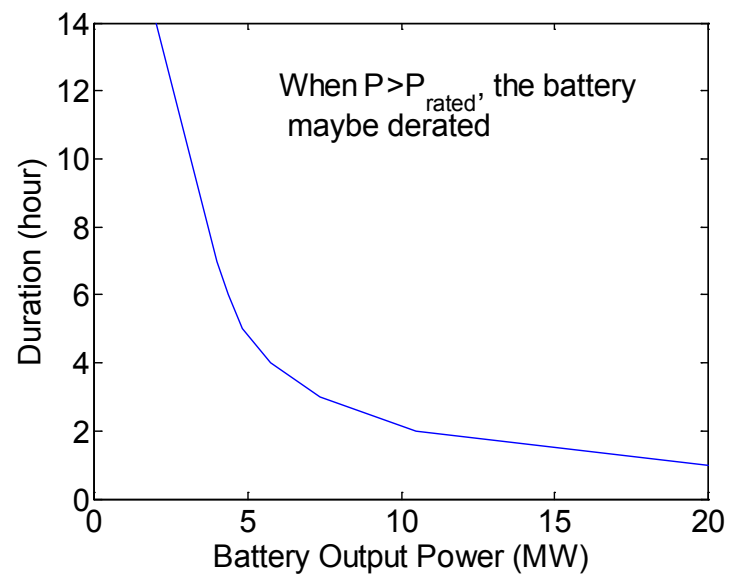

Figure 4: The $28 \mathrm{MWh}$ NaS battery capacity to power ratio

- As also shown in Table 2 and Table 3, at higher-rated power, there is a tradeoff between the DOD and battery life. At $4 \mathrm{MW}$, the DOD does not result in a shortened battery life because the 28 MWh battery is underused when providing the regulation service. At $20 \mathrm{MW}$, however, the battery lives are significantly shorter at higher DODs.

- The NaS battery provides almost the same amount of regulation or real-time dispatch services for the "with $20 \%$ renewables" and "without wind" cases. Thus, the breakeven prices were similar. More batteries contribute greater ancillary service capacity and therefore, allow more intermittent generation resources to connect to the power grid. However, the amount of regulation and realtime dispatch services that an individual battery provides depends mainly on its power rating. For the "with $20 \%$ r enewables" and "without wind" cas es, signals sent to the NaS battery ar e all within its rated power output $\pm 4 \mathrm{MW}$. For example, although $193 \mathrm{MW}$ are needed for regulation without wind, and $248 \mathrm{MW}$ are needed for regulation with $20 \%$ renewable, for the $4 \mathrm{M} \mathrm{W} \mathrm{NaS}$ battery, it provides s ervices within $\pm 4 \mathrm{MW}$ in both cases; therefore, the a mounts of e nergy provided in both cases are similar.

- The regulation and real-time dispatch signals sent to the $\mathrm{NaS}$ battery are scaled total regulation and real-time dispatch signals, so that the signals are within the battery rated power output, for example, $\pm 4 \mathrm{MW}$. As shown in Figure 5, for the case in which $50 \%$ of the time, the normalized signal is out side $\pm 4 \mathrm{MW}$, the battery a verage pow er out put is much higher than that of the $5 \%$ case, resulting in more economical services, as shown in Table 4 . For the $50 \%$ of signals outside the ba ttery's c apability, s torage de vices $\mathrm{w}$ ith hi gh pow er out puts but less e nergy s torage capacities, such as a flywheel, would be be tter suited to p rovide the regulation and $\mathrm{r}$ eal-time dispatch signals.

Future research should focus on the economics of the combined services of batteries. By providing services to the energy, regulation, real-time dispatch, and reserve markets, the battery owner can collect revenue from different markets, resulting in a more economical operation than bidding in a single market. However, providing multiple services requires an optimization of the battery's commitment schedule. To address these optimal operation strategies, a battery commitment problem needs to be well de fined and solved. 


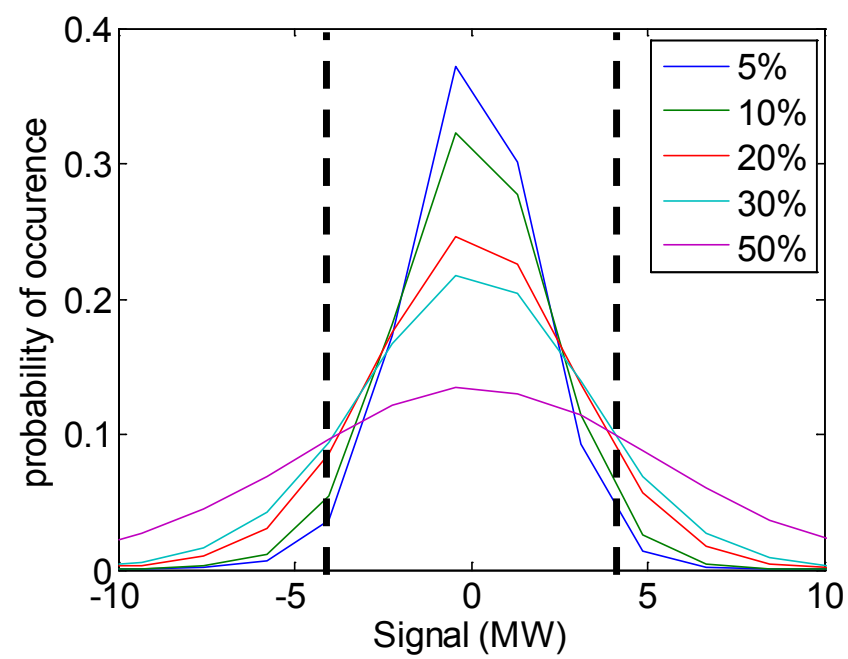

Figure 5: The probability distribution functions of the regulation signals

Table 4: A comparison of breakeven prices for different normalized signals

\begin{tabular}{|c|c|c|c|c|c|c|c|c|c|c|c|}
\hline \multicolumn{7}{|c|}{ Breakeven Price (High End) } & \multicolumn{5}{|c|}{ Breakeven Price (Low End) } \\
\hline & \multirow{2}{*}{$\begin{array}{c}\text { Signal } \\
\text { Outliers }\end{array}$} & \multicolumn{5}{|c|}{ DOD } & \multicolumn{5}{|c|}{ DOD } \\
\hline & & 1 & 0.8 & 0.6 & 0.4 & 0.2 & 1 & 0.8 & 0.6 & 0.4 & 0.2 \\
\hline \multirow[t]{2}{*}{ Regulation } & $5 \%$ & 197 & 206 & 204 & 198 & 238 & 101 & 105 & 104 & 101 & 122 \\
\hline & $10 \%$ & 175 & 177 & 176 & 171 & 203 & 90 & 90 & 90 & 87 & 104 \\
\hline \multirow{3}{*}{$\begin{array}{c}20 \% \\
\text { Renewables }\end{array}$} & $20 \%$ & 138 & 140 & 135 & 148 & 160 & 71 & 72 & 69 & 76 & 82 \\
\hline & $30 \%$ & 131 & 129 & 127 & 143 & 146 & 67 & 66 & 65 & 73 & 75 \\
\hline & $50 \%$ & 112 & 105 & 101 & 112 & 116 & 59 & 55 & 52 & 57 & 60 \\
\hline & & & & & & & & & & & \\
\hline \multirow{3}{*}{$\begin{array}{l}\text { Realtime } \\
\text { Dispatch }\end{array}$} & $\%$ & 231 & 238 & \begin{tabular}{|l}
257 \\
\end{tabular} & 285 & 381 & 118 & 122 & \begin{tabular}{|l|}
132 \\
\end{tabular} & 146 & 195 \\
\hline & $10 \%$ & 205 & 217 & 228 & 270 & 355 & 105 & 111 & 117 & 138 & 182 \\
\hline & $20 \%$ & 174 & 181 & \begin{tabular}{|l}
195 \\
\end{tabular} & 231 & 308 & 89 & 93 & 100 & 118 & 158 \\
\hline \multirow{2}{*}{$\begin{array}{c}20 \% \\
\text { Renewables }\end{array}$} & $30 \%$ & 151 & 159 & \begin{tabular}{|l|}
177 \\
\end{tabular} & 204 & \begin{tabular}{|l|}
278 \\
\end{tabular} & 77 & 82 & 91 & 104 & 142 \\
\hline & $50 \%$ & 135 & 142 & 155 & 180 & 239 & 70 & 73 & 79 & 92 & 123 \\
\hline \multirow{5}{*}{$\begin{array}{l}\text { Regulation } \\
\text { No-wind }\end{array}$} & $5 \%$ & 191 & 193 & 193 & 190 & 202 & 98 & 99 & 99 & 97 & 104 \\
\hline & $10 \%$ & 175 & 172 & 175 & 172 & 185 & 90 & 88 & \begin{tabular}{|l|}
89 \\
\end{tabular} & 88 & 95 \\
\hline & $20 \%$ & 144 & 144 & 143 & 149 & 156 & 74 & 74 & 73 & 76 & 80 \\
\hline & $30 \%$ & 132 & 131 & 129 & 140 & 144 & 68 & 67 & 66 & 72 & 74 \\
\hline & $50 \%$ & 117 & 112 & 108 & 113 & 119 & 61 & 58 & 55 & 58 & 61 \\
\hline & & & & & & & & & & & \\
\hline \multirow{5}{*}{$\begin{array}{l}\text { Realtime } \\
\text { Dispatch } \\
\text { No-wind }\end{array}$} & $5 \%$ & 249 & 251 & 283 & 322 & 426 & 128 & 129 & 145 & 165 & 218 \\
\hline & $10 \%$ & 217 & 226 & \begin{tabular}{|l|}
254 \\
\end{tabular} & 285 & 387 & 111 & 116 & 130 & 146 & 198 \\
\hline & $20 \%$ & 183 & 201 & 219 & 250 & 339 & 94 & 103 & 112 & 128 & 174 \\
\hline & $30 \%$ & 167 & 183 & 193 & 224 & 312 & 86 & 94 & 99 & 115 & 160 \\
\hline & $50 \%$ & 143 & 147 & 161 & 192 & 267 & 73 & 75 & 82 & 98 & 137 \\
\hline
\end{tabular}




\section{Acknowledgment}

This work has been funded by the California Energy Commission and supported by the California Institute for Energy and Environment (CIEE). The preparation of this report was conducted with support from the California Independent System Operator (CAISO).

The authors w ould like t o t hank Mike G ravely, California E nergy C ommission ( CEC); Merwin Brown, Larry Miller and Jim Cole, California Institute for Energy and Environment (CIEE); and David L. Hawkins, California I ndependent $\mathrm{S}$ ystem $\mathrm{O}$ perator, for $\mathrm{p}$ roviding the $\mathrm{p}$ roject team $\mathrm{w}$ ith advice and guidance essential to this work.

The a uthors would also like to thank R oss Guttromson, C arl I mhoff, E van J ones, Mark Morg an, Suresh Baskaran, and Sheena Kanyid, Pacific Northwest National Laboratory, for providing the project team with advice and support to this work.

Nishtha Ghosh, a PNNL Undergraduate Summer Intern, has provided the project team with literature reviews. We thank her for her efforts.

The a uthors would 1 ike to express their sincere thanks to $\mathrm{S}$ usan Arey a nd Susan E nnor, P acific Northwest National Laboratory, for providing editorial reviews to the report. 


\section{Nomenclature}

\begin{tabular}{|c|c|}
\hline$A C E$ & Area control error (MW) \\
\hline$I_{a}$ & Net interchange (MW) \\
\hline$I$ & Scheduled net interchange (MW) \\
\hline$B$ & Area frequency bias constant \\
\hline$F_{a}$ & Actual frequency $(\mathrm{Hz})$ \\
\hline$F_{s}$ & Scheduled frequency $(\mathrm{Hz})$ \\
\hline$G_{h a}$ & Hour-ahead generation schedule (MW) \\
\hline$G_{s}$ & Scheduled generation (MW) \\
\hline$G_{a}$ & Actual generation (MW) \\
\hline$G_{h a}^{w}$ & Hour-ahead wind generation (MW) \\
\hline$G^{r}$ & Regulation (MW) \\
\hline$G^{l f}$ & Load following (MW) \\
\hline$G^{w}$ & Wind generation (MW) \\
\hline$\Delta G^{u d}$ & Total deviation of generation from the dispatched instructions (MW) \\
\hline$\Delta G^{w}$ & Wind generation real-time schedule forecast error (MW) \\
\hline$\Delta G^{l f}$ & The deviation of the load following unit from its base point (MW) \\
\hline$\Delta G^{r}$ & The deviation of the regulation unit from its base point (MW) \\
\hline$L_{h a}$ & Hour-ahead load (MW) \\
\hline$L_{a}$ & Actual load (MW) \\
\hline$G_{r t f, 5 \min }^{w, y}$ & 5-minute short-term forecasts of wind generation (MW) \\
\hline$L_{r t f, 5 \min }^{y}$ & 5-minute short-term forecasts of load (MW) \\
\hline$P_{\text {rated }}$ & Battery rated power (MW) \\
\hline$P_{a v e}$ & Battery average power output (MW) \\
\hline$E_{B}$ & Battery rated capacity (MWh) \\
\hline$L_{c}$ & Life (cycle) \\
\hline$L_{y}$ & Life (year) \\
\hline$n_{y}$ & Number of cycles in a year \\
\hline$n_{h}$ & Number of cycles in an hour \\
\hline$k_{D O D}$ & Depth of discharge (DOD) \\
\hline$K$ & Utilization factor \\
\hline
\end{tabular}




$\begin{array}{ll}\eta & \text { Efficiency } \\ E_{\text {life }} & \text { Lifetime energy (MWh) } \\ E_{\text {Annual }} & \text { Annual energy (MWh) } \\ B_{B E} & \text { Breakeven price (\$/MW) } \\ R & \text { Revenue (\$) } \\ C_{\text {install }} & \text { Installation cost }(\$ / \mathrm{kW}) \\ C_{c a p} & \text { Capital cost }(\$) \\ k_{o p} & \text { Operation cost factor } \\ C_{o p} & \text { Operation cost }(\$) \\ C & \text { Total op+cap } \\ \pi & \text { Profit } \\ \text { NPV } & \text { Net present value }(\$) \\ R_{y r} & \text { Annual benefit }(\$) \\ C_{y r} & \text { Annual levelized cost }(\$) \\ i & \text { Discount rate } \\ n & \text { Plant life in years }\end{array}$




\section{Contents}

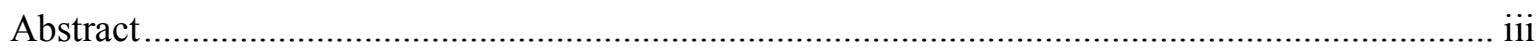

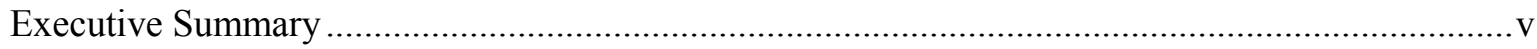

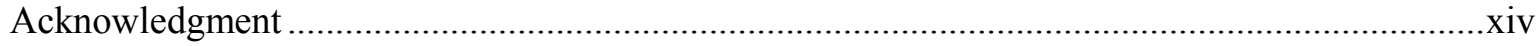

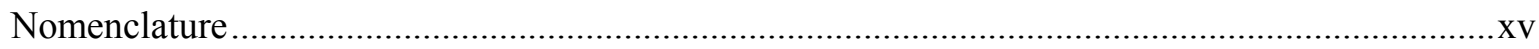

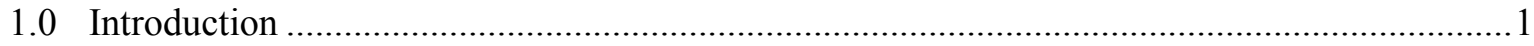

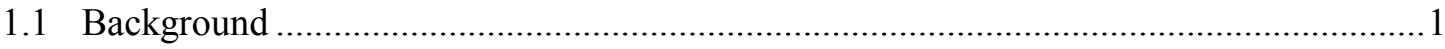

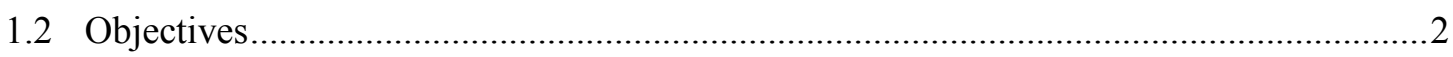

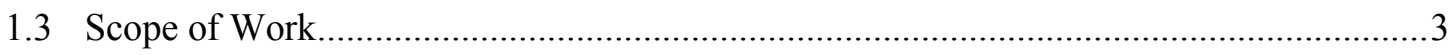

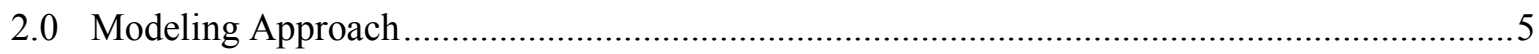

2.1 Regulation and Real-time Dispatch Signal Generation..................................................

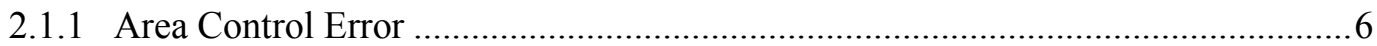

2.1.2 Separating Regulation and Real-time Dispatch.................................................

2.2 The Modeling of the NaS Battery Performance ............................................................. 8

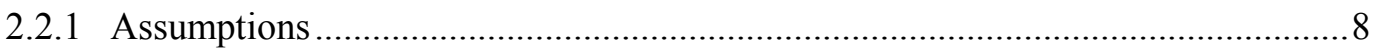

2.2.2 Normalization of the Regulation and Real-time Signals..................................... 12

2.2.3 Bi-directional and One-directional Services ................................................... 15

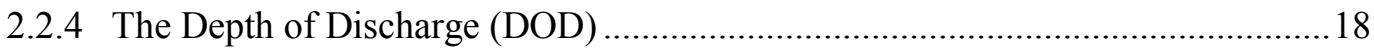

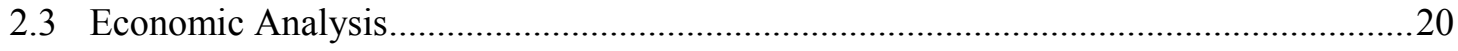

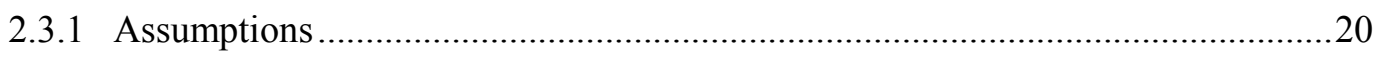

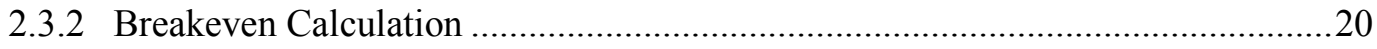

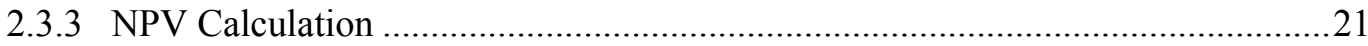

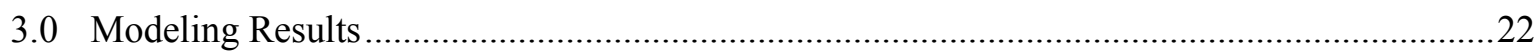

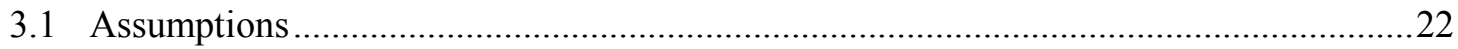

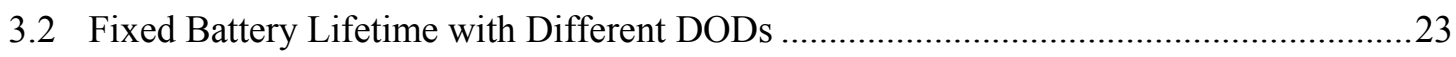

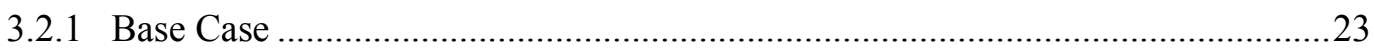

3.2.2 Impact of improved lifecycle-DOD characteristics..........................................27

3.3 Different Regulation and Real-time Dispatch Signals .................................................. 30

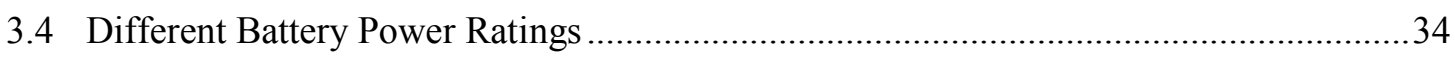

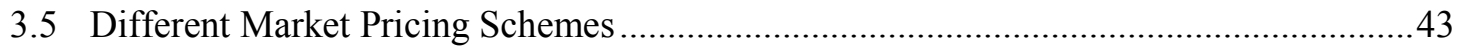

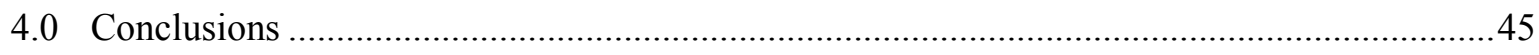

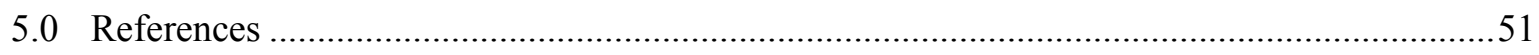




\section{List of Tables}

Table 1: The breakeven prices of two lifecycle-DOD curves.................................................... viii

Table 2: The breakeven prices, utilization rates, and battery lifetimes (Pay-by-energy)...................ix

Table 3: The breakeven price comparison between pay-by-energy and pay-by-capacity ..................

Table 4: A comparison of breakeven prices for different normalized signals .............................. xiii

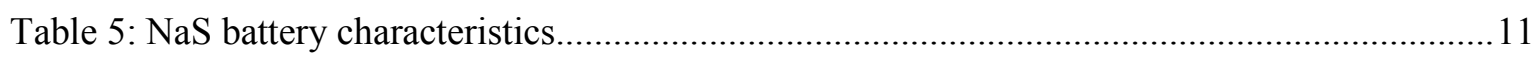

Table 6: The values to normalize the regulation and real-time dispatch signals ............................ 14

Table 7: The utilization rates of the NaS Battery when providing bi-directional ancillary services 15

Table 8: The lifecycles of the NaS battery with respect to the DODs ...........................................22

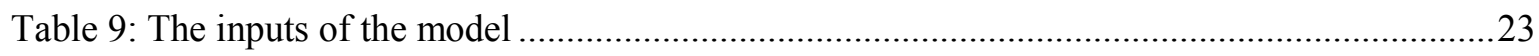

Table 10: The breakdown of the total O\&M cost ........................................................................23

Table 11: The cost calculations - base case (fixed lifetime at 20 years) ........................................25

Table 12: The NaS battery performance characteristics (fixed lifetime at 20 years) ......................26

Table 13: A cost comparison of the base case and the improved lifecycle case.............................28

Table 14: The values used to normalize the regulation and real-time dispatch signals to $4 \mathrm{MW}$.....30

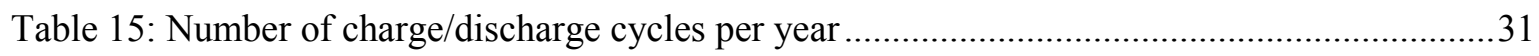

Table 16: The breakeven prices, utilization rates, and battery lifetimes...........................................32

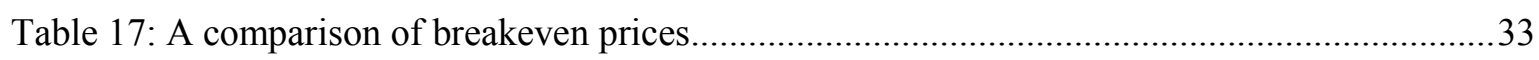

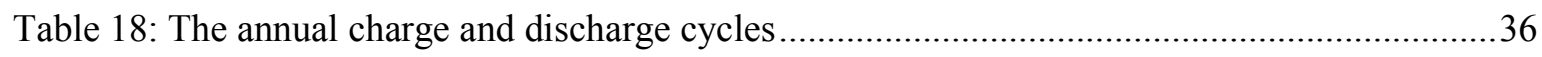

Table 19: The breakeven prices, utilization rates, and battery lifetimes (different rated battery

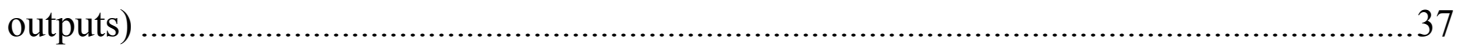

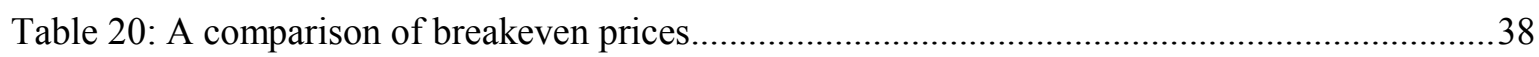

Table 21: The breakeven price comparison between pay-by-energy and pay-by-capacity ..............44

Table 22: The breakeven prices, utilization rates, and battery lifetimes (Pay-by-energy)................46

Table 23: The breakeven price comparison between pay-by-energy and pay-by-capacity ..............47

Table 24: A comparison of breakeven prices for different normalized signals .............................49 


\section{List of Figures}

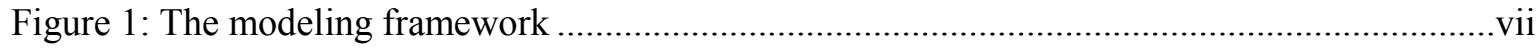

Figure 2: The battery lifetime with respect to the depth of discharge..............................................

Figure 3: A comparison of high-end and low-end breakeven prices of the improved battery

lifecycle case (dash-lines) and the base case (solid lines) ........................................................

Figure 4: The $28 \mathrm{MWh}$ NaS battery capacity to power ratio .............................................................ii

Figure 5: The probability distribution functions of the regulation signals................................... xiii

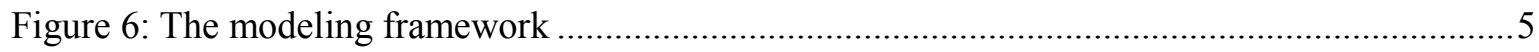

Figure 7. Separation of regulation from real-time dispatch based on simulated hour-ahead

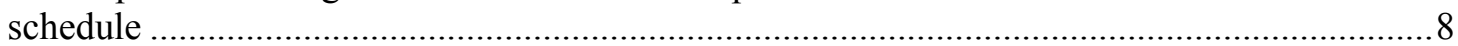

Figure 8: The battery lifetime with respect to the depth of discharge [7] ....................................

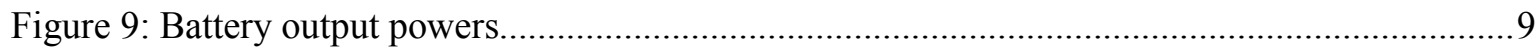

Figure 10: The charging/discharge profiles of an NaS battery ................................................... 10

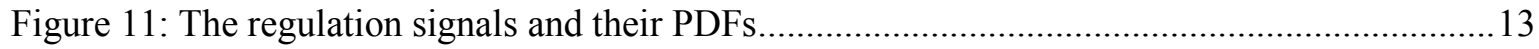

Figure 12: The real-time dispatch signals and their PDFs ..................................................... 13

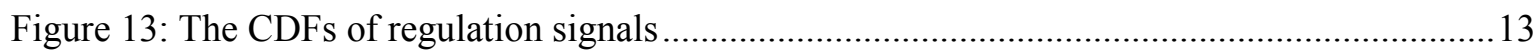

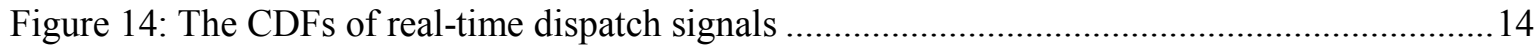

Figure 15: The bi-directional regulation services provided by the $28 \mathrm{MWh} / 4 \mathrm{MW}$ NaS battery.

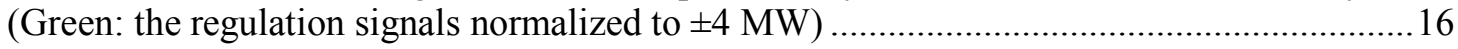

Figure 16: The one-directional service provided by the NaS battery ............................................. 17

Figure 17: The regulation "up" (black lines) and "down" (red lines) signals................................. 17

Figure 18: A comparison of bi-directional services and one-directional services provided by the

$\mathrm{NaS}$ battery (Dotted lines: without wind; Solid lines: with wind) .......................................... 18

Figure 19: The battery charging and discharging profiles (DOD: 20\% - 100\%) ............................. 19

Figure 20: The battery lifetime energy (DOD: 5\% - 100\%) ….................................................. 19

Figure 21: The breakeven prices (fixed lifetime at 20 years) .....................................................25

Figure 22: The battery lifecycle curves.......................................................................................27

Figure 23: A comparison of high-end and low-end breakeven prices of the improved battery

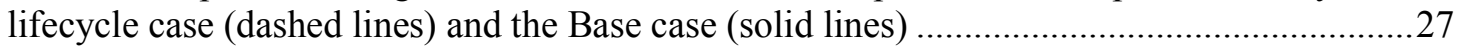

Figure 24: The breakdown of the breakeven price.....................................................................29

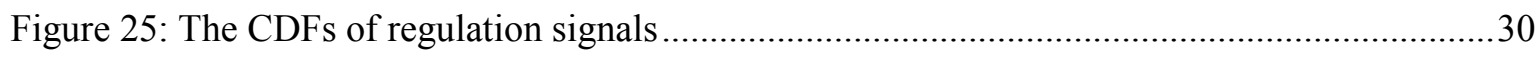

Figure 26: The regulation signals for different $\mathrm{NaS}$ battery output ratings ....................................34

Figure 27: The battery charge/discharge profiles for different NaS battery output ratings ..............34

Figure 28: The annual regulation energy provided by battery (dash: without wind, solid: with

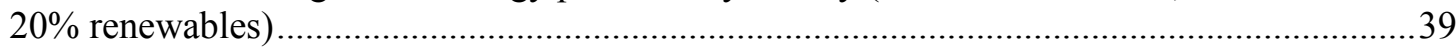

Figure 29: The calculated lifetimes of the NaS battery (solid: with $20 \%$ renewables; dash: without

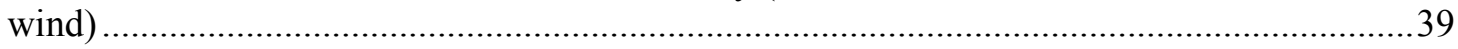

Figure 30: Battery charging/discharging profiles when providing regulation service.....................40

Figure 31: Battery charging/discharging profiles when providing real-time dispatch service .........40 
Figure 32: The box plot of battery charging time at different rated power outputs and DODs (regulation).

Figure 33: The box plot of battery discharging time at different rated power outputs and DODs (regulation).

Figure 34: The box plot of battery charging time at different rated power outputs and DODs (real-

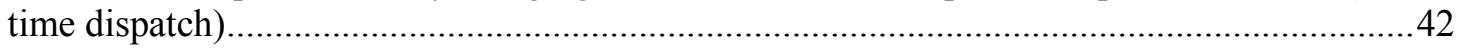

Figure 35: The box plot of battery discharging time at different rated power outputs and DODs

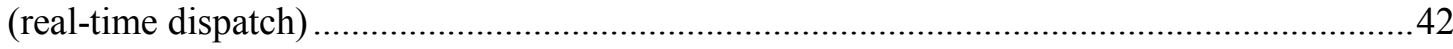

Figure 36: The battery lifetime with respect to the depth of discharge..........................................45

Figure 37: A comparison of high-end and low-end breakeven prices of the improved battery

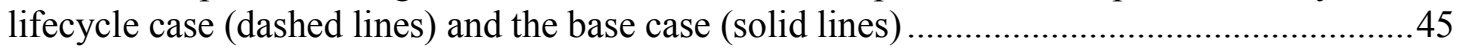

Figure 38: The $28 \mathrm{MWh}$ NaS battery capacity to power ratio ......................................................48

Figure 39: The probability distribution functions of the regulation signals..................................49 


\subsection{Introduction}

This doc ument de scribes the a pproach a nd $\mathrm{r}$ esults developed by $\mathrm{t}$ he $\mathrm{P}$ acific Northwest $\mathrm{N}$ ational Laboratory (PNNL) a nd u sed in evaluating the $4 \mathrm{MW}, 28 \mathrm{M}$ Wh s odium s ulfur (NaS) b attery under a contract with the California Institution for Energy and Environment (CIEE). The project has been funded by the California Energy Commission (CEC). In this report, the motivation, objectives, and benefits of the research are discussed. Next, the scope of the project is outlined, and finally, results and conclusions are provided.

\subsection{Background}

California has set the goal of reaching 20\% renewable energy by 2012. Moving quickly towards this goal, the California Independent System Operator (CAISO) needs to find possible means to mitigate the intermittence and fast-ramp that occurs at higher penetration levels of intermittent resources, the majority of w hich a re w ind and s olar pow er. P umped-hydro pow er pl ants, ba tteries, f lywheels, distributed generation resources, and de mand side $m$ anagement are $f$ lexible ene rgy st orage opt ions that could potentially prov ide $t$ he ne eded fast $r$ esponsive anc illary ser vice $r$ esources. Pacific $G$ as and Electric (PG\&E) is planning to build a $4 \mathrm{MW}, 28 \mathrm{MWh}$ NaS battery storage. To evaluate operational, market, and regulatory opportunities and limitations concerning the use of the PG\&E Battery Storage Facility, PNNL proposed this research to CIEE and CEC.

Ford Motor Company pioneered the NaS battery in the 1960s to pow er e arly-model el ectric cars; NGK and Tokyo Electric refined it for the power grid. The benefits of the NaS battery are its high energy density, efficiency, and long-term durability [1][2]. For example, its energy density is approximately three times larger than lead-acid batteries. Furthermore, the battery can be charged and discharged over periods of 7 hours or stored indefinitely if the temperature is maintained at 600 degrees Fahrenheit. The cycle life of $\mathrm{NaS}$ batteries is based on depth of discharge and environmental factors. However, when a battery is providing regulation or real-time dispatch services, the battery capacity may not be fully used, resulting in a low ut ilization factor. Whether or not the services are eco nomical is unk nown. We expect that this research will lay a solid foundation for an extensive energy storage evaluation study, which will include the economics of all energy storage options for both the energy and ancillary services.

To accept and accommodate the ancillary services provided by those devices in the CAISO market, CAISO needs answers to the following questions:

- What is the quantity (in terms of the downward and upward power capacity and energy) and quality (in terms of the availability, flexibility, ramping capability, ramp duration capability, etc.) of the ancillary service that an energy storage device can provide?

- Will the services provided be economically justified? What needs to be done to make them economical?

- What are the existing market opportunities for energy storage providers in the California market? Is there a need to introduce changes to the existing market rules and/or to the operating procedures in California to make the use of energy storage resources more cost effective and beneficial to grid reliability? 
- What a re the de sired device pe rformance ch aracteristics for e nergy st orage de vices ne eded to provide more valuable ancillary services to the grid? The answer to this question could provide design guidance for the battery manufacturers and designers.

Motivated by CAISO's needs, CEC (Mike Gravely) proposed this battery storage e valuation study. Because of funding limitations, the scope was limited to evaluating the economics and performance of an existing $4 \mathrm{MW} \mathrm{NaS}$ battery ene rgy st orage de vice while performing r egulation and real-time di spatch services in the electricity markets operated by CAISO.

\subsection{Objectives}

The goal of this research is to investigate technical characteristics and economics of the NaS battery energy st orage us ed for regulation and real-time di spatch (also called load following) services in the electricity market operated by the California Independent System Operator (CAISO). This report is part of the de liverables for Phase II of the Wide Area Energy Storage and Management System (WAEMS) project.

The tasks addressed in Phase I are as follow:

- Evaluate and compare available energy st orage opt ions. Review the w orld experience. Identify top three technologies that can meet the needs of this project.

- Design and evaluate con figurations and integration schemes of $t$ he en ergy st orage, generation resources, their combinations, and other options. Identify the most promising configurations and their benefits.

- Analyze technical and market compatibility of the proposed integration schemes with the existing regulation and load following systems at BPA and CAISO.

- Collect data needed for experiments at BPA and CAISO.

- Develop a lgorithms $\mathrm{f}$ or the en ergy st orage and generation control. Implement $\mathrm{t}$ hem as MATLAB $^{\mathrm{TM}}$ codes.

- Conduct experiments using the MATLAB ${ }^{\mathrm{TM}}$ model and collected data.

- Carry out the cost benefit analysis based on simulation results.

- Provide a summary of results and recommendations for possible continuation of the project.

The tasks addressed in Phase II are as follow:

- Study the value of the ancillary services that can be provided by the NaS battery for the following two wind energy penetration scenarios: (1) a hypothetical scenario without wind energy resource and (2) a scenario with $20 \%$ of CAISO's energy supply being provided by renewable resources including the wind energy $r$ esource. Scenario (1) was analyzed to compare the i ncremental effects of wind power production.

- Evaluate technical and economical characteristics of the $\mathrm{NaS}$ battery when it is us ed to provide regulation and real-time dispatch services.

- Consider di fferent op erational conditions, $f$ ind limitations, a nd recommend additional opportunities for the NaS battery arising in the California energy market. 
- Suggest de sign improvements for the following $\mathrm{NaS}$ battery phy sical characteristics helping to increase the value and expand market opportunities in California: energy capacity, power output, and lifetime.

\subsection{Scope of Work}

The original scope of work is listed as follows:

- Evaluate operational, market, and regulatory opportunities and limitations concerning the use of the Pacific Gas and Electric (PG\&E) Battery Storage Facility.

- Identify and analyze potential uses of the sodium sulfur energy storage facility that include peak shaving, intraday energy storage, black start applications, wind and solar generation intermittency mitigation, regulation, real-time dispatch, voltage support, stability enhancement, frequency response, and other potential uses.

- Analyze market and operational conditions, limitations, and opportunities associated with each potential application for NaS battery storage. Determine whether the battery's physical characteristics such as the size, energy capacity, cycling capacity, lifetime, and others can appropriately support (economically, etc.) the intended application.

- Identify what changes might be needed in CAISO's market (operating procedures and practices, control systems) Federal Energy Regulatory Commission (FERC) regulations or North American Reliability Corporation (NERC)/Western Electricity Coordinating Council (WECC) standards to create feasible, economic applications for the $\mathrm{NaS}$ battery storage.

- Provide a summary report addressing each of the above bulleted points.

On April 10, 200 9, a di scussion w ith Mike Gravely (CEC) w as followed by a num ber of phone interviews w ith Dave Hawkins (CAISO) and Jon Eric Thalman (PG\&E). Based on Mike G ravely's recommendations and a consensus from the CIEE project managers, to address changes in research needs, the scope of work was revised slightly as follows:

Evaluate operational and market opportunities and limitations concerning the use of PG\&E Battery Storage Facility (4 MW, $28 \mathrm{MWh}$ ).

- Analyze $t$ he $\mathrm{m}$ arket a nd operational c onditions, 1 imitations, and oppo rtunities $\mathrm{f}$ or real-time dispatch for $\mathrm{NaS}$ battery s torage in conjunction with $\mathrm{w}$ ind and solar g eneration intermittency. Determine lifecycle costs and NPV under CAISO conditions associated with renewable energy penetration at $33 \%$ of total supply.

- Determine whether the battery's performance envelope (physical) characteristics such as the size, energy capa city, cycling capa city, lifetime, and o thers, can a ppropriately support ( based on economics and technical characteristics) the intended application.

- Update Phase I NaS battery evaluation with regard to regulation within the market redesign and technology upg rade (MRTU) pricing s chedule. U pdate P hase I N PV m ethodology to e valuate CAISO regulation with CAISO simulation data.

- Identify $\mathrm{w}$ hat changes $\mathrm{m}$ ight be needed in $\mathrm{C}$ alifornia's $\mathrm{m}$ arket ( operating procedures a nd practices, control sy stems) F ERC $\mathrm{r}$ egulations o $\mathrm{r}$ N ERC/WECC standards t o create f easible, economic application associated real-time dispatch and regulation for the $\mathrm{NaS}$ battery storage. If time and money permit, evaluate changes required for regulation using the NaS battery. 
There were three minor changes to the revised scope when we conducted this study:

- Because there was no active non-disclosure agreement (NDA) with CAISO in place, we couldn't obtain planning data for 33\% renewable penetration from CAISO. Therefore, in this study, we used $\mathrm{r}$ egulation a nd $\mathrm{r}$ eal-time $\mathrm{d}$ ispatch si gnals generated i $\mathrm{n}$ P hase I for $20 \% \mathrm{r}$ enewables penetration.

- Net present value (NPV) was not calculated because this study only evaluated the battery for each service sepa rately, and neither of the service's breakeven prices (costs) were low e nough to provide a pos itive net present value given assumed CAISO prices for regulation and real-time dispatch services.

- Market $r$ ules $f$ or $b$ attery st orage de vices t $o$ bid into ancillary ser vice $m$ arkets $w$ ere unde $r$ development at $t$ he $t$ ime $w$ hen this $r$ esearch was $c$ onducted. Therefore, $s$ uggestions $f$ or $r$ ule changes are not provided. 


\subsection{Modeling Approach}

The modeling framework is shown in Figure 6. The regulation and real-time dispatch signals were simulated us ing $2006 \mathrm{C}$ AISO hi storical da ta s ets. The battery model w as developed based on battery depth of discharge characteristics. The methodology us ed in P hase I of this project w as improved by considering the physical characteristics of the $\mathrm{NaS}$ battery storage so that the number of battery lifecycles and annual energy provided are realistic. The battery performance was simulated by feeding the simulated minute-to-minute $r$ egulation a nd $r$ eal-time di spatch signals i nto $t$ he ba ttery model. To ev aluate $t$ he efficacy of the $\mathrm{N}$ aS ba ttery st orage i n mitigating the i ntermittence br ought by the $h$ igher 1 evels of penetration of renewable energy, a scenario was studied with $20 \%$ of the CAISO load being supplied by renewable energy resources including wind generation, and compared it against a scenario with zero wind generation.

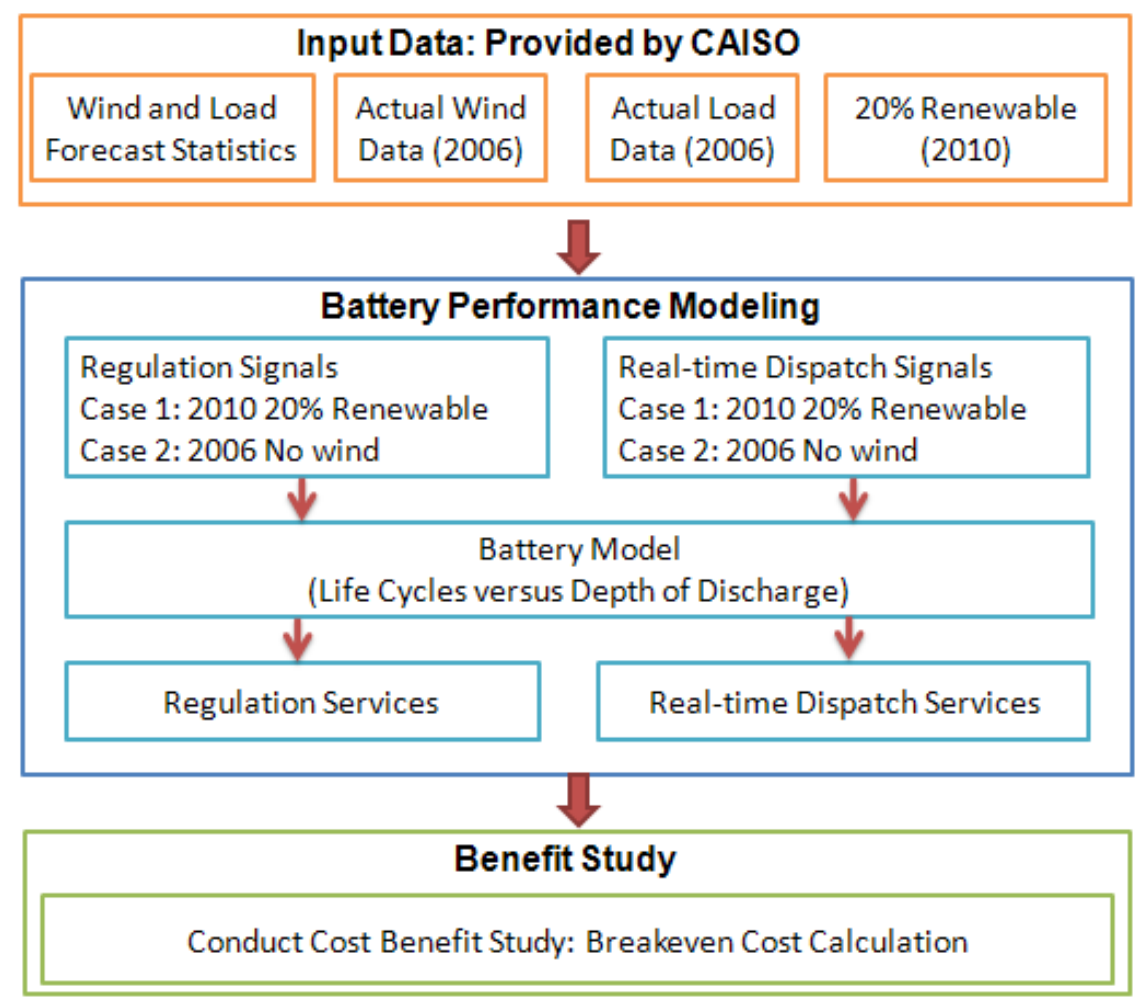

Figure 6: The modeling framework

To provide regulation or real-time dispatch service, an NaS battery can run at either the bi-directional or one -directional m ode. I $\mathrm{n} t$ he b i-directional m ode, the ba ttery $\mathrm{r}$ esponds to both " up" a nd " down" signals. In the one-directional mode, the battery responds to the "up" signal when it is discharging and the "down" signal when charging. The one-directional operation scheme was selected and modeled in detail in this study. This is because the one-directional operation allows the NaS battery to have a longer service life and is easier to implement compared with bi-directional operation schemes. 
In the benefit study, the economics of the four services in terms of breakeven ${ }^{1}$ costs were evaluated and compared for different device performance characteristics and operation mechanisms to find the best options. Net present value (NPV) ${ }^{2}$ was not calculated because the service's breakeven prices were not low enough to provide a positive N PV given a ssumed CAISO market pr ices for regulation a nd r eal-time dispatch services. There were two sets of breakeven prices considered: the high-end cost and the low-end cost. The high-end cost was obtained by applying pessimistic estimations of input variables, and the lowend cost was obtained by applying the optimistic ones.

Two payment methods were studied for the regulation service: pay-by-capacity and pay-by-energy ${ }^{3}$. For the real-time dispatch service, we only considered the pay-by-energy method.

\subsection{Regulation and Real-time Dispatch Signal Generation}

The algorithm us ed to generate regulation and real-time dispatch signals was developed in previous research. For detailed information, please refer to [5] and [6].

\subsubsection{Area Control Error}

The CAISO's operations control objective is to minimize its area control error (ACE) [5] to the extent sufficient to comply with the NERC Control P erformance Standards. T herefore, $t$ he " ideal" regulation/real-time di spatch signal is the s ignal that opp oses de viations of ACE f rom $z$ ero when it exceeds a certain threshold:

$$
\begin{aligned}
-A C E & =-\left(I_{a}-I_{s}\right)+\underbrace{10 B\left(F_{a}-F_{s}\right)}_{\text {Neglected }} \\
& \approx G_{s}-L_{s}-G_{a}+L_{a} \rightarrow \text { min }
\end{aligned}
$$

where $I_{a}$ denotes ne $\mathrm{t}$ i nterchange ( $\mathrm{MW}$ flow out of the c ontrol a rea); $I_{s}$ refers to scheduled net interchange; $B$ is area frequency bias constant; $F_{a}$ and $F_{s}$ are actual and scheduled frequency, respectively. Impacts of wind generation on the interconnection frequency are not modeled. This is a valid assumption given the large interconnection ( $>140 \mathrm{GW}$ peak load) whose frequency deviates very slightly with normal imbalances and that is maintained by several balancing authorities. The generation component of the ACE equation can be represented as follows:

$$
\begin{gathered}
G_{s}=G_{h a}+G_{h a}^{w} \\
G_{a}=G_{s}+\Delta G^{l f}+\Delta G^{r}+\Delta G^{w}+\Delta G^{u d}
\end{gathered}
$$

where ha denotes the hour-ahead generation schedule; If denotes instructed de viations from the hou rahead schedule ca used by generators involved in the real-time di spatch process; $r$ denotes instructed deviations caused by generators involved in the regulation process, $\Delta G^{l f}$ and $\Delta G^{r}$ are the deviations of the

\footnotetext{
${ }^{1}$ The break-even point [4] for a product is the point where total revenue received equals the total costs associated with the sale of the product.

${ }^{2}$ Net present value (NPV) or net present worth (NPW) [1] is defined as the total present value (PV) of a time series of revenues - costs.

${ }^{3}$ Pay-by-capacity means that a unit is paid by the capacity that it bids into the market regardless of the actual energy that it provides to the grid. Pay-by-energy means that a unit is paid by the actual energy that it provides to the grid.
} 
regulation and real-time dispatch units from their base points, $\Delta G^{w}$ is the deviation of the wind generators from their schedule (wind generation real-time schedule forecast error), and $\Delta G^{u d}$ is the total deviation of generators from the dispatched instructions. $\Delta G^{u d}$ is simulated similarly to the load forecast error (random number generator based on truncated normal distriution).

The to tal de viation of $g$ enerators $f$ rom di spatch in structions $f$ or $\mathrm{c}$ onventional un its th are no $t$ involved in regulation and real-time dispatch can be represented as follows:

$$
\begin{aligned}
\Delta G^{\text {ud }} & =G_{a}-G_{h a} \\
\Delta G^{w} & =G_{a}^{w}-G_{h a}^{w} \\
\Delta L & =L_{a}-L_{h a} .
\end{aligned}
$$

Because the control objective is $A C E \rightarrow 0$, Equation (1) can be rewritten as:

$$
\Delta G^{\text {lf }}+\Delta G^{r}=\Delta L-\Delta G^{w}-\Delta G^{u d}
$$

where $\Delta L$ is the deviation of the actual load from its real-time scheduled value (load forecast error).

Equation (7) is written for instantaneous values of $\Delta L, \Delta G^{w}$, and $\Delta G^{u d}$. Therefore, the statistical interaction between the load forecast error and the wind generation forecast e rror is fully pre served in Equation (7). The load and wind generation errors can vary depending on the wind generation penetration level within the CAISO control area and the accuracy of the load forecast compared with the accuracy of the wind generation forecast. Because the percent wind generation forecast error is more significant than the percent load forecast error, the former may have a considerable impact on $\Delta G^{l f}+\Delta G^{r}$.

Wind generation would have no impact on regulation and real-time dispatch requirements if

$$
\Delta G^{w}=0 .
$$

By substituting Equation (8) into (7), we have

$$
\Delta G^{r l f}=\Delta G^{l f}+\Delta G^{r}=\Delta L-\Delta G^{u d}
$$

\subsubsection{Separating Regulation and Real-time Dispatch}

Real-time dispatch is understood as the difference between the hourly energy schedule including 20minute ramps (shown as the red line) and the short-term 5-minute forecast/schedule and applied "limited ramping capability" function (blue line). This difference is also shown as the blue area below the curves. Regulation is interpreted as the difference be tween the ac tual C AISO generation requirement and the short-term 5-minute dispatch shown in Figure 7, as the red area between the blue and green lines. 


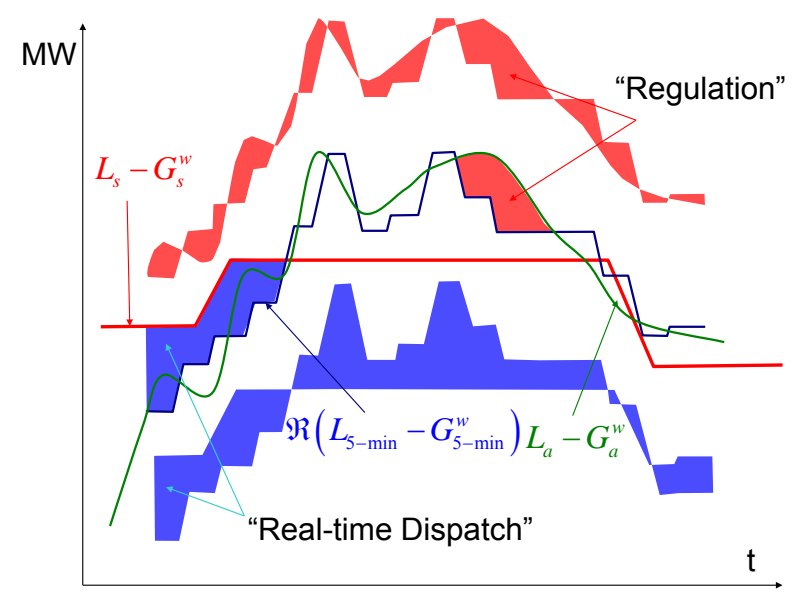

Figure 7. Separation of regulation from real-time dispatch based on simulated hour-ahead schedule

By s imulating hour -ahead and 5-minute s chedules for 1 oad a nd hou $\mathrm{r}$-ahead schedules $\mathrm{f}$ or $\mathrm{w}$ ind generation, regulation $\mathrm{c}$ an be s eparated from real-time di spatch. The schedule/forecast based a pproach uses the short-term forecasts of wind generation and load, $G_{r f, 5 \min }^{w, y}$ and $L_{r f, 5 \min }^{y}$. In this case, the following formulas can be used:

$$
\begin{gathered}
\Delta G^{r}(m)=L_{a}^{y}(m)-G_{a}^{w, y}(m)-L_{r t f, 5 \min }^{y}(m)+G_{r t f, 5 \min }^{w, y}(m) \\
\Delta G^{l f}(m)=L_{r t f .5 \min }^{y}(m)-G_{r t f, 5 \min }^{w, y}(m)-L_{r t f, 1 h r}^{y}(m)+G_{h a, 1 h r}^{w, y}(m)
\end{gathered}
$$

\subsection{The Modeling of the NaS Battery Performance}

\subsubsection{Assumptions}

The following assumptions have been made:

- Because this study focuses on the regulation and real-time dispatch services, it is assumed that the $\mathrm{NaS}$ ba ttery is a lways in an "on" s tate, e ither c harging or di scharging. Therefore, neither start-up nor shut-down costs are considered in this cost calculation.

- Within the battery rated power output, the battery is able to ramp up a nd ramp down to any power output in milliseconds as often as required without shortening its lifecycles. There are two implications from this assumption. First, the battery can provide perfect regulation and real-time dispatch services without ramp rate concerns. Second, as long as the battery power output is within its rating, the on ly factor th at d rives the $b$ attery li fetime is the de pth of discharge (DOD), as shown in Figure 8. 


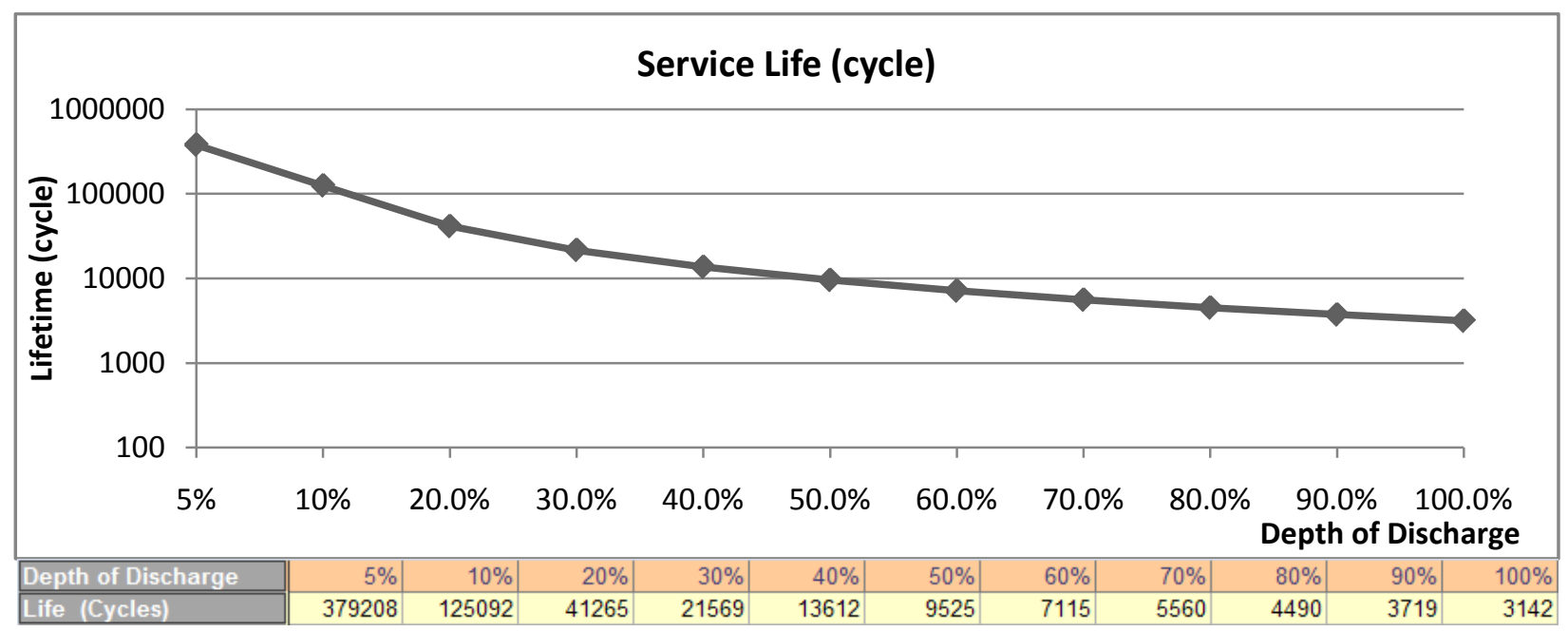

Figure 8: The battery lifetime with respect to the depth of discharge [7]

- It is also assumed that variation of pow er out puts will not negatively influence the battery life. For example, the life of an $\mathrm{NaS}$ battery charging/discharging at a constant power output of 2 MW (Figure 9: blue line) and the life of another $\mathrm{NaS}$ b attery charging/discharging at variable power outputs with an average of 2 MW (Figure 9: purple line) will have the same lifetime. This is an opt imistic a ssumption be cause there will be more wear and tear of the battery and its pow er el ectronics when batteries a re frequently cha rging or di scharging at variable pow er out puts than when they a re charging/discharging at c onstant po wer out put. However, the statistics for such lifetime reduction are not available. Because all cases in this study have been modeled under the same assumption, the results should be comparable.

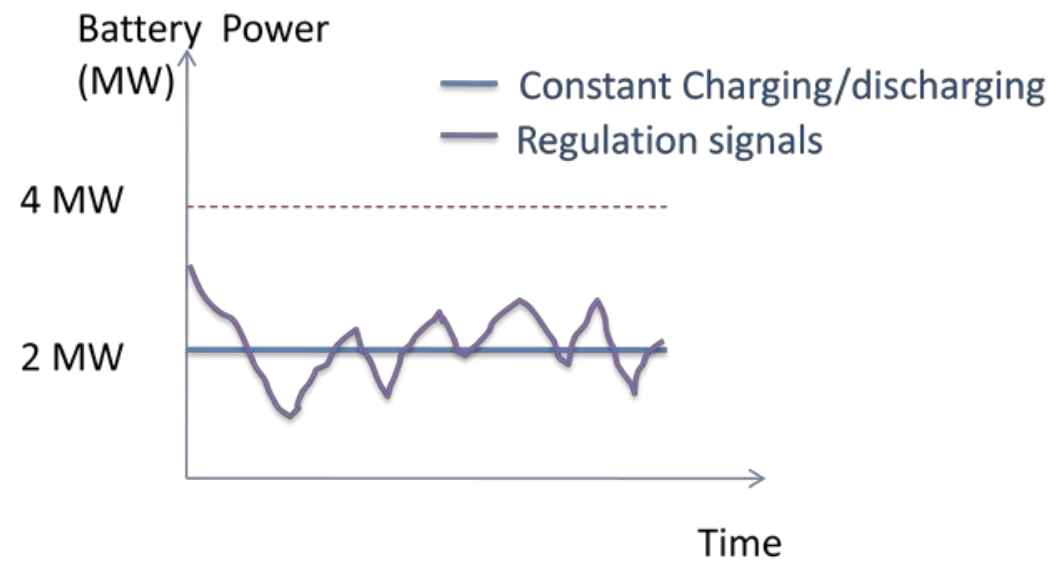

Figure 9: Battery output powers

- The speed of completing a c harging a nd di scharging c ycle ha s no ne gative i mpact on $t$ he battery life. As shown in Figure 10, the wear and tear of a cycle completed in 14 hours is equivalent to a cycle completed in 30 hours. Because the battery life is counted by number of cycles, the longer a cycle is completed, the longer the battery life is. This optimistic assumption may r esult in a non -realistic ba ttery $l$ ife, suc $h$ as 100 years. For example, as shown in Figure 8, the battery life is determined by the number of cycles $w$ ith $\mathrm{r}$ espect to different DODs. Assume that a ba ttery is used for 100 cycles per year at $100 \%$ DOD. By 
calculation, the battery lifetime is 31.42 y ears, which is much longer than the 12 to 20 years service life documented so far. Therefore, we have cappe $d$ the maximum service life of a battery to be 20 years to make our economic analysis realistic.

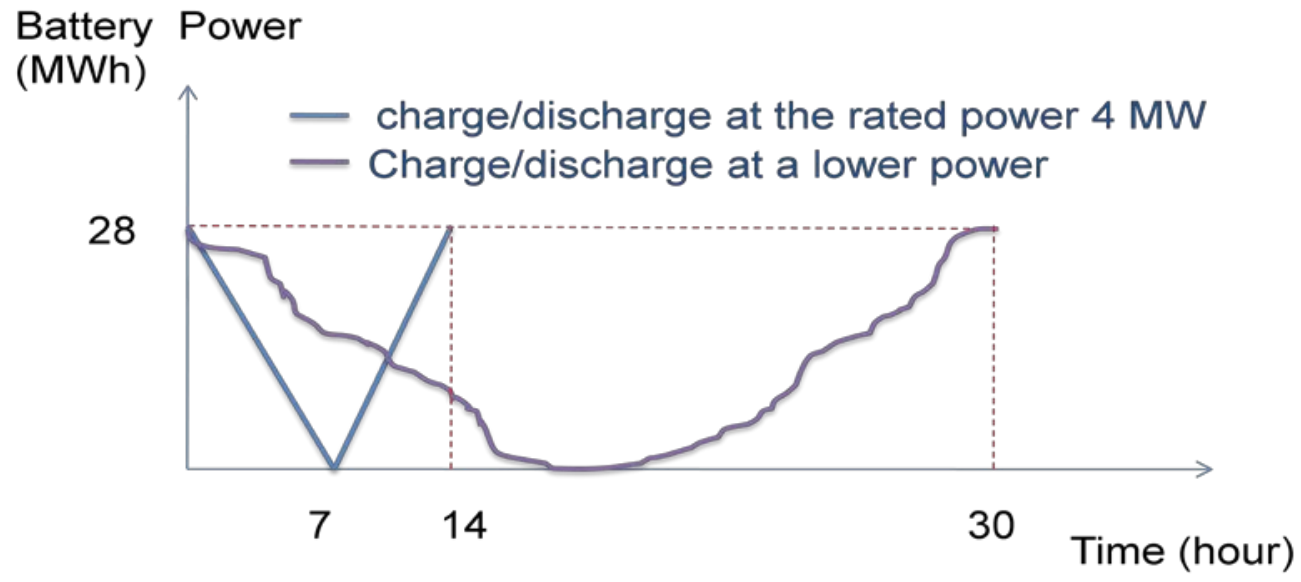

Figure 10: The charging/discharge profiles of an NaS battery

- The maximum service 1 ife of a ba ttery is assum ed to be 20 years to make our econom ic analysis realistic. In our simulation, the calculated lifetime may exceed 20 years.

- To address the influence of different power-capacity ratios, it is assumed that the rated power outputs of the NaS battery can reach $20 \mathrm{MW}$. The NaS battery that PG\&E plans to install has a capacity of $28 \mathrm{MWh}$ and rated power output at $4 \mathrm{MW}$. A $20 \mathrm{MW}$ may not be achievable for current ba ttery $t$ echnology. However, we $w$ ant $t$ he sen sitivity st udy t o provide ba ttery manufacturers a reasonable estimate on how much improvement in the battery is required to provide the regulation and real-time dispatch services. 
Table 5: NaS battery characteristics

\begin{tabular}{|c|c|c|c|}
\hline \multicolumn{2}{|c|}{ NaS Battery Characteristics } & Assumptions & Note \\
\hline \multirow{2}{*}{\multicolumn{2}{|c|}{\begin{tabular}{|l} 
Battery Capacity (MWh) \\
Battery Power (MW)
\end{tabular}}} & 28 & \\
\hline & & 4 & \\
\hline \multicolumn{2}{|c|}{ Battery Life (year) } & No more than 20 & Varies between 12 20 \\
\hline \multirow{4}{*}{ General } & Self Discharging & None & \\
\hline & Efficiency & $75-90 \%$ & $75-90 \%$ \\
\hline & Weight (MWh/kg) & $110 \mathrm{MWh} / \mathrm{kg}$ & \\
\hline & Depth of Discharge (DOD) & $20 \%-100 \%$ & \\
\hline \multirow{4}{*}{ Cost } & Installation Cost ( \$/kWh) & 200 & $150-300$ \\
\hline & Start-up Cost & Not included in the study & \\
\hline & Shut-down Cost & Not included in the study & \\
\hline & Operation Cost (\$) & $3 \%$ of capital cost & \\
\hline \multirow{4}{*}{ Operation } & UP (Discharge) & Ramp-up time in ms & May be limited \\
\hline & DowN (Charge) & Ramp-down time in $\mathrm{ms}$ & May be limited \\
\hline & Cold Start (sec) & Always on (No cold start) & \\
\hline & Shut-down Time & Always on (No shut-down) & \\
\hline
\end{tabular}




\subsubsection{Normalization of the Regulation and Real-time Signals}

The $2012 \mathrm{r}$ egulation and $\mathrm{r}$ eal-time di spatch signals $\mathrm{f}$ or $20 \%$ renewables an $\mathrm{d}$ no wind cases a re generated from 2006 C AISO data sets using methodology described in Section 2.1. As shown in Figure 11 and Figure 12, the regulation and real-time signals of the $20 \%$ renewables case have larger magnitudes than those of the no wind case. The generated signals are total CAISO regulation or real-time dispatch signals and are too big for the NaS battery. Therefore, these signals need to be normalized first, so that the normalized control signals sent to the battery will be mostly within the battery rated power output, $P_{\text {rated }}$.

Based on the probability distribution functions (PDFs) shown in Figure 11 and Figure 12, assuming the battery is required to respond to $95 \%, 90 \%, 80 \%$, and $50 \%$ control signals, values to normalize the total regulation and real-time dispatch signals to $1 \mathrm{MW}$ are calculated, as shown in Table 6 . To gi ve a better illustration, $\mathrm{c}$ umulative de nsity f unctions ( CDFs) of the $\mathrm{r}$ egulation a nd $\mathrm{r}$ eal-time di spatch are plotted in Figure 13 and Figure 14. As illustrated in these two figures, if we normalized the total control signals by the values highlighted in red in Table 6 , then $80 \%$ signals are in the boxes and $20 \%$ signals are outside the boxes. Note that there may be more outliers on one side than another.

The average battery power output $P_{a v e}$ can be calculated by

$$
P_{\text {ave }}=\frac{\sum_{t=1}^{N} \frac{P_{g s}}{P_{\text {norm }}}}{N}
$$

where

$$
\begin{array}{cl}
P_{a v e} & \text { The average battery power output (MW) } \\
P_{g s} & \text { The generated signal magnitude (MW) } \\
P_{\text {norm }} & \text { The value used to normalize the generated signals (MWh) } \\
t & \text { Time (minute) } \\
N & \text { The number of minutes that the battery operates in 1 year }
\end{array}
$$

Equation (12) indicates that a smaller $P_{\text {norm }}$ results in a greater $P_{a v e}$. This implies that if the battery does not respond to extreme regulation and real-time signals, it will run at a higher average output than otherwise. 

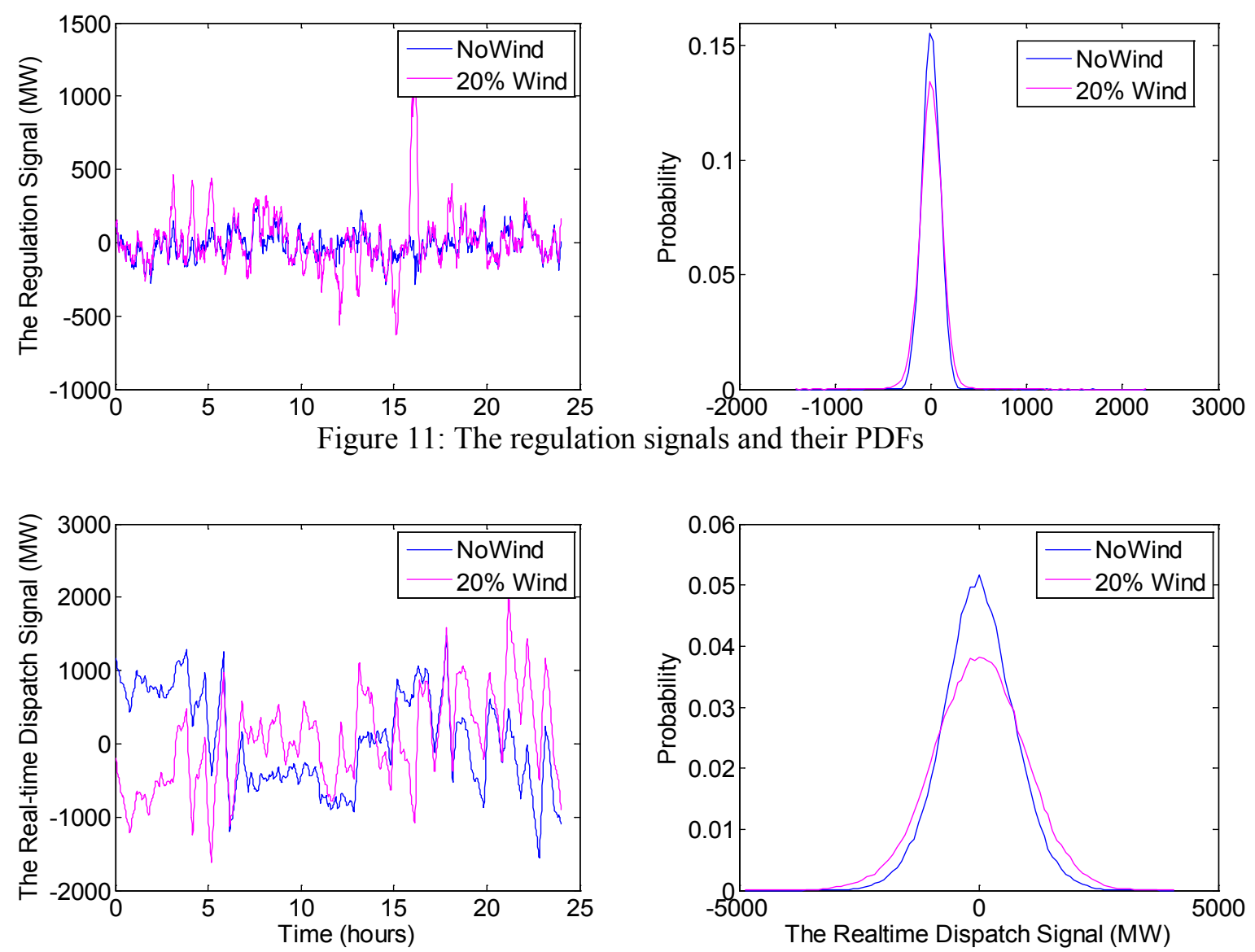

Figure 12: The real-time dispatch signals and their PDFs

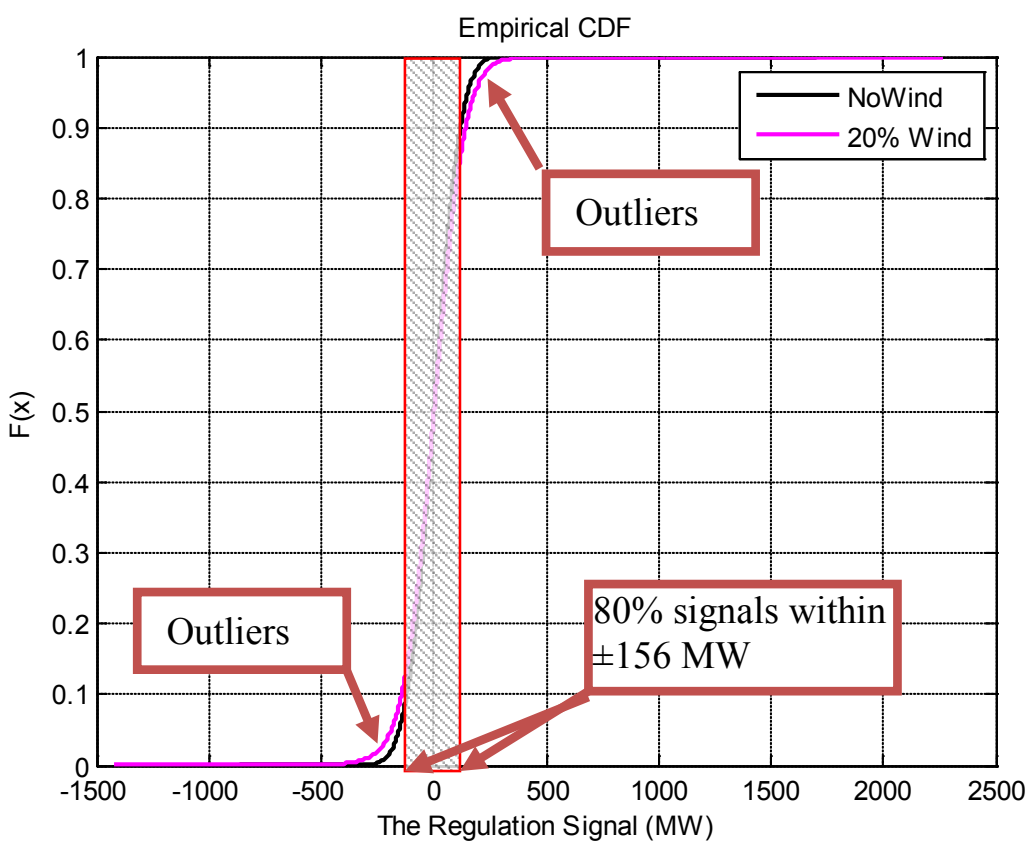

Figure 13: The CDFs of regulation signals 


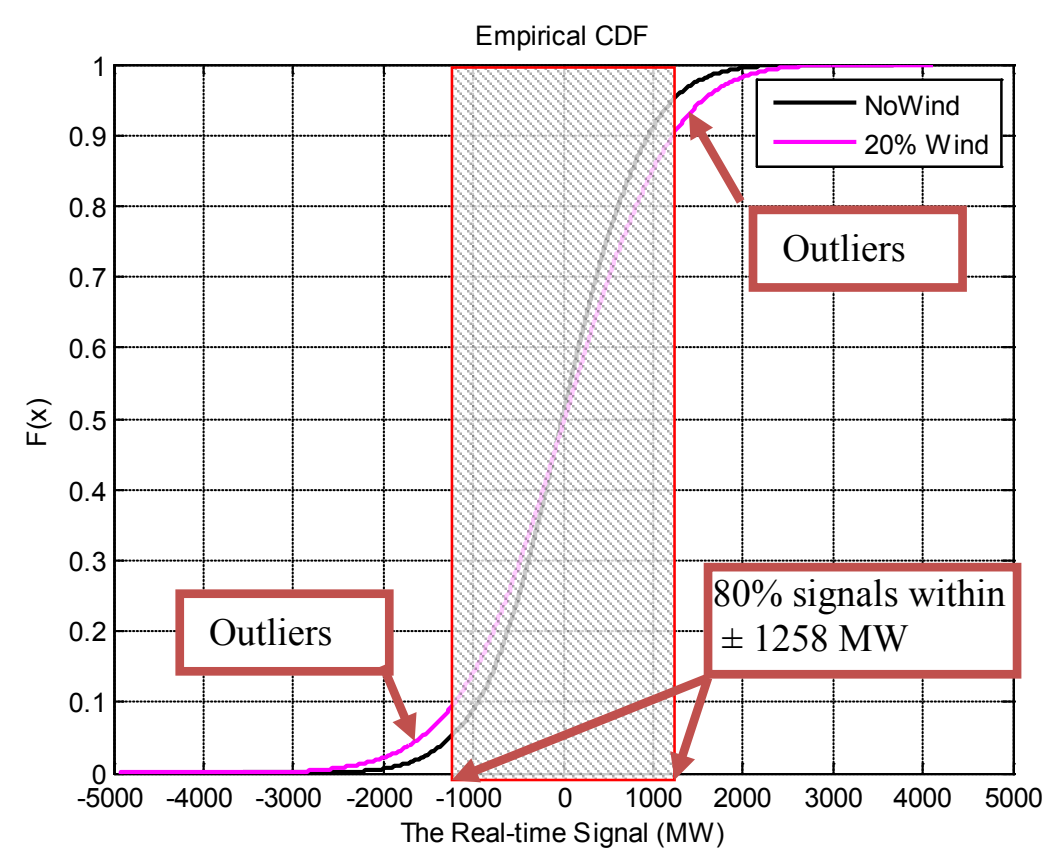

Figure 14: The CDFs of real-time dispatch signals

Table 6: The values to normalize the regulation and real-time dispatch signals

\begin{tabular}{|c|c|c|c|c|c|c|c|c|}
\hline Signals within $\pm 1 \mathrm{MW}$ & \multicolumn{2}{|c|}{$95 \%$} & \multicolumn{2}{|c|}{$90 \%$} & \multicolumn{2}{|c|}{$80 \%$} & \multicolumn{2}{|c|}{$50 \%$} \\
\hline Signals outside $\pm 1 \mathrm{MW}$ & \multicolumn{2}{|c|}{$5 \%$} & \multicolumn{2}{|c|}{$10 \%$} & \multicolumn{2}{|c|}{$20 \%$} & \multicolumn{2}{|c|}{$50 \%$} \\
\hline Case Description & No Wind & $\begin{array}{c}20 \% \\
\text { Renewables }\end{array}$ & No Wind & $\begin{array}{c}20 \% \\
\text { Renewables }\end{array}$ & No Wind & $\begin{array}{c}20 \% \\
\text { Renewables }\end{array}$ & No Wind & $\begin{array}{c}20 \% \\
\text { Renewables }\end{array}$ \\
\hline Regulation (MW) & 193 & 248 & 174 & 211 & 137 & 156 & 83 & 83 \\
\hline Real-time Dispatch (MW) & 1542 & 1903 & 1271 & 1619 & 1000 & 1258 & 535 & 716 \\
\hline
\end{tabular}




\subsubsection{Bi-directional and One-directional Services}

To provide regulation or real-time dispatch service, an $\mathrm{NaS}$ battery can run in either the bi-directional or one -directional m ode. I $\mathrm{t}$ he $\mathrm{b}$ i-directional m ode, t he ba ttery $\mathrm{r}$ esponds to both " up" a nd "down" signals. In the one -directional mode, the ba ttery r esponds to "up" s ignals when it is di scharging and “down" signals when charging.

Define the battery utilization rate $K_{u}$ as:

$$
K_{u}=\frac{P_{a v e}}{P_{\text {rated }}}
$$

or

$$
K_{u}=\frac{E_{\text {annual }}^{\text {actual }}}{E_{\text {annual }}^{\text {max }}}=\frac{P_{\text {ave }} \times 24 \times 365}{P_{\text {rated }} \times 24 \times 365}
$$

where

$$
\begin{aligned}
& P_{\text {ave }} \text { is the average output of the NaS battery (MW) } \\
& P_{\text {rated }} \text { is the rated power (MW) } \\
& E_{\text {annual }}^{\max } \text { is the maximum annual energy provided by the battery (MWh) } \\
& E_{\text {annual }}^{\text {actual }} \text { is the actual annual energy provided by the battery (MWh). }
\end{aligned}
$$

Then, the battery has a $100 \%$ utilization rate if charging or discharging at its rated power. If the regulation and real-time dispatch signals vary within the battery rated power, the utilization rates are normally 30 $40 \%$, as shown in Table 7.

Table 7: The utilization rates of the NaS Battery when providing bi-directional ancillary services

\begin{tabular}{|l|c|c|c|c|}
\hline & $\begin{array}{c}\text { Regulation } \\
\text { with Wind }\end{array}$ & $\begin{array}{c}\text { Real-time } \\
\text { with Wind }\end{array}$ & $\begin{array}{c}\text { Regulation } \\
\text { without Wind }\end{array}$ & $\begin{array}{c}\text { Real-time } \\
\text { without Wind }\end{array}$ \\
\hline $\begin{array}{l}\text { Annual Energy (MWh) } \\
\text { (At battery rated power 4 MW) }\end{array}$ & 35040 & 35040 & 35040 & 35040 \\
\hline $\begin{array}{l}\text { Annual Energy (MWh) } \\
\text { (Bi-directional ancillary services) }\end{array}$ & 13245 & 10893 & 12948 & 10376 \\
\hline Maximum Utilization & 0.38 & 0.31 & 0.37 & 0.30 \\
\hline
\end{tabular}

There are a few disadvantages to operating the battery to respond to bi-directional signals:

- The battery needs to switch from the charging to discharging mode frequently. This requires complicated control schemes and shortens battery life.

- Because signals are biased in nature, the battery capacity may be depleted from time to time, as shown in Figure 15. 
- Because the battery constantly charges and discharges, it is impossible to estimate the battery life from the relationship between the DODs and battery lifecycles.

This study focused on the one-directional service provided by the NaS battery, as shown in Figure 16. The advantages of the one-directional service are:

- The battery is either charging or discharging, so the control mechanism is simple.

- No operation point correction is needed. For example, the battery will switch from providing regulation up services to regulation down services when it reaches the discharging threshold.

- Lifecycles are relatively easy to estimate based on the DODs.

The disadvantages are:

- Lost opportunities. As shown in Figure 17, the battery c an only provide either the "up" or "down" s ervice in the one-direction mode but not both at the s ame time. This results in a revenue loss.

- A reduced utilization rate. At least half of the signals were not responded to. Therefore, the battery sells less energy in the one-direction mode than the bi-directional mode. For example, as shown in Figure 18, a $28 \mathrm{MWh} / 4 \mathrm{MW}$ battery at 100\% DOD in the one-directional mode provides $48 \%$ regulation energy than it provides in the bi-directional mode. Note that if a battery's cost depends on the capacity but not by the actual energy it supplied, then a reduced utilization rate will not result in revenue losses.

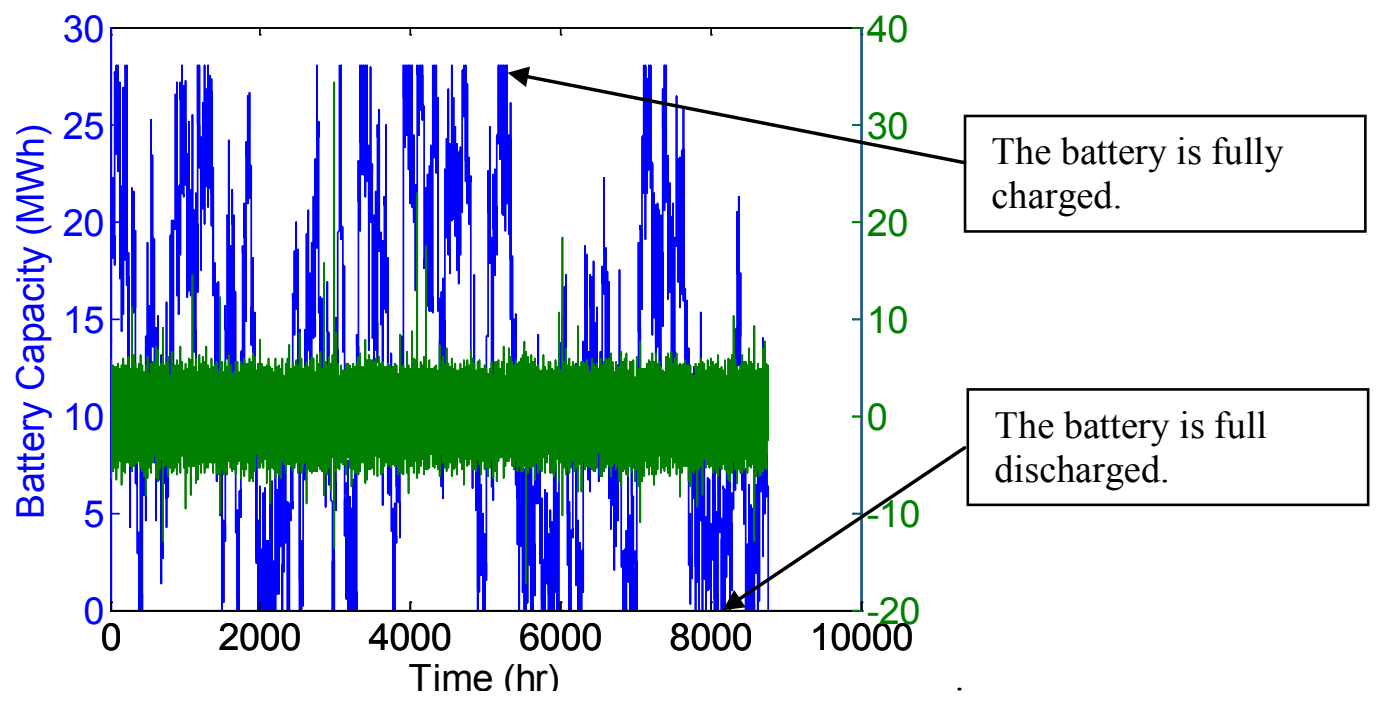

Figure 15: The bi-directional regulation services provided by the $28 \mathrm{MWh} / 4 \mathrm{MW}$ NaS battery. (Green: the regulation signals normalized to $\pm 4 \mathrm{MW}$ ) 


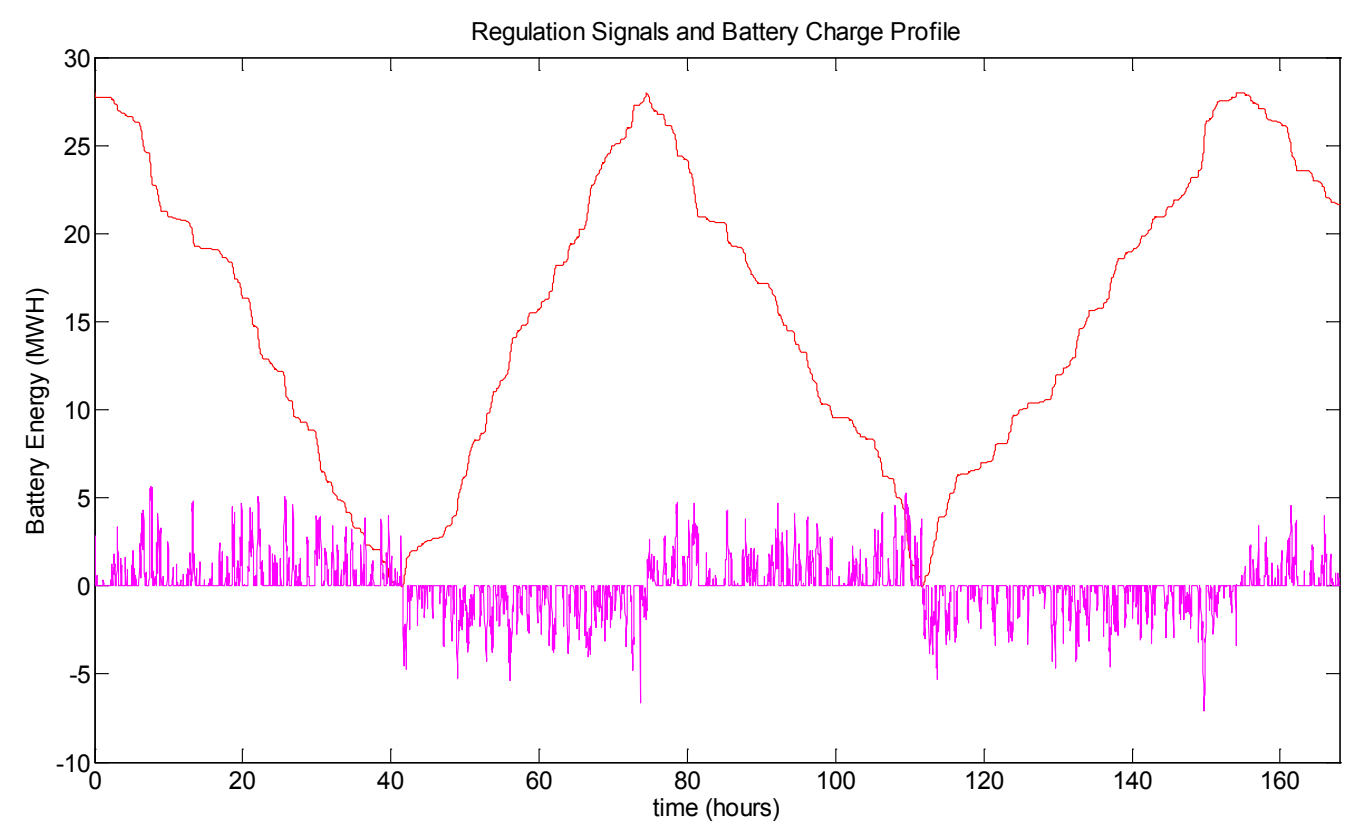

Figure 16: The one-directional service provided by the NaS battery

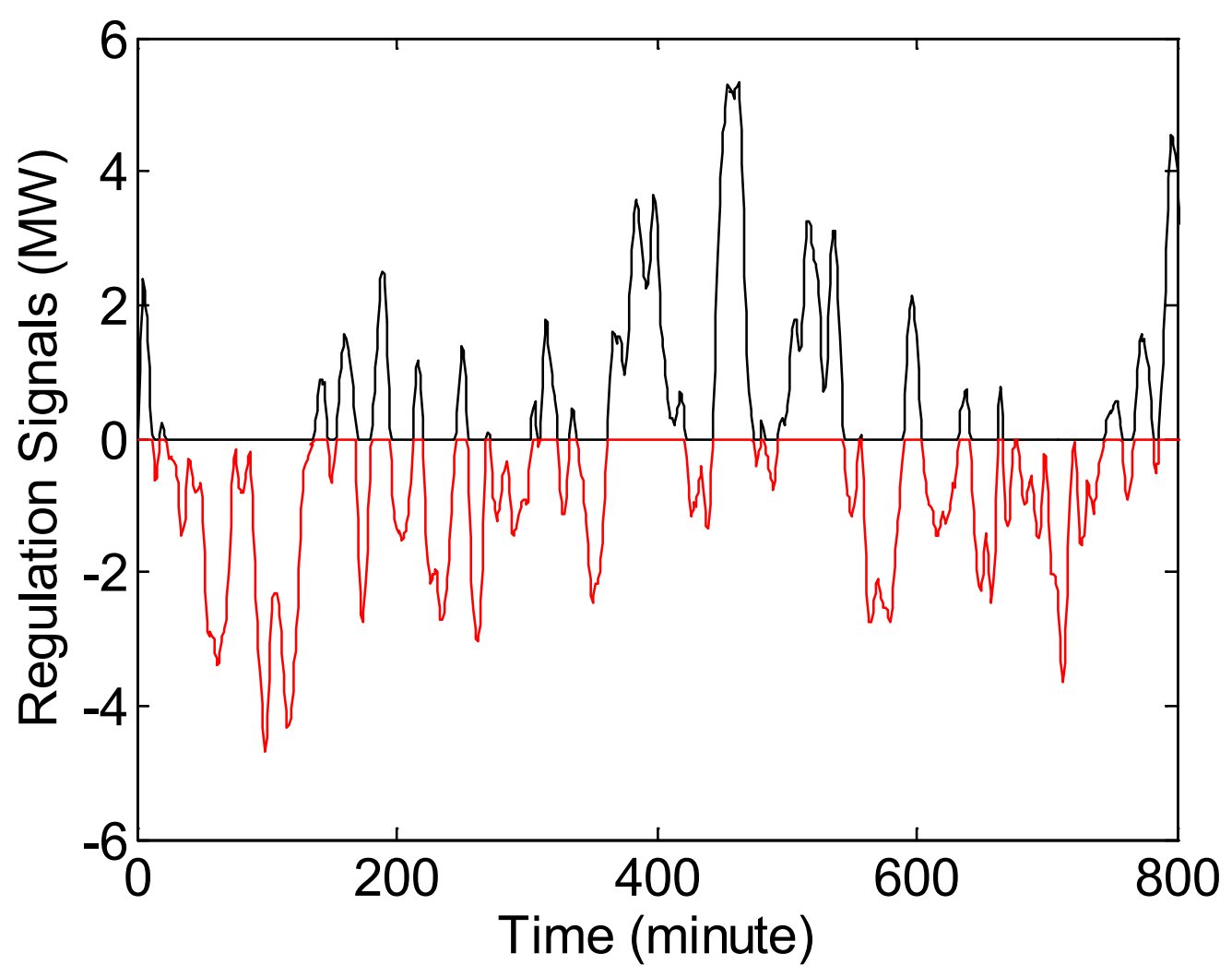

Figure 17: The regulation "up" (black lines) and "down" (red lines) signals 


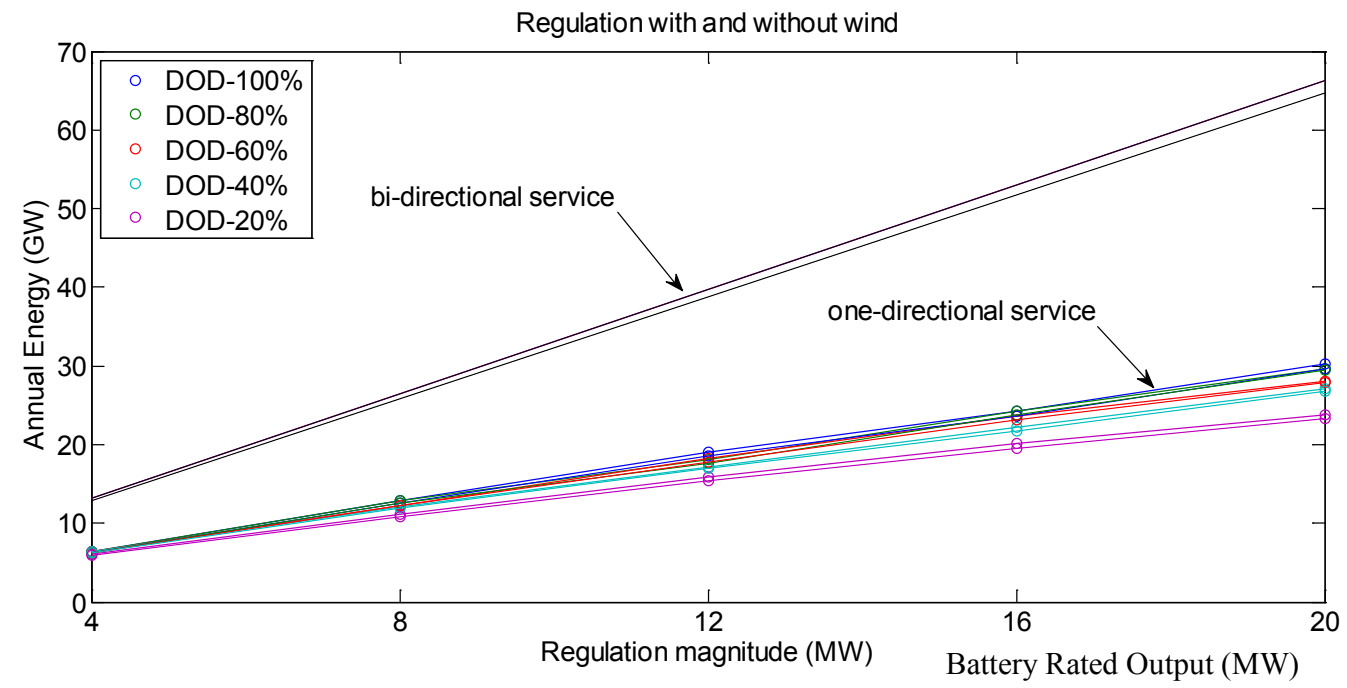

Figure 18: A comparison of bi-directional services and one-directional services provided by the $\mathrm{NaS}$ battery (Dotted lines: without wind; Solid lines: with wind)

\subsubsection{The Depth of Discharge (DOD)}

Operating at different depths of discharge, the NaS battery has different lifecycles. Figure 19 illustrates the charging and discharging profiles of an $\mathrm{NaS}$ battery in response to $4 \mathrm{MW}$ regulation signals. Note that the energy the NaS battery provides in a cycle is calculated as:

$$
E_{\text {cycle }}=2 E_{r} \times D O D \times \eta
$$

The battery lifetime energy is calculated as:

$$
E_{\text {lifetime }}=E_{\text {cycle }} \times L_{c}
$$

The battery lifetime is calculated as:

$$
L_{y}=\frac{L_{c}}{n_{c}}
$$

where

$E_{\text {cycle }}$ Cycling energy of the battery (MWh)

$E_{\text {life }} \quad$ Lifetime energy (MWh)

$E_{r} \quad$ The NaS battery rated capacity (MWh)

$L_{c} \quad$ Life (cycle)

DOD Depth of discharge (DOD)

$n_{c} \quad$ Number of charge/discharge cycles in a year 


\section{$\eta \quad$ Efficiency \\ $L_{y} \quad$ Life (years)}

The lifetime energy provided by an NaS battery at different DODs is plotted out in Figure 20.

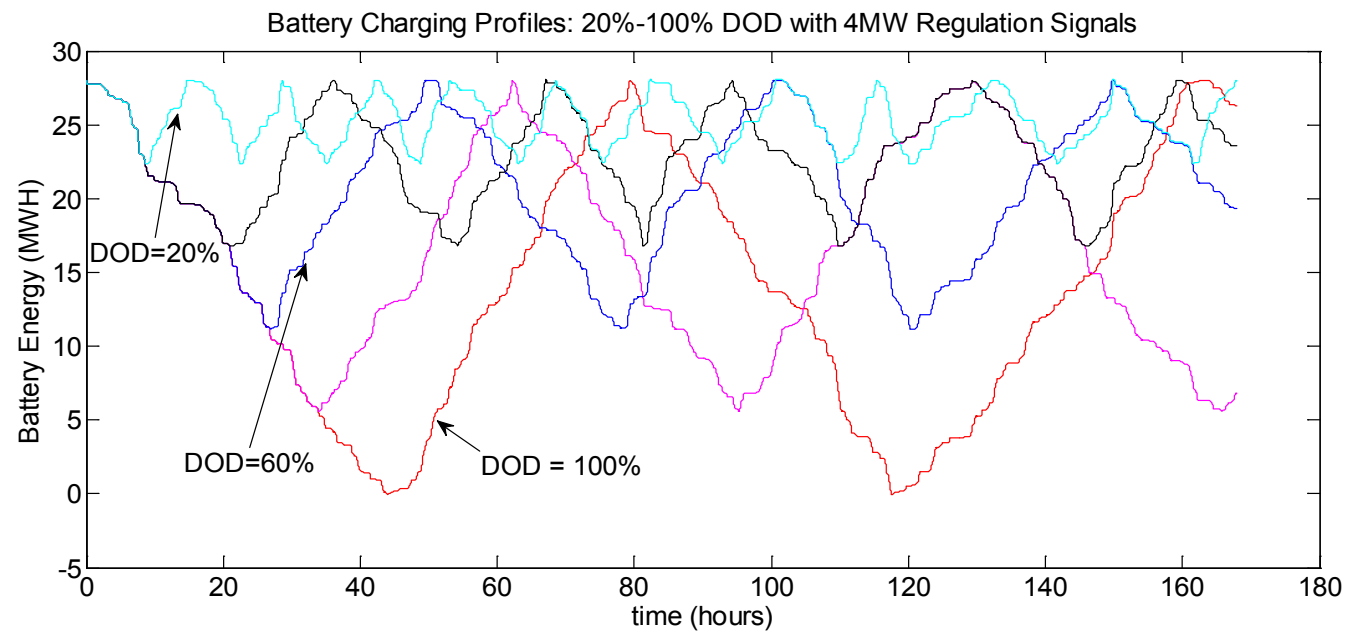

Figure 19: The battery charging and discharging profiles (DOD: 20\% - 100\%)

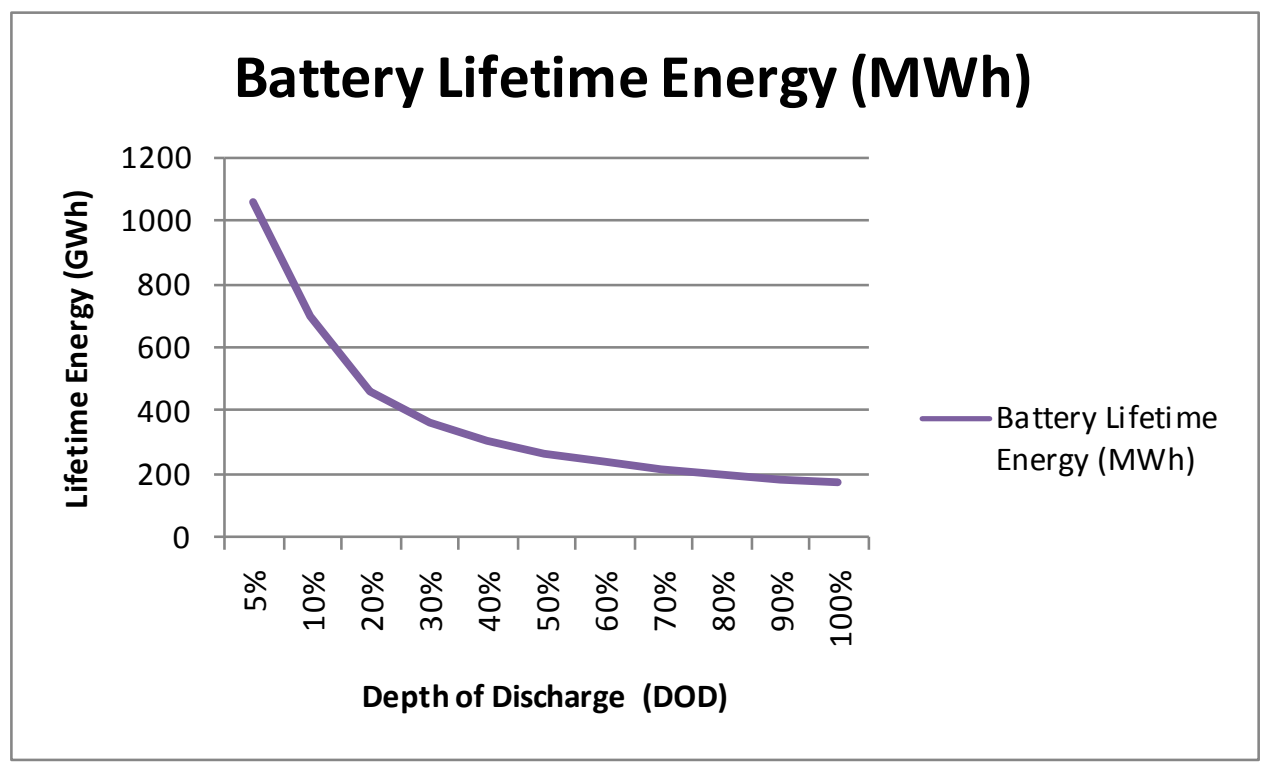

Figure 20: The battery lifetime energy (DOD: 5\% - 100\%) 


\subsection{Economic Analysis}

In this s tudy, the regulation and real-time di spatch ancillary ser vices w ere ev aluated sep arately to calculate the price $\mathrm{r}$ equired to breakeven for eac $\mathrm{h}$ service. NPV ne eds to be evaluated based on all revenue streams available to the battery. This analysis only evaluated the breakeven costs associated with individual se rvices. If $\mathrm{f}$ uture $\mathrm{w}$ ork scope is funded, an analysis that ev aluates the $\mathrm{m}$ ultiple s ervices simultaneously will be undertaken and a net present value analysis can be undertaken. Investors primarily look for the NPV of the after-tax cash flows from the investment over its life.

\subsubsection{Assumptions}

A 4 MW N aS ba ttery ba nk w ith a 28 MWh capacity w as ev aluated. Each ancillary ser vice w as evaluated against a simulated CAISO si gnal and a s imulated C AISO signal with $20 \%$ of supply be ing provided by renewable energy resources. In addition, the same battery bank was evaluated at MW power ratings of 8 to $20 \mathrm{MW}$ in $4 \mathrm{MW}$ increments adjusting the capacity for each power rating to maintain the same battery bank. Evaluating the battery ba nk at different power $r$ atings provides an e valuation of whether higher power ratings could be efficacious under certain circumstances. Thus, four basic analyses were pe rformed- regulation with current C AISO s ignal a nd a s imulated CAISO w ith 20 percent renewables, and the same was performed for the real-time dispatch ancillary service.

Regardless of the DOD, it was assumed that the maximum service life of the battery was 20 years. However, at some DODs, primarily 80 and 100 percent with higher MW power ratings, a reduced service life can occur. The analysis used the minimum of the calculated battery life or 20 years [8].

We assumed that the real discount rate was 8 percent, a real rate of return appropriate for a utility. In addition, 7 pe rcent, a di scount rate the $\mathrm{O}$ ffice of Management and Budget requires for market analysis was us ed [9]. The battery bank w as assumed to cost $\$ 200 / \mathrm{kWh}$ based on Walawalker and Apt [8]. A sensitivity case was evaluated based on $\$ 150 / \mathrm{kWh}$. At $\$ 200 / \mathrm{kWh}$, the $4 \mathrm{MW}, 28 \mathrm{MWh}$ battery bank cost $\$ 5.6 \mathrm{~m}$ illion. In a ddition, California s ales tax of $8.25 \% \mathrm{w}$ as a dded to the cost of the ba ttery capital, increasing $\mathrm{i}$ ts total $\mathrm{c}$ ost $\mathrm{t}$ o $\mathrm{m}$ ore $\mathrm{t}$ han $\$ 6 \mathrm{~m}$ illion. Operations a nd $\mathrm{m}$ aintenance ( O\&M) co sts $\mathrm{w}$ ere estimated at 3 percent of capital costs [8]. A sens itivity case 1 owered the O\&M cost to 1 percent. In addition, the total annual operations costs included a charge of $1 \%$ each for property taxes and insurance. Potentially, the efficiency of charge and recharge could affect the O\&M cost. However, the cost of energy to the battery was assumed to be $\$ 0 / \mathrm{kWh}$ as the ancillary service is to provide regulation and real-time dispatch, each of which occur as the battery charges and discharges. If a co st for charging the battery existed, the efficiency of $\mathrm{t}$ he $\mathrm{c}$ ycle $\mathrm{w}$ ould ha ve $\mathrm{b}$ een i ncluded. Walawalker a nd A pt indicated that efficiency of the $\mathrm{NaS}$ battery was $75 \%$ [8][8]. In our sensitivity study, efficiency was analyzed at $90 \%$, as indicated in Phase I report by Makarov et al [6].

\subsubsection{Breakeven Calculation}

The breakeven cost assumes that the annualized cost of capital provides an adequate rate of return to the investor. Thus, an 8 percent real rate of return is usually comparable to a nominal 10 to 11 percent rate of return before taxes. The discount rate is usually representative of the entity's weighted cost of capital. Breakeven costs include the annualized cost of capital plus the annual operations and maintenance costs. 
Thus the annualized cost of capital including profit before taxes is as follows

$$
C_{\text {cap }}=\frac{\left(C_{\text {install }} \times(1+i)^{n} \times i\right)}{(1+i)^{n}-1}
$$

where: $\quad C_{\text {cap }}$ is the annualized cost of capital

$C_{\text {install }}$ is the installed capital cost including sales taxes

$i$ is the discount rate

$n$ is the life of the asset.

$$
C_{O \& M}=\left(k_{o p}+k_{p t}+k_{p i}\right) \times C_{\text {install }}+(1-\eta) \times P
$$

where: $\quad C_{O \& M}$ is the annual operation and maintenance cost

$C_{\text {install }}$ is the installed capital cost

$k_{\text {op }}$ is the percent of the installed capital associated with annual O\&M

$k_{p t}$ is the percent of the installed capital associated with property tax

$k_{p i}$ is the percent of the installed capital associated with insurance

$\eta$ is the efficiency of recharge

$P$ is the price of energy in $\$ / \mathrm{kWh}$.

$$
P_{B E}=C_{c a p}+C_{O \& M}
$$

where: $\quad P_{B E}$ is the breakeven price in $\$ / \mathrm{kWh}$

\subsubsection{NPV Calculation}

The NPV calculation evaluates the stream of ca sh flows from a project using the company's hurdle rate as the discount rate. The hurdle rate is the company's required rate of return on projects. Investments with an NPV greater than 0 indicate that the project has a higher rate of return than the company's hurdle rate.

$$
N P V=\sum_{1}^{n} \frac{N C F}{(1+r)^{(n-1)}}
$$

where: $\quad N P V$ is net present value

$N C F$ is the annualized net cash flow

$r$ is the entities discount rate

$n$ is life in years of the battery 


\subsection{Modeling Results}

This section presents the modeling results.

\subsection{Assumptions}

The assumptions are as follows:

- At $t=0$, the NaS battery is fully charged.

- The battery is always online (charging, discharging, or idling)..

- To provide one-directional services, the NaS battery responds to "up" signals when it is discharging and "down" signals when it is charging.

- Battery lifecycles are determined by the DODs, as shown in Table 8.

Table 8: The lifecycles of the NaS battery with respect to the DODs

\begin{tabular}{||c||c|c|c|c|c|c|c|c|c|c|c|}
\hline \multicolumn{1}{|c|}{ DOD } & $5 \%$ & $10 \%$ & $20.0 \%$ & $30.0 \%$ & $40.0 \%$ & $50.0 \%$ & $60.0 \%$ & $70.0 \%$ & $80.0 \%$ & $90.0 \%$ & $100.0 \%$ \\
\hline \hline \multirow{2}{*}{ Life (Cycles) } & 379208 & 125092 & 41265 & 21569 & 13612 & 9525 & 7115 & 5560 & 4490 & 3719 & 3142 \\
\hline
\end{tabular}

- The maximum battery life is 20 years.

- Regulation signals are generated based on 2006 CAISO da ta. Two cases w ere considered: 2010 without wind and 2010 with $20 \%$ renewables.

- The NaS battery capacity is $28 \mathrm{MWH}$.

- In the base case, the battery rated power output is $4 \mathrm{MW}$. Rated power outputs at $8,12,16$, and $20 \mathrm{MW}$ were also studied to compare the influence of the NaS battery power to capacity ratio.

- The start-up or shut-down costs were not considered.

- Two pairs of parameters were considered in the economic analysis. The high-end and lowend costs are calculated based on Table 9. The breakdown of O\&M costs is shown in Table 10. Those costs highlighted in red are the parameters that have different high-end and lowend values. 
Table 9: The inputs of the model

\begin{tabular}{|l|c|c|}
\hline Variables & High-end Values & Low-end Values \\
\hline \hline Maximum Battery Life (yr) & 20 & 20 \\
\hline Discount Rate & 0.08 & 0.07 \\
\hline Capacity (MWh) & 28 & 28 \\
\hline Cost (\$/kWh) & 200 & 150 \\
\hline Sales Tax & 0.0825 & 0.0825 \\
\hline Capital Cost (\$) & $6,062,000$ & $4,546,500$ \\
\hline Efficiency & 0.75 & 0.9 \\
\hline Total O\&M (\% of Capital) & 0.05 & 0.03 \\
\hline
\end{tabular}

Table 10: The breakdown of the total O\&M cost

\begin{tabular}{|l|c||c|}
\hline \hline Variables & Values (High End) & Values (Low Ends) \\
\hline \hline Insurance & 0.01 & 0.01 \\
\hline Property Tax & 0.01 & 0.01 \\
\hline Annual fixed O\&M & 0.03 & 0.01 \\
\hline Total O\&M (\% of Capital) & 0.05 & 0.03 \\
\hline
\end{tabular}

\subsection{Fixed Battery Lifetime with Different DODs}

The first scenario is the fixed battery lifetime (20 years) study for a $28 \mathrm{MWh}$ battery with rated power output of $4 \mathrm{MW}$. This study is purely a cost study to show how many cycles a battery needs to run each year at different DODs and how much energy it can provide to the grid if the battery runs for 20 years. It also shows, assuming that the battery is paid-by-energy, at what cost the battery owner can breakeven.

\subsubsection{Base Case}

Note that in this calculation, we do not consider the c ost of the e nergy lost in the charging a nd discharging process. Therefore, the O\&M cost is calculated by letting price $P=0$ in Equation (19):

$$
C_{O \& M}=\left(k_{o p}+k_{p t}+k_{p i}\right) \times C_{\text {install }}+(1-\eta) \times P=\left(k_{o p}+k_{p t}+k_{p i}\right) \times C_{\text {install }}
$$

Two breakeven prices are calculated for the high-end and low-end cases: the breakeven prices of $0 \%$ and $8 \%$ profits with high-end cases and $0 \%$ and $7 \%$ profits with $10 \mathrm{w}$-end cases. The DODs are varied from 5\% to $100 \%$. The input parameters a re shown in Table 9. The costs are calculated based on the method discussed in Section 2.3.2. The breakeven prices are shown in Table 11 and plotted in Figure 21. The battery performance characteristics are calculated by: 


$$
\begin{gathered}
n_{y}=\frac{L_{c}}{L_{y}}=\frac{L_{c}}{20} \\
n_{h}=\frac{L_{c}}{L_{y} \times 24 \times 365}=\frac{L_{c}}{20 \times 24 \times 365} \\
P_{\text {ave }}=2 E_{B} n_{h}=2 E_{B} \frac{L_{c}}{20 \times 24 \times 365} \\
E_{\text {annual }}=L_{y} \times 2 E_{B} \times \eta \\
E_{\text {life }}=L_{c} \times 2 E_{B} \times \eta \\
K_{u}=\frac{P_{\text {ave }}}{P_{\text {rated }}}
\end{gathered}
$$

where

$$
\begin{array}{ll}
P_{\text {rated }} & \text { is the battery rated power (MW) } \\
P_{a v e} & \text { is the battery average power output (MW) } \\
E_{B} & \text { is the battery rated capacity (MWh) } \\
L_{c} & \text { is the battery life in cycle } \\
L_{y} & \text { is the battery life in year } \\
n_{y} & \text { is the number of cycles in 1 year } \\
n_{h} & \text { is the number of cycles in an hour } \\
k_{u} & \text { is the utilization factor } \\
\eta & \text { is the battery efficiency } \\
E_{\text {life }} \quad \text { is the battery lifetime energy (MWh) } \\
E_{\text {Annual }} \text { is the annual energy (MWh). }
\end{array}
$$

The calculated battery performance characteristics are shown in Table 12. 
Table 11: The cost calculations - base case (fixed lifetime at 20 years)

\begin{tabular}{|c|c|c||c|c||c|c|}
\hline \multicolumn{3}{|c||}{\begin{tabular}{c} 
Base Case \\
\multicolumn{2}{|c||}{ With current technology }
\end{tabular}} & \multicolumn{2}{c||}{$\begin{array}{c}\text { High End Breakeven Price } \\
\text { (\$/MWh) }\end{array}$} & \multicolumn{2}{c|}{$\begin{array}{c}\text { Low End Breakeven } \\
\text { Price (\$/MWh) }\end{array}$} \\
\hline \hline Life & DOD & Life (cycle) & 0\% Profit & $8 \%$ Profit & 0\% Profit & $7 \%$ Profit \\
\hline \hline 20 & $5 \%$ & 379208 & 15.22 & 23.12 & 7.61 & 11.84 \\
\hline 20 & $10 \%$ & 125092 & 23.08 & 35.04 & 11.54 & 17.94 \\
\hline 20 & $20 \%$ & 41265 & 34.98 & 53.11 & 17.49 & 27.19 \\
\hline 20 & $30 \%$ & 21569 & 44.61 & 67.74 & 22.31 & 34.68 \\
\hline 20 & $40 \%$ & 13612 & 53.02 & 80.51 & 26.51 & 41.22 \\
\hline 20 & $50 \%$ & 9525 & 60.61 & 92.04 & 30.31 & 47.12 \\
\hline 20 & $60 \%$ & 7115 & 67.62 & 102.68 & 33.81 & 52.57 \\
\hline 20 & $70 \%$ & 5560 & 74.17 & 112.63 & 37.08 & 57.66 \\
\hline 20 & $80 \%$ & 4490 & 80.36 & 122.03 & 40.18 & 62.48 \\
\hline 20 & $90 \%$ & 3719 & 86.24 & 130.96 & 43.12 & 67.05 \\
\hline 20 & $100 \%$ & 3142 & 91.87 & 139.51 & 45.94 & 71.43 \\
\hline
\end{tabular}

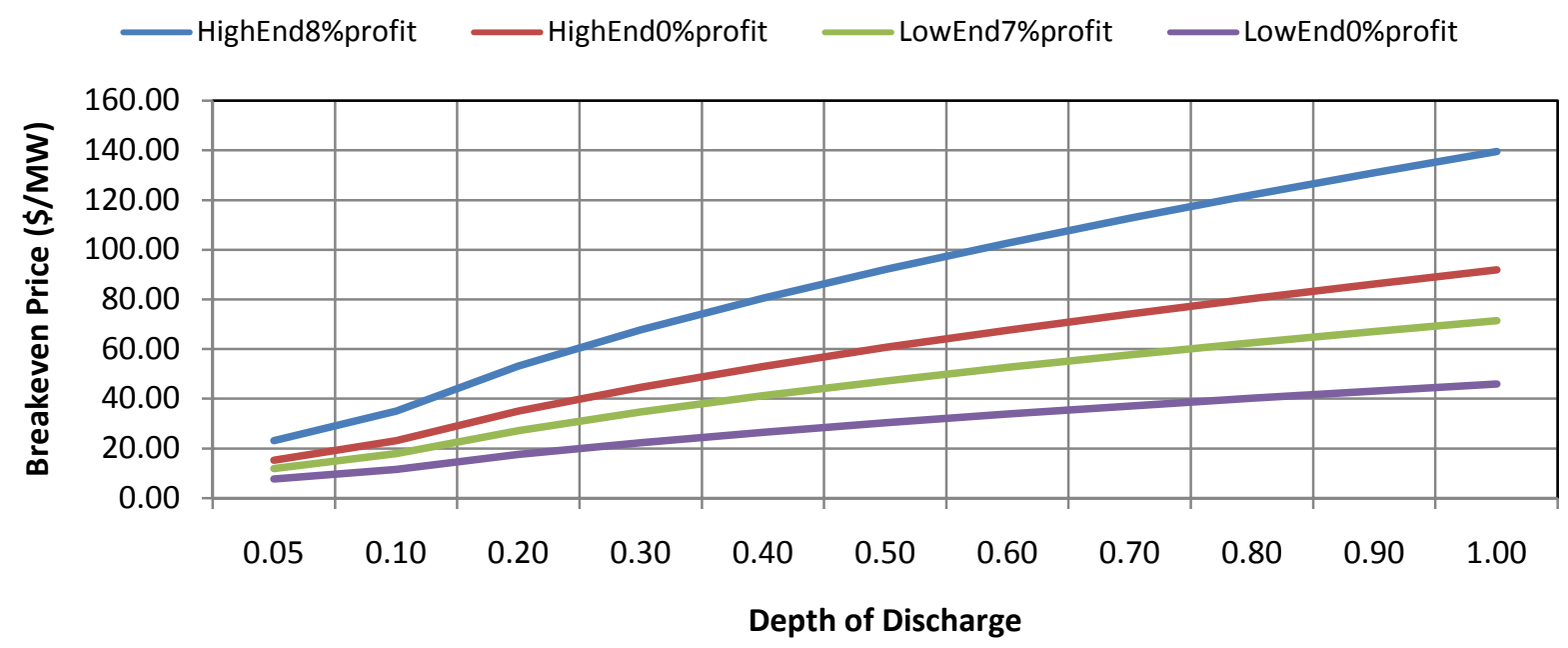

Figure 21: The breakeven prices (fixed lifetime at 20 years) 
Table 12: The NaS battery performance characteristics (fixed lifetime at 20 years)

\begin{tabular}{|c|c|c|c|c|c|c|c|c|}
\hline $\begin{array}{l}\text { Life } \\
\text { (year) }\end{array}$ & $E_{B}(M W h)$ & $\begin{array}{l}P_{\text {rated }} \\
(\mathrm{MW})\end{array}$ & DOD & $\begin{array}{l}\text { Life } \\
\text { (cycle) }\end{array}$ & cycle/yr & cycle/hr & $P_{\text {ave }}(M W)$ & $\mathbf{K}_{\mathbf{u}}$ \\
\hline 20.00 & 28 & 4 & 0.05 & 379208 & 18960 & 2.1644 & 4.00 & 1.00 \\
\hline 20.00 & 28 & 4 & 0.10 & 125092 & 6255 & 0.714 & 4.00 & 1.00 \\
\hline 20.00 & 28 & 4 & 0.20 & 41265 & 2063 & 0.236 & 2.64 & 0.66 \\
\hline 20.00 & 28 & 4 & 0.30 & 21569 & 1078 & 0.123 & 2.07 & 0.52 \\
\hline 20.00 & 28 & 4 & 0.40 & 13612 & 681 & 0.078 & 1.74 & 0.44 \\
\hline 20.00 & 28 & 4 & 0.50 & 9525 & 476 & 0.054 & 1.52 & 0.38 \\
\hline 20.00 & 28 & 4 & 0.60 & 7115 & 356 & 0.041 & 1.36 & 0.34 \\
\hline 20.00 & 28 & 4 & 0.70 & 5560 & 278 & 0.032 & 1.24 & 0.31 \\
\hline 20.00 & 28 & 4 & 0.80 & 4490 & 225 & 0.026 & 1.15 & 0.29 \\
\hline 20.00 & 28 & 4 & 0.90 & 3719 & 186 & 0.021 & 1.07 & 0.27 \\
\hline 20.00 & 28 & 4 & 1.00 & 3142 & 157 & 0.018 & 1.00 & 0.25 \\
\hline
\end{tabular}

Below are a few observations:

- The breakeven price calculation indicates that the energy price has to be higher than the $0 \%$ profit breakeven price for the owner to make a profit. As shown in Table 11, we also studied the case with $7 \%$ and $8 \%$ profit for the low-end and high-end cases, respectively. Most companies would require at least the $7 \%$ return to consider the investment.

- Table 11 and Figure 21 show that if an NaS battery is operated for 20 years at its rated output, operating at a lower DOD results in less cost with the current lifecycle-DOD curve.

- Table 12 shows that at higher DODs, maintaining a fixed battery lifetime of 20 years, the $\mathrm{NaS}$ battery must be operated less frequently. As a result, the average power output of the battery is lower. F or example, if a n N aS battery ope rates at $10 \% \mathrm{D}$ OD, it can $\mathrm{r}$ un at $4 \mathrm{M} \mathrm{W}$ and 6255 cycles/year. However, at 100\% DOD, the battery can only run at an average output of $1 \mathrm{MW}$ and 157 cycle/year. Thus, if the battery runs at $4 \mathrm{MW}$ and $100 \%$ DOD, it will not last 20 years. 


\subsubsection{Impact of improved lifecycle-DOD characteristics}

If lifecycles at higher DODs can be significantly increased (the red line in Figure 22), the breakeven prices will drop significantly when running at higher DODs because more energy will be provided during the 20 -year service life. As shown in the da shed lines in Figure 23 and the lower portion of Table 13, running at higher DODs may become cheaper than at lower DODs. As shown in Figure 24, the annual capital cost will drop below \$20/MWh, and the annual O\&M will drop below \$10/MWh at 100\% DOD.

Note that when the battery is providing energy services, it can run at a selected constant power output. However, when it responds to ancillary ser vice si gnals, the signals vary within a range. As show $\mathrm{n}$ in Table 7, when providing regulation and real-time dispatch services, an NaS battery runs at $30 \%$ to $40 \%$ of its rated power output. Therefore, it is only realistic to model the battery performance with regulation and real-time dispatch signals to determine the economics of the battery when providing the ancillary service.

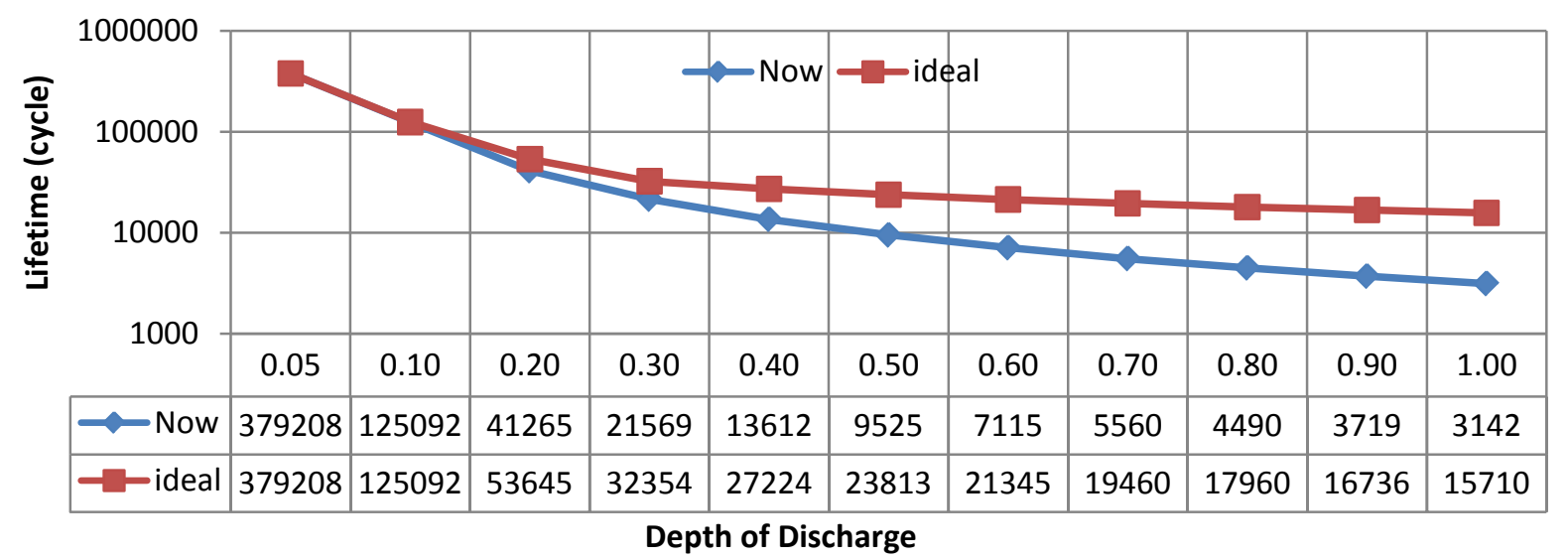

Figure 22: The battery lifecycle curves

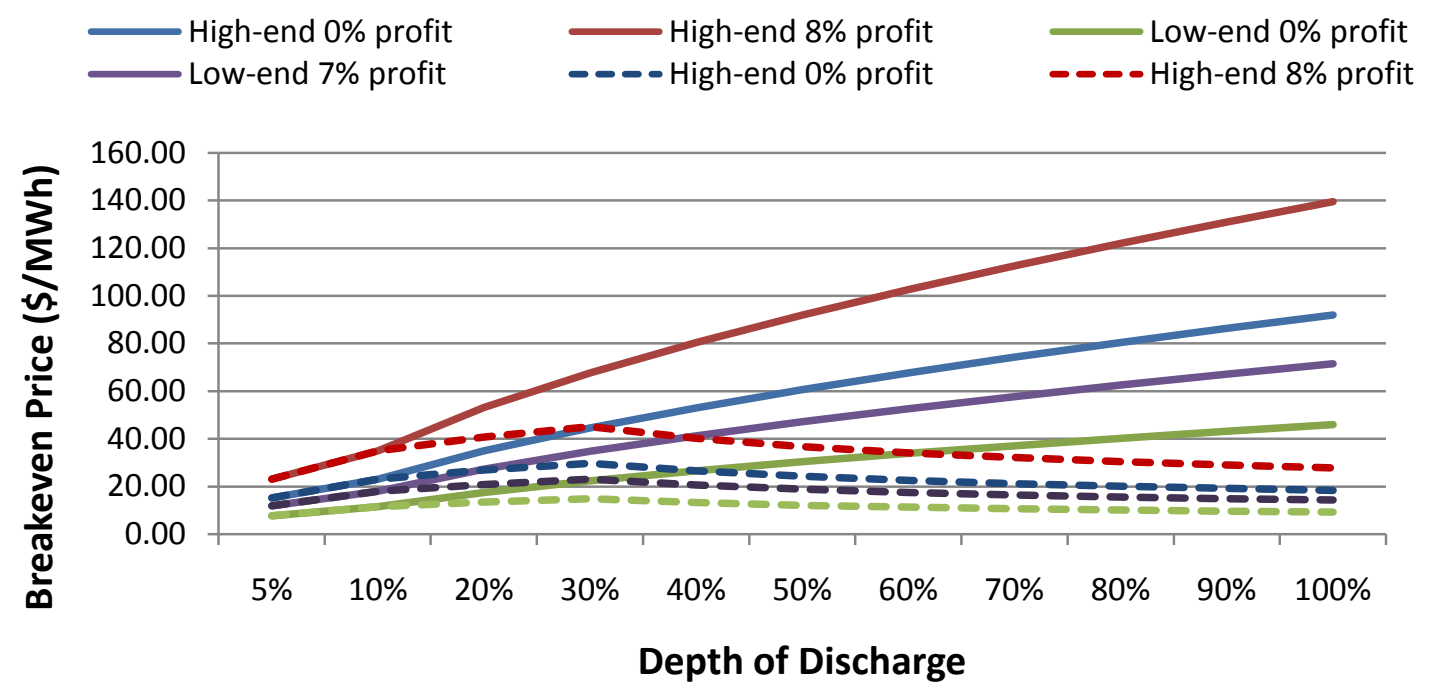

Figure 23: A comparison of high-end and low-end breakeven prices of the improved battery lifecycle case (dashed lines) and the Base case (solid lines) 
Table 13: A cost comparison of the base case and the improved lifecycle case

\begin{tabular}{|c|c|c|c|c|c|c|}
\hline \multicolumn{3}{|c|}{$\begin{array}{c}\text { Base Case } \\
\text { With current technology }\end{array}$} & \multicolumn{2}{|c|}{$\begin{array}{l}\text { High End Breakeven Price } \\
\text { (\$/MWh) }\end{array}$} & \multicolumn{2}{|c|}{$\begin{array}{l}\text { Low End Breakeven } \\
\text { Price (\$/MWh) }\end{array}$} \\
\hline Life & DOD & Life (cycle) & 0\% Profit & 8\% Profit & 0\% Profit & $7 \%$ Profit \\
\hline 20 & $5 \%$ & 379208 & 15.22 & 23.12 & 7.61 & 11.84 \\
\hline 20 & $10 \%$ & 125092 & 23.08 & 35.04 & 11.54 & 17.94 \\
\hline 20 & $20 \%$ & 41265 & 34.98 & 53.11 & 17.49 & 27.19 \\
\hline 20 & $30 \%$ & 21569 & 44.61 & 67.74 & 22.31 & 34.68 \\
\hline 20 & $40 \%$ & 13612 & 53.02 & 80.51 & 26.51 & 41.22 \\
\hline 20 & $50 \%$ & 9525 & 60.61 & 92.04 & 30.31 & 47.12 \\
\hline 20 & $60 \%$ & 7115 & 67.62 & 102.68 & 33.81 & 52.57 \\
\hline 20 & $70 \%$ & 5560 & 74.17 & 112.63 & 37.08 & 57.66 \\
\hline 20 & $80 \%$ & 4490 & 80.36 & 122.03 & 40.18 & 62.48 \\
\hline 20 & $90 \%$ & 3719 & 86.24 & 130.96 & 43.12 & 67.05 \\
\hline 20 & $100 \%$ & 3142 & 91.87 & 139.51 & 45.94 & 71.43 \\
\hline \multicolumn{3}{|c|}{$\begin{array}{c}\text { Technology Improvement } \\
\text { Prolonged Lifecycles at Higher DODs }\end{array}$} & \multicolumn{2}{|c|}{$\begin{array}{l}\text { High End Breakeven Price } \\
\text { (\$/MWh) }\end{array}$} & \multicolumn{2}{|c|}{$\begin{array}{l}\text { Low End Breakeven } \\
\text { Price (\$/MWh) }\end{array}$} \\
\hline Life & DOD & Life (cycle) & 0\% Profit & 8\% Profit & 0\% Profit & $7 \%$ Profit \\
\hline 20 & "5\% & 379208 & 15.22 & 23.12 & 7.61 & 11.84 \\
\hline 20 & $10 \%$ & 125092 & 23.08 & 35.04 & 11.54 & 17.94 \\
\hline 20 & $20 \%$ & 53645 & 26.91 & 40.86 & 13.45 & 20.92 \\
\hline 20 & $30 \%$ & 32354 & 29.74 & 45.16 & 14.87 & 23.12 \\
\hline 20 & $40 \%$ & 27224 & 26.51 & 40.25 & 13.25 & 20.61 \\
\hline 20 & $50 \%$ & 23813 & 24.24 & 36.82 & 12.12 & 18.85 \\
\hline 20 & $60 \%$ & 21345 & 22.54 & 34.23 & 11.27 & 17.52 \\
\hline 20 & $70 \%$ & 19460 & 21.19 & 32.18 & 10.60 & 16.48 \\
\hline 20 & $80 \%$ & 17960 & 20.09 & 30.51 & 10.05 & 15.62 \\
\hline 20 & $90 \%$ & 16736 & 19.17 & 29.10 & 9.58 & 14.90 \\
\hline 20 & $100 \%$ & 15710 & 18.37 & 27.90 & 9.19 & 14.29 \\
\hline
\end{tabular}




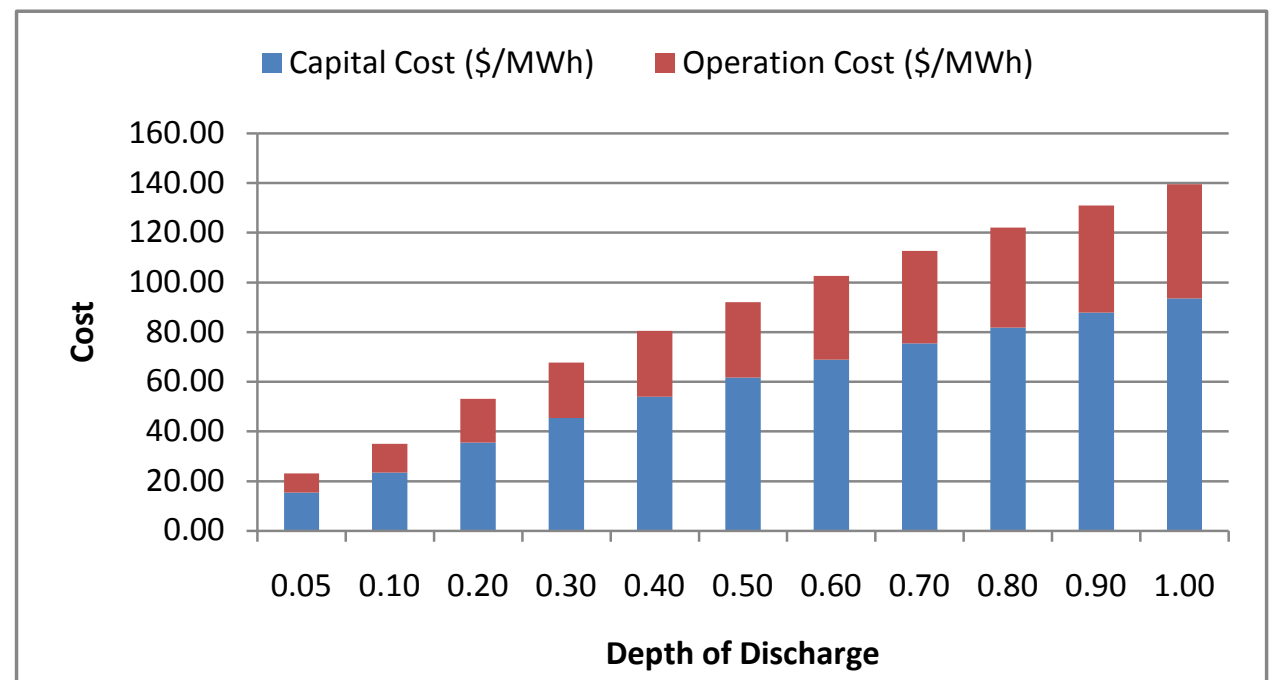

(a) Base case: Break-even cost break down

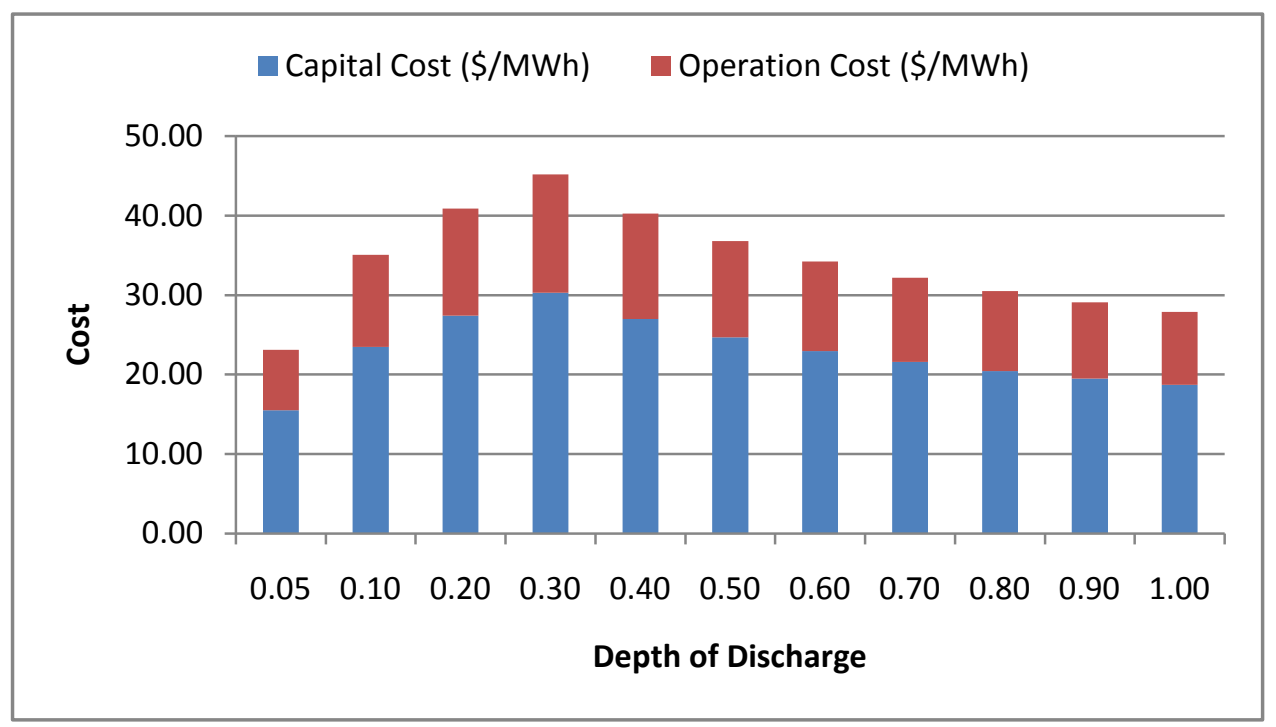

(b) The technology advancement case for prolonged lifecycles

Figure 24: The breakdown of the breakeven price 


\subsection{Different Regulation and Real-time Dispatch Signals}

The second scenario is the different regulation and real-time dispatch signal study. In this case, the total regulation and real-time dispatch signals were normalized with different values, as shown in Table 14 , so that there are $5 \%, 10 \%, 20 \%, 30 \%$, and $50 \%$ chances for the signal to be outside the range of $P_{\text {rated }}$ $( \pm 4 \mathrm{MW})$, as shown in Figure 25 . We assume that if the $\mathrm{NaS}$ battery receives a regulation signal that is outside $\pm 4 \mathrm{MW}$, its maximum output will be set at $\pm 4 \mathrm{MW}$.

The inputs are shown in Table 9. The modeling results are summarized in Table 15 and Table 17, which are color scaled for better visualization. The greener the color is, the better the value. Note that two pairs of values for four inputs have be en compared: the discount rate (profits), installation cost, battery efficiency, and the total operation and maintenance (O\&M) cost. The high-end and low-end costs of the energy provided for regulation and real-time di spatch services are calculated and presented in Table 16 and Table 17.

Table 14: The values used to normalize the regulation and real-time dispatch signals to $4 \mathrm{MW}$

\begin{tabular}{|c|c|c|c|c|c|c|c|c|c|c|}
\hline Probability of Outliers & \multicolumn{2}{|c|}{$5 \%$} & \multicolumn{2}{|c|}{$10 \%$} & \multicolumn{2}{|c|}{$20 \%$} & \multicolumn{2}{|c|}{$30 \%$} & \multicolumn{2}{|c|}{$50 \%$} \\
\hline Case Description & No Wind & 20\%Wind & No Wind & 20\%Wind & No Wind & 20\%Wind & No Wind & 20\%Wind & No Wind & $20 \%$ Wind \\
\hline Regulation (MW) & 48 & 62 & 44 & 53 & 34 & 39 & 30 & 34 & 21 & 21 \\
\hline Real-time Dispatch (MW) & 385 & 476 & 318 & 405 & 250 & 314 & 202 & 250 & 134 & 179 \\
\hline
\end{tabular}

\section{Regulation Signals}

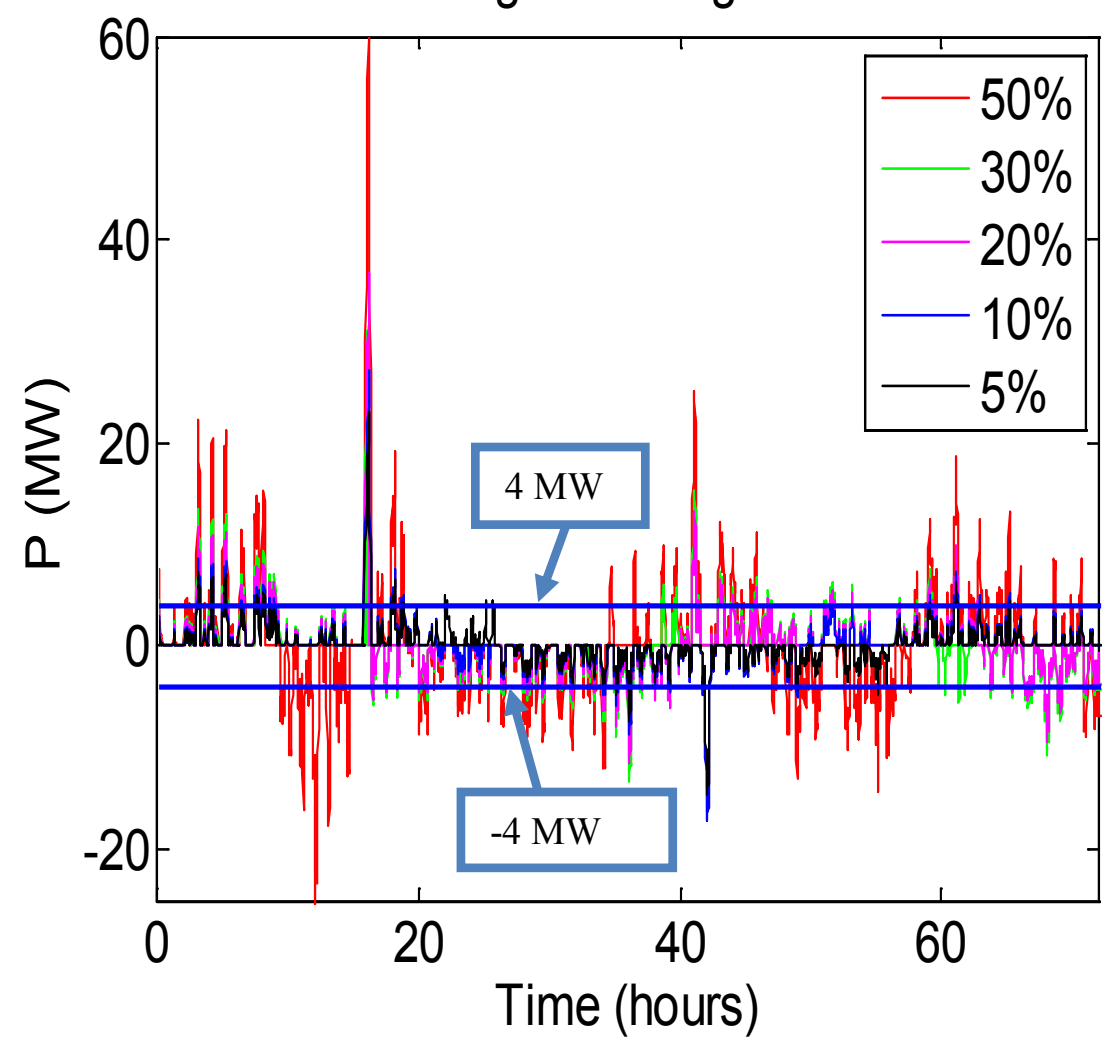

Figure 25: The CDFs of regulation signals 
Below are a few observations:

- If the battery does not respond to extreme regulation or real-time dispatch signals, the battery average power output $P_{\text {ave }}$ will increase. Normally, the higher $P_{a v e}$ is, the more economical the battery service is.

- The study shows that there is no s ignificant difference between "with" and "without" wind cases, when the $\mathrm{NaS}$ ba ttery prov ides the r egulation and real-time di spatch services. The annual charge and discharge cycles are similar, as shown in Table 15.

- As shown in Table 16, the breakeven price is positively correlated with the battery utilization rate $K_{u}$. A higher utilization results in a lower breakeven price.

- As shown in Table 16, there is a tradeoff between the battery utilization rate $K_{u}$ and battery lifetime. A higher utilization may result in a shortened battery life. This shortened life occurs because of the limited number of cycles that a battery can run in its lifetime. However, if the battery $r$ uns 1 ess often at low er D ODs, the ba ttery li fe limitation is no $t$ th e num ber of lifecycles but mainly wear-and-tear. In Table 16, the 20 y ears in green cells a re limited by wear-and-tear. In those cases, finding ways to run the battery at a h igher utilization rate (a higher average output) would increase profits.

- In Table 17, two cases are compared: high-end cost and low-end cost. If the installation and O\&M costs can be reduced, then the breakeven price can be brought down significantly.

Table 15: Number of charge/discharge cycles per year

\begin{tabular}{|c|c|c|c|c|c|c|c|c|c|c|c|c|}
\hline \multicolumn{13}{|c|}{ Annual charge/discharge cycles } \\
\hline & \multirow{2}{*}{$\begin{array}{c}\text { Signal } \\
\text { Outliers }\end{array}$} & \multicolumn{5}{|c|}{ DOD } & & \multicolumn{5}{|c|}{ DOD } \\
\hline & & 1 & 0.8 & 0.6 & 0.4 & 0.2 & & 1 & 0.8 & 0.6 & 0.4 & 0.2 \\
\hline Regulation & $5 \%$ & 111 & 133 & 179 & 277 & 460 & Regulation & 115 & 142 & 189 & 288 & 542 \\
\hline \multirow[t]{4}{*}{$20 \%$ wind } & $10 \%$ & 125 & 155 & 207 & 321 & 541 & No wind & 125 & 159 & 209 & 319 & 591 \\
\hline & $20 \%$ & 159 & 195 & 270 & 369 & 686 & & 152 & 190 & 256 & 367 & 701 \\
\hline & $30 \%$ & 172 & 212 & 288 & 383 & 750 & & 169 & 209 & 283 & 391 & 763 \\
\hline & $50 \%$ & 219 & 280 & 363 & 491 & 942 & & 203 & 255 & 339 & 484 & 921 \\
\hline Realtime & $5 \%$ & 95 & 115 & 142 & 192 & 288 & Realtime & 88 & 109 & 129 & 170 & 257 \\
\hline Dispatch & $10 \%$ & 107 & 126 & 160 & 203 & 309 & Dispatch & 101 & 121 & 144 & 192 & 283 \\
\hline \multirow[t]{3}{*}{$20 \%$ Wind } & $20 \%$ & 126 & 151 & 187 & 237 & 356 & No Wind & 120 & 136 & 167 & 219 & 323 \\
\hline & $30 \%$ & 145 & 172 & 206 & 269 & 394 & & 131 & 150 & 189 & 245 & 351 \\
\hline & $50 \%$ & 164 & 193 & 236 & 305 & 458 & & 153 & 187 & 227 & 285 & 411 \\
\hline
\end{tabular}


Table 16: The breakeven prices, utilization rates, and battery lifetimes

\begin{tabular}{|c|c|c|c|c|c|c|c|c|c|c|c|c|c|c|c|c|}
\hline \multicolumn{7}{|c|}{ Breakeven Price (8\% Profit) (\$MWh) } & \multicolumn{5}{|c|}{ Jtilization Rate (Pave/Prated) } & \multicolumn{5}{|c|}{ Adjusted Lifetime (Year) } \\
\hline & \multirow{2}{*}{$\begin{array}{l}\text { Signal } \\
\text { Outliers }\end{array}$} & \multicolumn{5}{|c|}{ DOD } & \multicolumn{5}{|c|}{ DOD } & \multicolumn{5}{|c|}{ DOD } \\
\hline & & 1 & 0.8 & 0.6 & 0.4 & 0.2 & 1 & 0.8 & 0.6 & 0.4 & 0.2 & 1 & 0.8 & 0.6 & 0.4 & 0.2 \\
\hline Regulation & $5 \%$ & 197 & 206 & 204 & 198 & 238 & 0.18 & 0.17 & 0.17 & 0.18 & 0.15 & 20 & 20 & 20 & 20 & 20 \\
\hline \multirow{4}{*}{$\begin{array}{c}20 \% \\
\text { Renew ables }\end{array}$} & $10 \%$ & 175 & 177 & 176 & 171 & 203 & 0.20 & 0.20 & 0.20 & 0.21 & 0.17 & 20 & 20 & 20 & 20 & 20 \\
\hline & $20 \%$ & 138 & 140 & 135 & 148 & 160 & 0.25 & 0.25 & 0.26 & 0.24 & 0.22 & 20 & 20 & 20 & 20 & 20 \\
\hline & $30 \%$ & 131 & 129 & 127 & 143 & 146 & 0.27 & 0.27 & 0.28 & 0.24 & 0.24 & 18 & 20 & 20 & 20 & 20 \\
\hline & $50 \%$ & 112 & 105 & 101 & 112 & 116 & 0.35 & 0.36 & 0.35 & 0.31 & 0.30 & 14 & 16 & 20 & 20 & 20 \\
\hline Real-time & $5 \%$ & 231 & 238 & 257 & 285 & 381 & 0.15 & 0.15 & 0.14 & 0.12 & 0.09 & 20 & 20 & 20 & 20 & 20 \\
\hline Dispatch & $10 \%$ & 205 & 217 & 228 & 270 & 355 & 0.17 & 0.16 & 0.15 & 0.13 & 0.10 & 20 & 20 & 20 & 20 & 20 \\
\hline \multirow{3}{*}{$\begin{array}{c}20 \% \\
\text { renew albes }\end{array}$} & $20 \%$ & 174 & 181 & 195 & 231 & 308 & 0.20 & 0.19 & 0.18 & 0.15 & 0.11 & 20 & 20 & 20 & 20 & 20 \\
\hline & $30 \%$ & 151 & 159 & 177 & 204 & 278 & 0.23 & 0.22 & 0.20 & 0.17 & 0.13 & 20 & 20 & 20 & 20 & 20 \\
\hline & $50 \%$ & 135 & 142 & 155 & 180 & 239 & 0.26 & 0.25 & 0.23 & 0.19 & 0.15 & 19 & 20 & 20 & 20 & 20 \\
\hline Regulation & $5 \%$ & 191 & 193 & 193 & 190 & 202 & 0.18 & 0.18 & 0.18 & 0.18 & 0.17 & 20 & 20 & 20 & 20 & 20 \\
\hline \multirow[t]{4}{*}{ No-wind } & $10 \%$ & 175 & 172 & 175 & 172 & 185 & 0.20 & 0.20 & 0.20 & 0.20 & 0.19 & 20 & 20 & 20 & 20 & 20 \\
\hline & $20 \%$ & 144 & 144 & 143 & 149 & 156 & 0.24 & 0.24 & 0.25 & 0.23 & 0.22 & 20 & 20 & 20 & 20 & 20 \\
\hline & $30 \%$ & 132 & 131 & 129 & 140 & 144 & 0.27 & 0.27 & 0.27 & 0.25 & 0.24 & 19 & 20 & 20 & 20 & 20 \\
\hline & $50 \%$ & 117 & 112 & 108 & 113 & 119 & 0.32 & 0.33 & 0.33 & 0.31 & 0.29 & 15 & 18 & 20 & 20 & 20 \\
\hline Real-time & $5 \%$ & 249 & 251 & 283 & 322 & 426 & 0.14 & 0.14 & 0.12 & 0.11 & 0.08 & 20 & 20 & 20 & 20 & 20 \\
\hline Dispatch & $10 \%$ & 217 & 226 & 254 & 285 & 387 & 0.16 & 0.15 & 0.14 & 0.12 & 0.09 & 20 & 20 & 20 & 20 & 20 \\
\hline \multirow[t]{3}{*}{ No-wind } & $20 \%$ & 183 & 201 & 219 & 250 & 339 & 0.19 & 0.17 & 0.16 & 0.14 & 0.10 & 20 & 20 & 20 & 20 & 20 \\
\hline & $30 \%$ & 167 & 183 & 193 & 224 & 312 & 0.21 & 0.19 & 0.18 & 0.16 & 0.11 & 20 & 20 & 20 & 20 & 20 \\
\hline & $50 \%$ & 143 & 147 & 161 & 192 & 267 & 0.24 & 0.24 & 0.22 & 0.18 & 0.13 & 20 & 20 & 20 & 20 & 20 \\
\hline
\end{tabular}


Table 17: A comparison of breakeven prices

\begin{tabular}{|c|c|c|c|c|c|c|c|c|c|c|c|}
\hline \multicolumn{7}{|c|}{ Breakeven Price (High End) } & \multirow{2}{*}{\multicolumn{5}{|c|}{$\begin{array}{c}\text { Breakeven Price (Low End) } \\
\text { DOD }\end{array}$}} \\
\hline & \multirow{2}{*}{$\begin{array}{c}\text { Signal } \\
\text { Outliers }\end{array}$} & \multicolumn{5}{|c|}{ DOD } & & & & & \\
\hline & & 1 & 0.8 & 0.6 & 0.4 & 0.2 & 1 & 0.8 & 0.6 & 0.4 & 0.2 \\
\hline \multirow[t]{2}{*}{ Regulation } & $5 \%$ & 197 & 206 & 204 & 198 & 238 & 101 & 105 & 104 & 101 & 122 \\
\hline & $10 \%$ & 175 & 177 & 176 & 171 & 203 & 90 & 90 & 90 & 87 & 104 \\
\hline \multirow{3}{*}{$\begin{array}{c}20 \% \\
\text { Renewables }\end{array}$} & $20 \%$ & 138 & 140 & 135 & 148 & 160 & 1 & 12 & & 6 & 82 \\
\hline & $30 \%$ & 131 & 129 & 127 & 143 & 146 & 67 & 66 & 65 & 73 & 75 \\
\hline & & 112 & 105 & 101 & 112 & 116 & 50 & 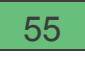 & - & 57 & 60 \\
\hline \multirow{3}{*}{$\begin{array}{l}\text { Real-time } \\
\text { Dispatch }\end{array}$} & & 231 & 238 & 257 & 285 & 381 & 118 & 122 & 132 & 146 & 195 \\
\hline & $10 \%$ & 205 & 217 & 228 & 270 & 355 & 105 & 111 & 117 & 138 & 182 \\
\hline & $20 \%$ & 174 & 181 & 195 & 231 & 308 & 8 & 93 & 100 & 8 & 158 \\
\hline \multirow{2}{*}{$\begin{array}{c}20 \% \\
\text { Renewables }\end{array}$} & $30 \%$ & 151 & 159 & 177 & 204 & 278 & 77 & 82 & 91 & 104 & 142 \\
\hline & $50 \%$ & 135 & 142 & 155 & 180 & 239 & $7 c$ & 73 & 79 & 92 & 123 \\
\hline \multirow{5}{*}{$\begin{array}{l}\text { Regulation } \\
\text { No-wind }\end{array}$} & & 191 & 193 & 193 & 190 & 202 & 98 & 99 & 99 & 97 & 104 \\
\hline & & 175 & 172 & 175 & 172 & 185 & 90 & 88 & 89 & 88 & 95 \\
\hline & $20 \%$ & 144 & 144 & 143 & 149 & 156 & 7 & 7 & 73 & 7 & 80 \\
\hline & $30 \%$ & 132 & 131 & 129 & 140 & 144 & 68 & br & 66 & 72 & 74 \\
\hline & $50 \%$ & 117 & 112 & 108 & 113 & 119 & 61 & 58 & 55 & 58 & 61 \\
\hline & & & & & & & & & & & \\
\hline \multirow{5}{*}{$\begin{array}{l}\text { Real-time } \\
\text { Dispatch } \\
\text { No-wind }\end{array}$} & & 249 & 251 & 283 & 322 & 426 & 128 & 129 & 145 & 165 & 218 \\
\hline & $10 \%$ & 217 & 226 & 254 & 285 & 387 & 111 & 116 & 130 & 146 & 198 \\
\hline & $20 \%$ & 183 & 201 & 219 & 250 & 339 & 94 & 103 & 112 & 128 & 174 \\
\hline & $30 \%$ & 167 & 183 & 193 & 224 & 312 & 86 & 94 & 99 & 115 & 160 \\
\hline & $50 \%$ & 143 & 147 & 161 & 192 & 267 & 73 & 75 & 82 & 98 & 137 \\
\hline
\end{tabular}




\subsection{Different Battery Power Ratings}

In this scenario, the battery rated pow er output $P_{\text {rated }}$ is a ssumed to range from 4 to $20 \mathrm{M} \mathrm{W}$. This study ev aluates $w$ hether or not the op eration is $m$ ore econom ical when $t$ he battery out put pow er is increased. The inputs are shown in Table 9. The regulation and real-time dispatch signals are normalized so that there are $5 \%$ signals outside $\pm P_{\text {rated, }}$ as shown in Figure 26. As shown in Figure 27, at a higher rated power output, the battery can complete more cycles in a fixed time period. The modeling results are summarized in Table 18 and Table 20, which are color scaled for better visualization. The greener the color is, the better the value is.

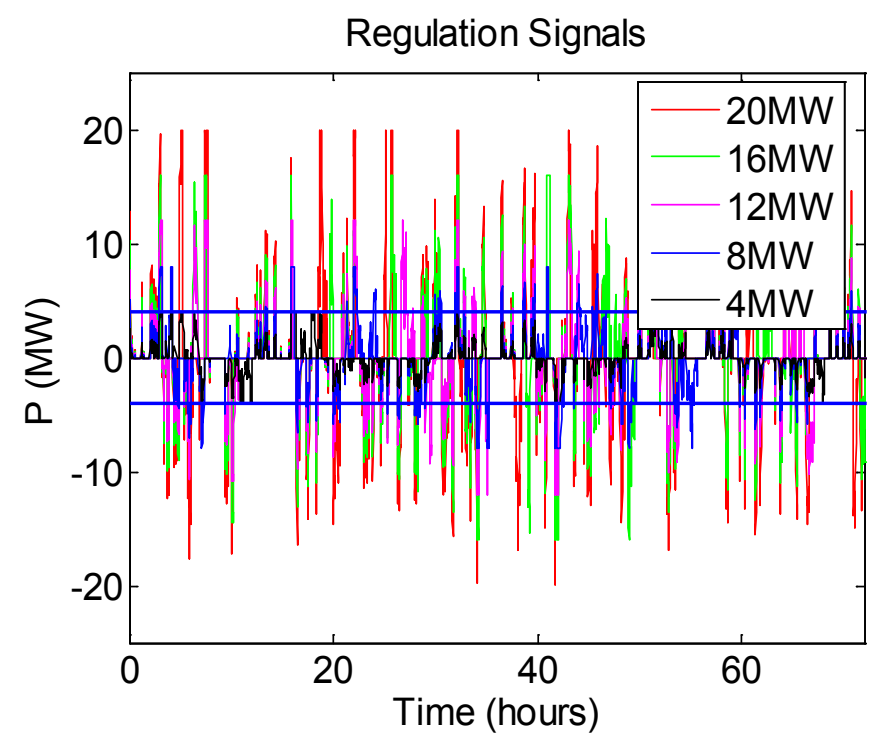

Figure 26: The regulation signals for different NaS battery output ratings

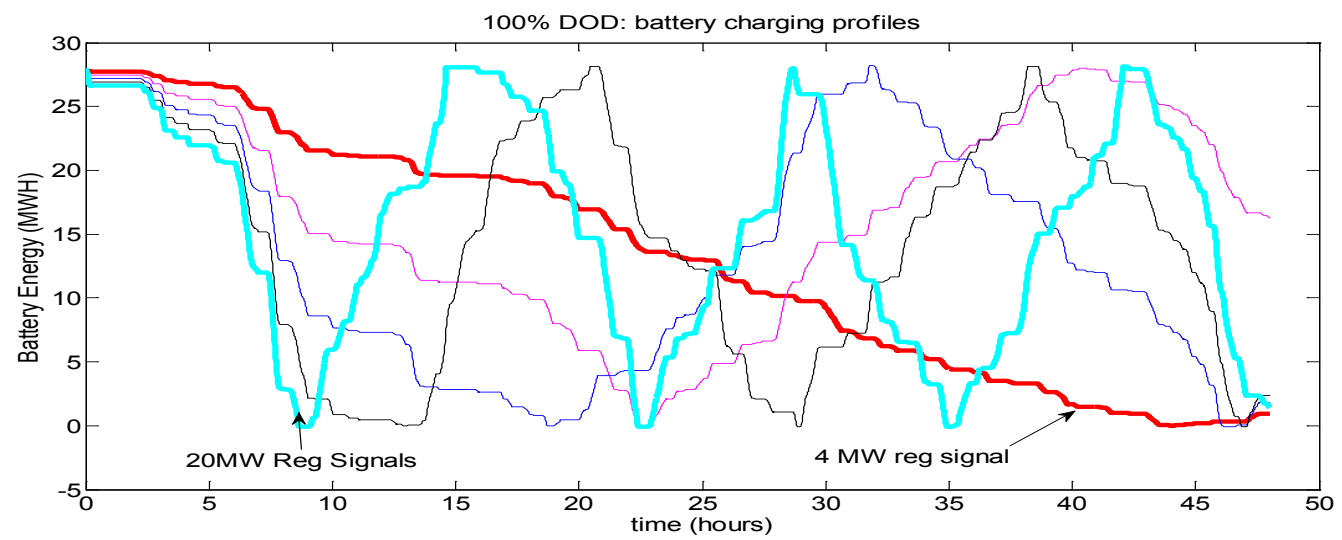

Figure 27: The battery charge/discharge profiles for different $\mathrm{NaS}$ battery output ratings 
Below are a few observations:

- Increasing the battery's rated power output helps the battery provide regulation services more economically at a lower DOD. As shown in Table 19, the higher the battery's rated power is, the more economical it is for the battery to provide the regulation service at $20 \%$ DOD. At a higher rated power output, the battery can complete more cycles in a year, as shown in Table 18. Therefore, more energy will be provided annually, as shown in Figure 28.

- The higher the battery's rated power output, the shorter the battery life is (see Table 19 and Figure 29). Note that the calculated battery lives may exceed 20 years. For those cases, the battery life was limited to be 20 years.

- As shown in Table 19, the higher the battery rated power, the lower the utilization rate $K_{u}$. However, the utilization rates and the breakeven prices are no longer positively correlated.

- When considering both the battery lifetime and the economics, the be st choice is to run the battery at $20 \% \mathrm{DOD}$ and $20 \mathrm{MW}$ for regulation and at $60 \% \mathrm{DOD}$ and $20 \mathrm{MW}$ for real-time dispatch.

- We compared two cases: high-end and low-end costs (see Table 20). As shown in the table, if the installation and O\&M cost can be reduced, the breakeven price will drop significantly.

- The battery charging and discharging profiles when providing regulation and real-time dispatch services are shown in Figure 30 and Figure 31. The box plot portrays the battery charging and $d$ ischarging times at different $b$ attery rated-power outputs and DODs $w$ hen providing regulation and real-time dispatch services (Figure 32 to Figure 35).

- At $4 \mathrm{MW}$, the DOD does not result in a shortened battery life because the $28 \mathrm{MWh}$ battery is underused when providing r egulation services. However, a t hi gher-rated power, there is a tradeoff $\mathrm{b}$ etween D OD a nd ba ttery 1 ife. Therefore, based on the $\mathrm{c}$ urrent D OD-lifecycle relationship, if battery manufacturers could increase the battery's rated-power output to 8 or $12 \mathrm{MW}$, breakeven prices could decline by $1 / 2$ to $2 / 3$. A bove $12 \mathrm{MW}$, the price drop is not significant and the battery life is also shortened dramatically. 
Table 18: The annual charge and discharge cycles

\begin{tabular}{|c|c|c|c|c|c|c|c|c|c|c|c|c|}
\hline \multicolumn{13}{|c|}{ Annual charge/discharge cycles } \\
\hline & \multirow{2}{*}{$\begin{array}{c}\mathbf{P}_{\text {rated }} \\
(\mathbf{M W})\end{array}$} & \multicolumn{5}{|c|}{ DOD } & & \multicolumn{5}{|c|}{ DOD } \\
\hline & & 1 & 0.8 & 0.6 & 0.4 & 0.2 & & 1 & 0.8 & 0.6 & 0.4 & 0.2 \\
\hline \multirow[t]{2}{*}{ Regulation } & 4 & 111 & 133 & 179 & 277 & 460 & Regulation & 115 & 142 & 189 & 288 & 542 \\
\hline & 8 & 220 & 277 & 355 & 460 & 883 & No wind & 231 & 288 & 366 & 542 & 989 \\
\hline \multirow{3}{*}{$\begin{array}{c}20 \% \\
\text { Renew ables }\end{array}$} & 12 & 329 & 368 & 460 & 684 & 1262 & & 337 & 403 & 542 & 772 & 1416 \\
\hline & 16 & 380 & 460 & 616 & 883 & 1619 & & 432 & 542 & 702 & 989 & 1790 \\
\hline & 20 & 460 & 588 & 762 & 1076 & 1933 & & 542 & 670 & 853 & 1230 & 2132 \\
\hline \multirow{2}{*}{$\begin{array}{l}\text { Real-time } \\
\text { Dispatch }\end{array}$} & 4 & 95 & 115 & 142 & 192 & 288 & Real-time & 88 & 109 & 129 & 170 & 257 \\
\hline & 8 & 163 & 192 & 227 & 288 & 411 & Dispatch & 144 & 170 & 203 & 257 & 356 \\
\hline \multirow{3}{*}{$\begin{array}{c}20 \% \\
\text { Renew ables }\end{array}$} & 12 & 209 & 238 & 288 & 359 & 525 & No Wind & 192 & 216 & 257 & 321 & 453 \\
\hline & 16 & 248 & 288 & 338 & 411 & 623 & & 229 & 257 & 298 & 356 & 530 \\
\hline & 20 & 288 & 324 & 375 & 467 & 710 & & 257 & 285 & 332 & 406 & 602 \\
\hline
\end{tabular}


Table 19: The breakeven prices, utilization rates, and battery lifetimes (different rated battery outputs)

\begin{tabular}{|c|c|c|c|c|c|c|c|c|c|c|c|c|c|c|c|c|}
\hline \multicolumn{7}{|c|}{ Breakeven Price (8\% Profit) (\$MWh) } & \multirow{2}{*}{\multicolumn{5}{|c|}{$\begin{array}{c}\text { Utilization Rate }\left(\mathrm{P}_{\text {ave }} / \mathrm{P}_{\text {rated }}\right) \\
\text { DOD }\end{array}$}} & \multirow{2}{*}{\multicolumn{5}{|c|}{$\begin{array}{c}\text { Adjusted LifeTime (Year) } \\
\text { DOD }\end{array}$}} \\
\hline & \multirow{2}{*}{$\begin{array}{l}\mathbf{P}_{\text {rated }} \\
\text { (MW) }\end{array}$} & \multicolumn{5}{|c|}{ DOD } & & & & & & & & & & \\
\hline & & 1 & 0.8 & 0.6 & 0.4 & 0.2 & 1 & 0.8 & 0.6 & 0.4 & 0.2 & 1 & 0.8 & 0.6 & 0.4 & 0.2 \\
\hline \multirow{5}{*}{$\begin{array}{c}\text { Regulation } \\
20 \% \\
\text { Renew ables }\end{array}$} & 4 & 197 & 206 & 204 & 198 & 238 & 0.18 & 0.17 & 0.17 & 0.18 & 0.15 & 20 & 20 & 20 & 20 & 20 \\
\hline & 8 & 112 & 106 & 103 & 119 & 124 & 0.18 & 0.18 & 0.17 & 0.15 & 0.14 & 14 & 16 & 20 & 20 & 20 \\
\hline & 12 & 89 & 89 & 86 & 80 & 87 & 0.18 & 0.16 & 0.15 & 0.15 & 0.13 & 10 & 12 & 15 & 20 & 20 \\
\hline & 16 & 84 & 79 & \begin{tabular}{|l|}
73 \\
\end{tabular} & 67 & 68 & 0.15 & 0.15 & 0.15 & 0.14 & 0.13 & 8 & 10 & 12 & 15 & 20 \\
\hline & 20 & 77 & 71 & 65 & 60 & 57 & 0.15 & 0.15 & 0.15 & 0.14 & 0.12 & 7 & 8 & 9 & 13 & 20 \\
\hline \multirow{3}{*}{$\begin{array}{l}\text { Real-time } \\
\text { Dispatch }\end{array}$} & 4 & 164 & 169 & 183 & 203 & 270 & 0.15 & 0.15 & 0.14 & 0.12 & 0.09 & 20 & 20 & 20 & 20 & 20 \\
\hline & 8 & 97 & 101 & 114 & 135 & 189 & 0.13 & 0.12 & 0.11 & 0.09 & \begin{tabular}{|l|}
0.07 \\
\end{tabular} & 19 & 20 & 20 & 20 & 20 \\
\hline & 12 & 82 & 83 & 90 & 108 & 148 & 0.11 & 0.10 & 0.09 & 0.08 & 0.06 & 15 & 19 & 20 & 20 & 20 \\
\hline \multirow{2}{*}{$\begin{array}{c}20 \% \\
\text { Renew ables }\end{array}$} & 16 & 74 & 73 & 77 & 95 & 125 & 0.10 & 0.09 & 0.08 & 0.07 & 0.05 & 13 & 16 & 20 & 20 & 20 \\
\hline & 20 & 68 & 68 & 70 & 83 & 110 & 0.09 & 0.08 & 0.07 & 0.06 & 0.05 & 11 & 14 & 19 & 20 & 20 \\
\hline \multirow{5}{*}{$\begin{array}{l}\text { Regulation } \\
\text { No-wind }\end{array}$} & 4 & 135 & 137 & 137 & 135 & 144 & 0.18 & 0.18 & 0.18 & 0.18 & 0.17 & 20 & 20 & 20 & 20 & 20 \\
\hline & 8 & 77 & 73 & 71 & 72 & 79 & 0.18 & 0.18 & 0.18 & 0.17 & 0.16 & 14 & 16 & 19 & 20 & 20 \\
\hline & 12 & 63 & 60 & 55 & 52 & 55 & 0.18 & 0.17 & 0.17 & 0.16 & 0.15 & 9 & 11 & 13 & 18 & 20 \\
\hline & 16 & 56 & 52 & 48 & 45 & 43 & 0.17 & 0.17 & 0.17 & 0.16 & 0.14 & 7 & 8 & 10 & 14 & 20 \\
\hline & 20 & 52 & 48 & 44 & 40 & 37 & 0.17 & 0.17 & 0.16 & 0.16 & 0.14 & 6 & 7 & 8 & 11 & 19 \\
\hline \multirow{5}{*}{$\begin{array}{l}\text { Real-time } \\
\text { Dispatch } \\
\text { No-wind }\end{array}$} & 4 & 177 & 179 & 201 & 229 & 303 & 0.14 & 0.14 & 0.12 & 0.11 & 0.08 & 20 & 20 & 20 & 20 & 20 \\
\hline & 8 & 108 & 115 & 128 & 151 & 219 & 0.12 & 0.11 & 0.10 & 0.08 & 0.06 & 20 & 20 & 20 & 20 & 20 \\
\hline & 12 & 86 & 90 & 101 & 121 & 172 & 0.10 & 0.09 & 0.08 & 0.07 & 0.05 & 16 & 20 & 20 & 20 & 20 \\
\hline & 16 & 77 & 79 & 87 & 109 & 147 & 0.09 & 0.08 & 0.07 & 0.06 & 0.04 & 14 & 17 & 20 & 20 & 20 \\
\hline & 20 & 72 & 74 & 78 & 96 & 129 & 0.08 & 0.07 & 0.06 & 0.05 & 0.04 & 12 & 16 & 20 & 20 & 20 \\
\hline
\end{tabular}


Table 20: A comparison of breakeven prices

\begin{tabular}{|c|c|c|c|c|c|c|c|c|c|c|c|}
\hline & \multicolumn{6}{|c|}{$\begin{array}{l}\text { High-end Breakeven Price } \\
(\$ / M W h)\end{array}$} & \multirow{2}{*}{\multicolumn{5}{|c|}{\begin{tabular}{|c}
$\begin{array}{c}\text { Low-end Breakeven Price } \\
(\$ / M W h)\end{array}$ \\
DOD
\end{tabular}}} \\
\hline & \multirow{2}{*}{$\begin{array}{c}\mathbf{P}_{\text {rated }} \\
(\mathrm{MW})\end{array}$} & \multicolumn{5}{|c|}{ DOD } & & & & & \\
\hline & & 1 & 0.8 & 0.6 & 0.4 & 0.2 & 1 & 0.8 & 0.6 & 0.4 & 0.2 \\
\hline \multirow[t]{5}{*}{ Regulation } & 4 & 197 & 206 & 204 & 198 & 238 & 86 & 90 & 89 & 86 & 104 \\
\hline & 8 & 112 & 106 & 103 & 119 & 124 & 50 & 47 & 45 & 52 & 54 \\
\hline & 12 & 89 & 89 & 86 & 80 & 87 & 41 & 40 & 38 & 35 & 38 \\
\hline & 16 & 84 & 79 & 73 & 67 & 68 & 39 & 37 & 33 & 30 & 30 \\
\hline & 20 & 77 & 71 & 65 & 60 & 57 & 37 & 33 & 30 & 27 & 25 \\
\hline \multirow{3}{*}{$\begin{array}{l}\text { Real-time } \\
\text { Dispatch }\end{array}$} & 4 & 164 & 169 & 183 & 203 & 270 & 101 & 104 & 112 & 125 & 166 \\
\hline & 8 & 9 & 101 & 114 & 135 & 189 & 59 & 62 & 0 & 83 & 116 \\
\hline & 12 & 82 & 83 & 90 & 108 & 148 & 51 & 51 & 55 & 67 & 91 \\
\hline \multirow{2}{*}{$\begin{array}{c}20 \% \\
\text { Renew ables }\end{array}$} & 16 & 74 & 73 & 77 & 95 & 125 & 47 & 46 & 47 & 58 & 77 \\
\hline & 20 & 68 & 68 & 70 & 83 & 110 & 44 & 43 & 43 & 51 & 67 \\
\hline \multirow{5}{*}{$\begin{array}{l}\text { Regulation } \\
\text { No-wind }\end{array}$} & 4 & 135 & 137 & 137 & 135 & 144 & 83 & 84 & 84 & 83 & 88 \\
\hline & 8 & 77 & 10 & 71 & 12 & 79 & 49 & 46 & 44 & 44 & 48 \\
\hline & 12 & 63 & 60 & 55 & 52 & 55 & 41 & 39 & 35 & 32 & 34 \\
\hline & 16 & 56 & 52 & 48 & 45 & 43 & 37 & 34 & 31 & 28 & 27 \\
\hline & 20 & 52 & 48 & 4 & 40 & 7 & 35 & 32 & 9 & 5 & 23 \\
\hline \multirow{5}{*}{$\begin{array}{l}\text { Real-time } \\
\text { Dispatch } \\
\text { No-wind }\end{array}$} & 4 & 171 & 179 & 201 & 229 & 303 & 109 & 110 & 124 & 141 & 186 \\
\hline & 8 & 108 & 115 & 128 & 151 & 219 & 66 & 70 & 79 & 93 & 134 \\
\hline & 12 & 86 & 90 & 101 & 121 & 172 & 54 & 55 & 62 & 75 & 106 \\
\hline & 16 & 77 & \begin{tabular}{|l|}
79 \\
\end{tabular} & 87 & 109 & 147 & 49 & 49 & 54 & \begin{tabular}{|l|}
67 \\
\end{tabular} & 90 \\
\hline & 20 & 72 & 74 & 78 & 96 & 129 & 46 & 46 & 48 & 59 & 79 \\
\hline
\end{tabular}




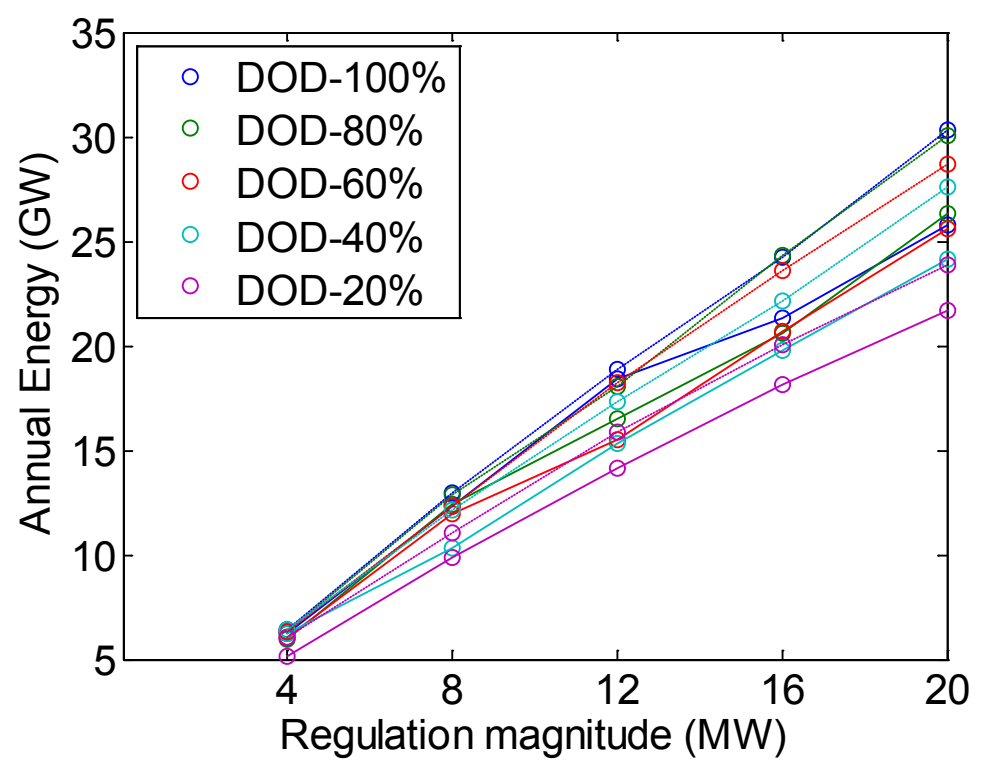

Figure 28: The annual regulation energy provided by battery (dash: without wind, solid: with $20 \%$ renewables)

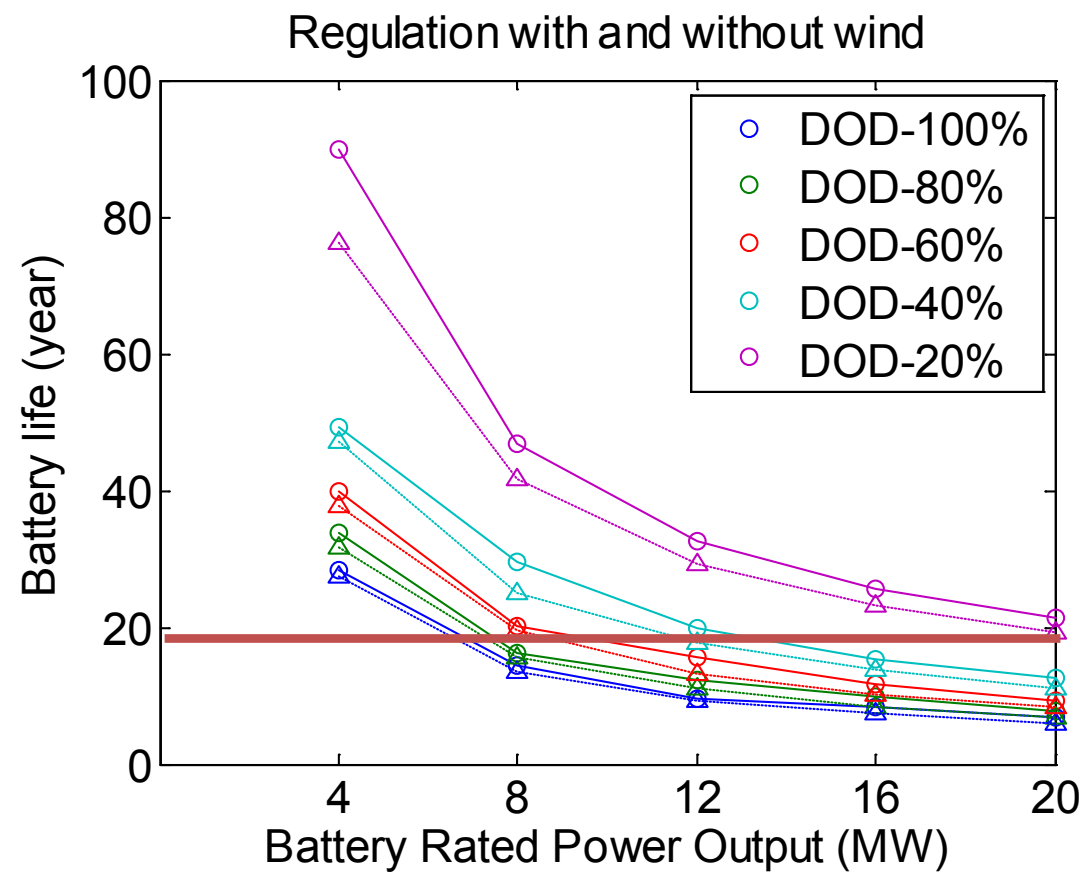

Figure 29: The calculated lifetimes of the NaS battery (solid: with $20 \%$ renewables; dash: without wind) 


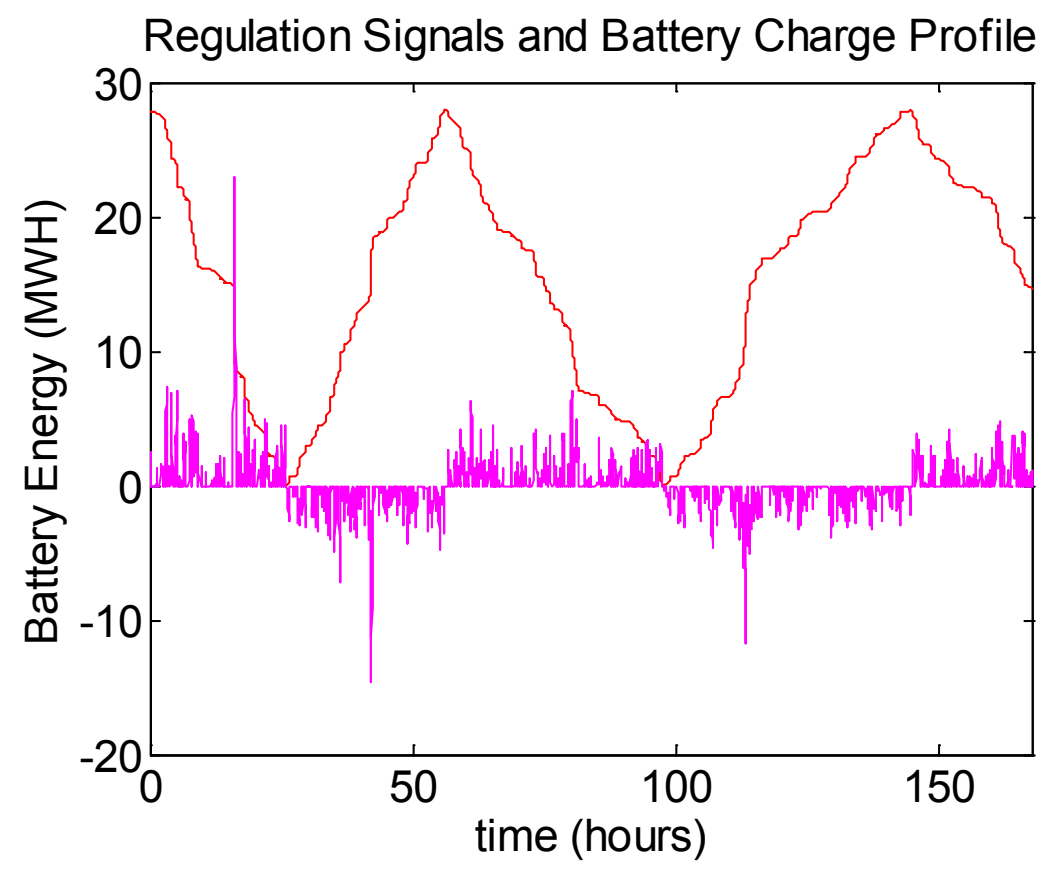

Figure 30: Battery charging/discharging profiles when providing regulation service

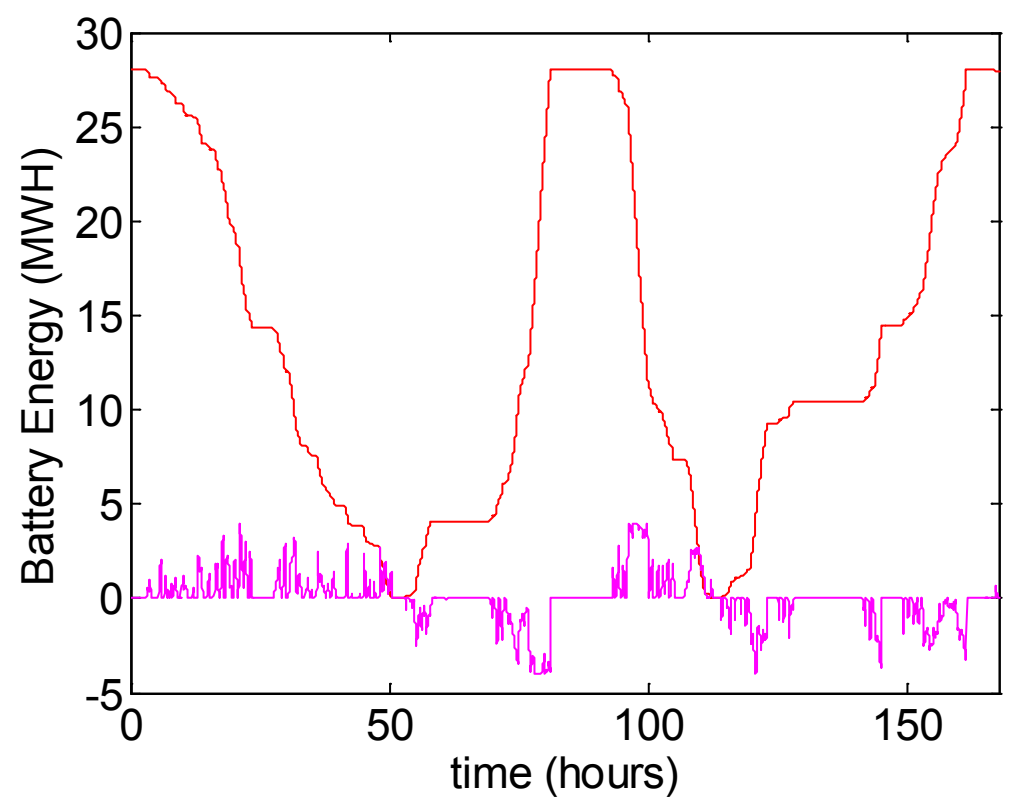

Figure 31: Battery charging/discharging profiles when providing real-time dispatch service 


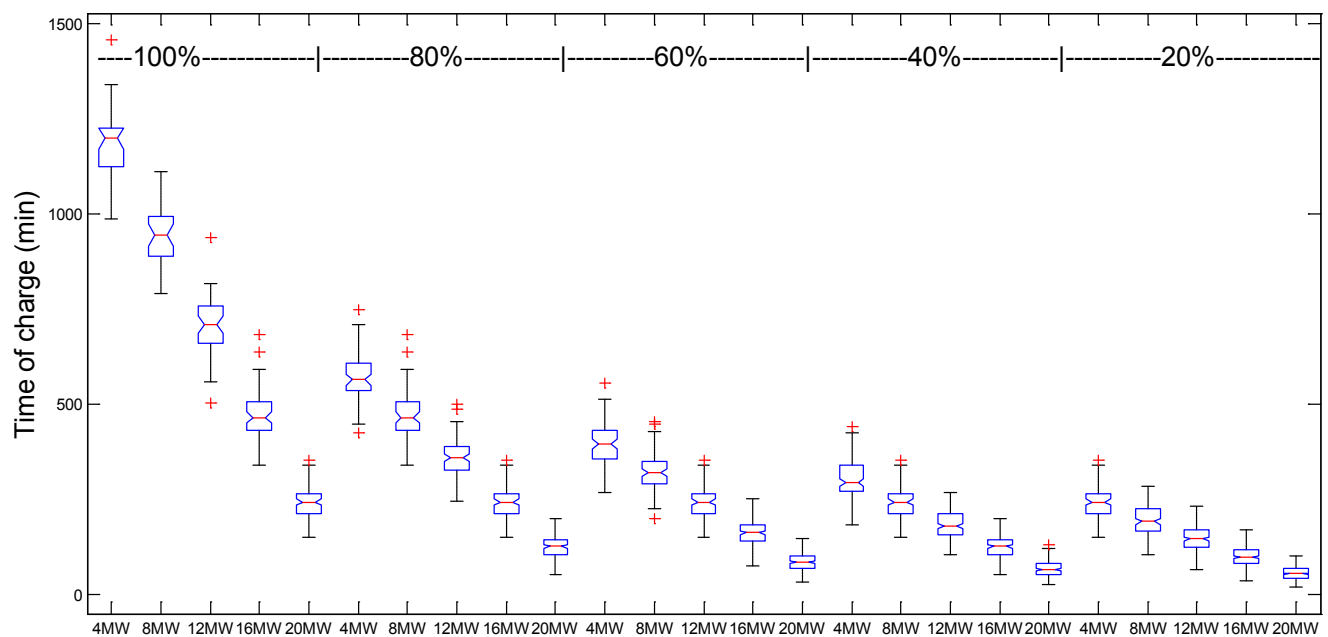

Figure 32: The box plot of battery charging time at different rated power outputs and DODs (regulation)

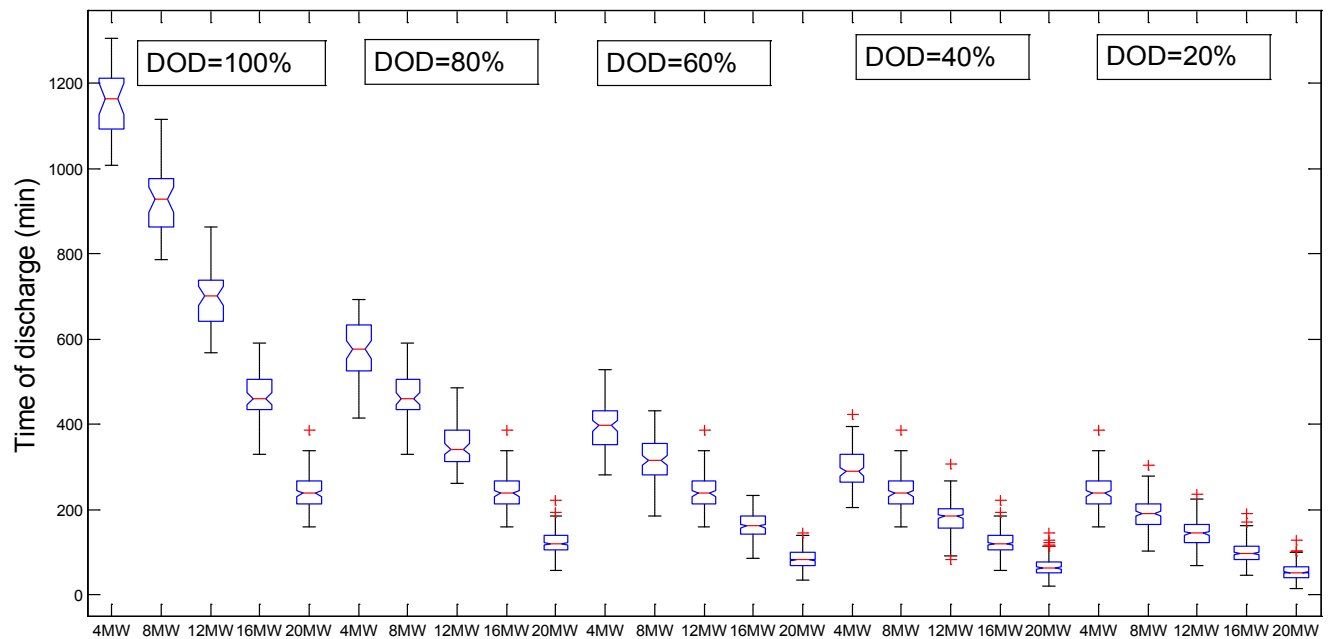

Figure 33: The box plot of battery discharging time at different rated power outputs and DODs (regulation) 


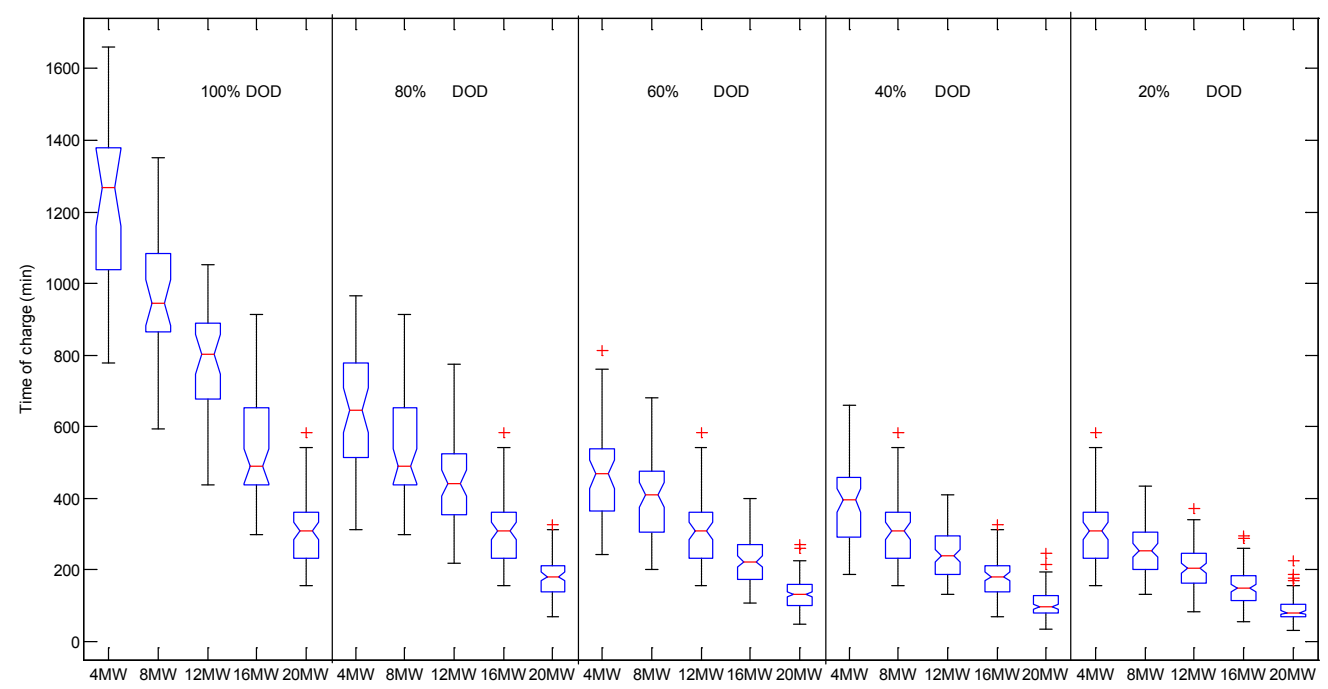

Figure 34: The box plot of battery charging time at different rated power outputs and DODs (real-time dispatch)

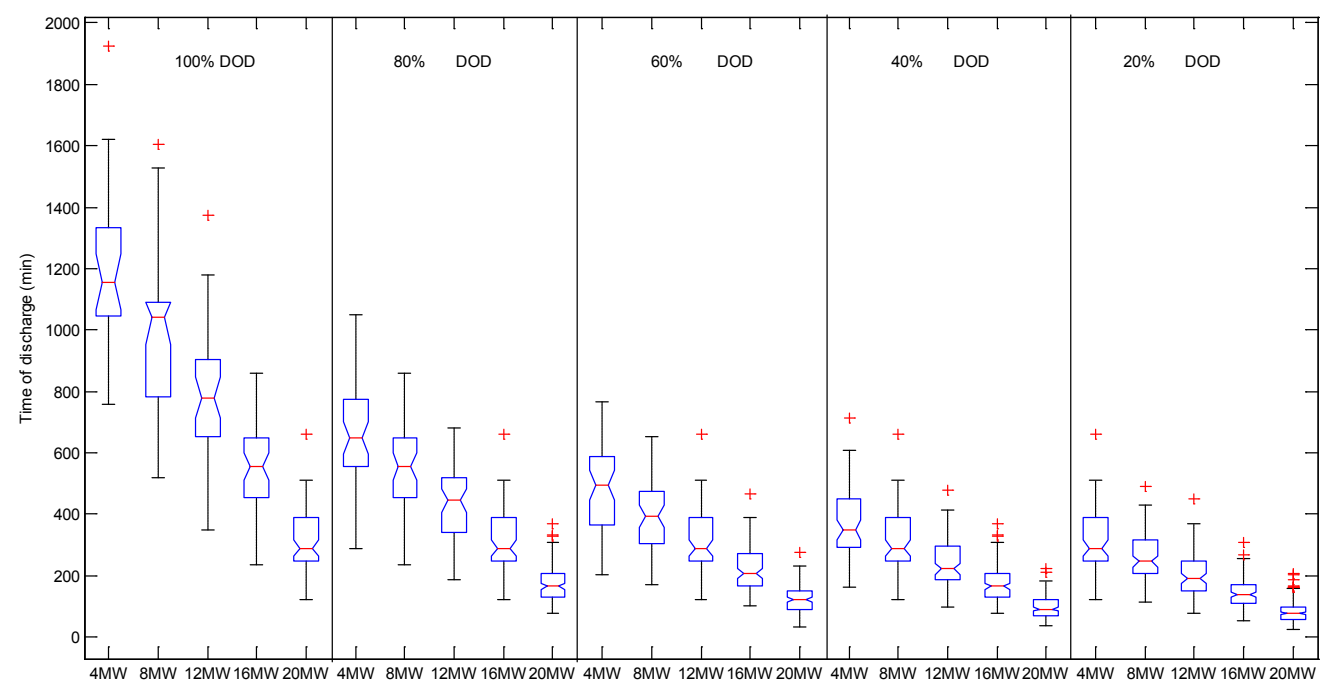

Figure 35: The box plot of battery discharging time at different rated power outputs and DODs (real-time dispatch) 


\subsection{Different Market Pricing Schemes}

So far, the e conomic s tudy for the regulation and real-time di spatch services provided by the $\mathrm{NaS}$ battery is fundamentally a cos t-based study. The breakeven price indicates to the battery owner the cost for $1 \mathrm{MWh}$ energy that the battery provides for the regulation and real-time dispatch services. If a battery is paid-by-energy provided to the grid, the owner needs to bid into the market with a price equal to or greater than the breakeven price to make expected profits.

In the CAISO market, the real-time di spatch is paid-by-energy. However, the regulation service is paid-by-capacity. If one bids in $4 \mathrm{MW}$ to the regulation market, then he is paid for $4 \mathrm{MW}$ for the hours that are bid for the service. Even if the battery actually runs at a lower power output during the hour, it still collects the revenue as if it ran at $4 \mathrm{MW}$ for the whole hour.

In $t$ his s ection, the $t$ wo $p$ ricing $s$ chemes $f$ or regulation are $\mathrm{c}$ ompared $\mathrm{f}$ or $\mathrm{t}$ he $\mathrm{r}$ egulation service provided by the NaS battery: pay-by-energy and pay-by-capacity. Using the simulation results obtained in Section 3.4, an economic analysis was performed on the pay-by-capacity pricing scheme. Note that in the pay-by-energy pricing scheme, the energy is a ctual energy provided to the grid; in the pay-by-capacity pricing scheme, the energy is the total capacity the battery provides to the grid.

$$
\begin{aligned}
& E_{\text {life }}^{\text {actual }}=L_{y} P_{\text {ave }} \times 24 \times 365 \\
& E_{\text {life }}^{\text {Cap }}=L_{y} P_{\text {rated }} \times 24 \times 365
\end{aligned}
$$

where:

$$
\begin{aligned}
& E_{\text {life }}^{\text {actual }} \text { is the actual energy provided in a battery lifetime (MWh) } \\
& E_{\text {life }}^{\text {Cap }} \text { is total capacity the battery provides to the grid in it lifetime (MWh). }
\end{aligned}
$$

With current technology, the battery's rated-power out put is $4 \mathrm{M} \mathrm{W}$. As shown in Table 21 , if the battery is paid-by-capacity in the regulation market, the high-end cost will be $\$ 26 / \mathrm{MW}$ and the low-end cost will be $\$ 16 / \mathrm{MW}$. In the California market, this means that the regulation service provided by the NaS battery may become profitable. 
Table 21: The breakeven price comparison between pay-by-energy and pay-by-capacity

\begin{tabular}{|c|c|c|c|c|c|c|c|c|c|c|c|c|c|c|c|c|}
\hline & & \multirow{2}{*}{\multicolumn{5}{|c|}{$\begin{array}{l}\text { High-end Pay-by-Capacity } \\
\text { (\$/MW) } \\
\text { DOD }\end{array}$}} & \multirow{2}{*}{\multicolumn{5}{|c|}{$\begin{array}{l}\text { Low-end Pay-by-Capacity } \\
\text { (\$/MW) } \\
\text { DOD }\end{array}$}} & \multicolumn{5}{|c|}{ Adjusted Life Time (Year) } \\
\hline & \multirow{2}{*}{$\begin{array}{l}\mathbf{P}_{\text {rated }} \\
\text { (MW) }\end{array}$} & & & & & & & & & & & & & DOD & & \\
\hline & & 1 & 0.8 & 0.6 & 0.4 & 0.2 & 1 & 0.8 & 0.6 & 0.4 & 0.2 & 1 & 0.8 & 0.6 & 0.4 & 0.2 \\
\hline \multirow[t]{2}{*}{ Regulation } & 4 & 26 & 26 & 26 & 26 & 26 & 16 & 16 & 16 & 16 & 16 & 20 & 20 & 20 & 20 & 20 \\
\hline & 8 & 15 & 14 & 13 & 13 & 13 & 9 & 9 & 8 & 8 & 8 & 14 & 16 & 20 & 20 & 20 \\
\hline \multirow{3}{*}{$\begin{array}{c}20 \% \\
\text { Renew ables }\end{array}$} & 12 & 12 & 10 & 10 & 9 & 9 & 8 & 7 & 6 & 5 & 5 & 10 & 12 & 15 & 20 & 20 \\
\hline & 16 & 10 & 9 & 8 & 7 & 7 & 6 & 6 & 5 & 4 & 4 & 8 & 10 & 12 & 15 & 20 \\
\hline & 20 & 9 & 8 & 7 & 6 & 5 & 6 & 5 & 5 & 4 & 3 & 7 & 8 & 9 & 13 & 20 \\
\hline \multirow{8}{*}{$\begin{array}{l}\text { Regulation } \\
\text { No-w ind }\end{array}$} & 4 & 26 & 26 & 26 & 26 & 26 & 16 & 16 & 16 & 16 & 16 & 20 & 20 & 20 & 20 & 20 \\
\hline & 8 & 15 & 14 & 13 & 13 & 13 & 9 & 9 & 8 & 8 & 8 & 14 & 16 & 19 & 20 & 20 \\
\hline & 12 & 12 & 11 & 10 & 9 & 9 & 8 & 7 & 6 & 6 & 5 & 9 & 11 & 13 & 18 & 20 \\
\hline & 16 & 10 & 10 & 9 & 7 & 7 & 7 & 6 & 6 & 5 & 4 & 7 & 8 & 10 & 14 & 20 \\
\hline & 20 & 9 & 9 & 8 & 7 & 5 & 6 & 6 & 5 & 4 & 3 & 6 & 7 & 8 & 11 & 19 \\
\hline & & \multicolumn{5}{|c|}{$\begin{array}{l}\text { High-end Pay-by-Energy } \\
\text { (\$/MWh) }\end{array}$} & \multicolumn{5}{|c|}{$\begin{array}{l}\text { Low-end Pay-by-Energy } \\
\text { (\$/MWh) }\end{array}$} & \multicolumn{5}{|c|}{ Adjusted Life Time (Year) } \\
\hline & \multirow{2}{*}{$\begin{array}{c}\mathbf{P}_{\text {rated }} \\
(\mathrm{MW})\end{array}$} & \multicolumn{5}{|c|}{ DOD } & \multicolumn{5}{|c|}{ DOD } & \multicolumn{5}{|c|}{ DOD } \\
\hline & & 1 & 0.8 & 0.6 & 0.4 & 0.2 & 1 & 0.8 & 0.6 & 0.4 & 0.2 & 1 & 0.8 & 0.6 & 0.4 & 0.2 \\
\hline \multirow[t]{2}{*}{ Regulation } & 4 & 197 & 206 & 204 & 198 & 238 & 86 & 90 & 89 & 86 & 104 & 20 & 20 & 20 & 20 & 20 \\
\hline & 8 & 112 & 106 & 103 & 119 & 124 & 50 & 47 & 45 & 52 & 54 & 14 & 16 & 20 & 20 & 20 \\
\hline \multirow{3}{*}{$\begin{array}{c}20 \% \\
\text { Renew ables }\end{array}$} & 12 & 89 & 89 & 86 & 80 & 87 & 41 & 40 & 38 & 35 & 38 & 10 & 12 & 15 & 20 & 20 \\
\hline & 16 & 84 & 79 & 73 & 67 & 68 & 39 & 37 & 33 & 30 & 30 & 8 & 10 & 12 & 15 & 20 \\
\hline & 20 & 77 & 71 & 65 & 60 & 57 & 37 & 33 & 30 & 27 & 25 & 7 & 8 & 9 & 13 & 20 \\
\hline \multirow{5}{*}{$\begin{array}{l}\text { Regulation } \\
\text { No-w ind }\end{array}$} & 4 & 135 & 137 & 137 & 135 & 144 & 83 & 84 & 84 & 83 & 88 & 20 & 20 & 20 & 20 & 20 \\
\hline & 8 & 77 & 73 & 71 & 72 & 79 & 49 & 46 & 44 & 44 & 48 & 14 & 16 & 19 & 20 & 20 \\
\hline & 12 & 63 & 60 & 55 & 52 & 55 & 41 & 39 & 35 & 32 & 34 & 9 & 11 & 13 & 18 & 20 \\
\hline & 16 & 56 & 52 & 48 & 45 & 43 & 37 & 34 & 31 & 28 & 27 & 7 & 8 & 10 & 14 & 20 \\
\hline & 20 & 52 & 48 & 44 & 40 & 37 & 35 & 32 & 29 & 25 & 23 & 6 & 7 & 8 & 11 & 19 \\
\hline
\end{tabular}




\subsection{Conclusions}

The conclusions of the study are summarized as follows:

- If manufacturers can improve the NaS battery lifecycles at high DODs, as shown by the red line in Figure 36, the breakeven price will drop significantly for high DOD c ases. The results are compared in Figure 36.

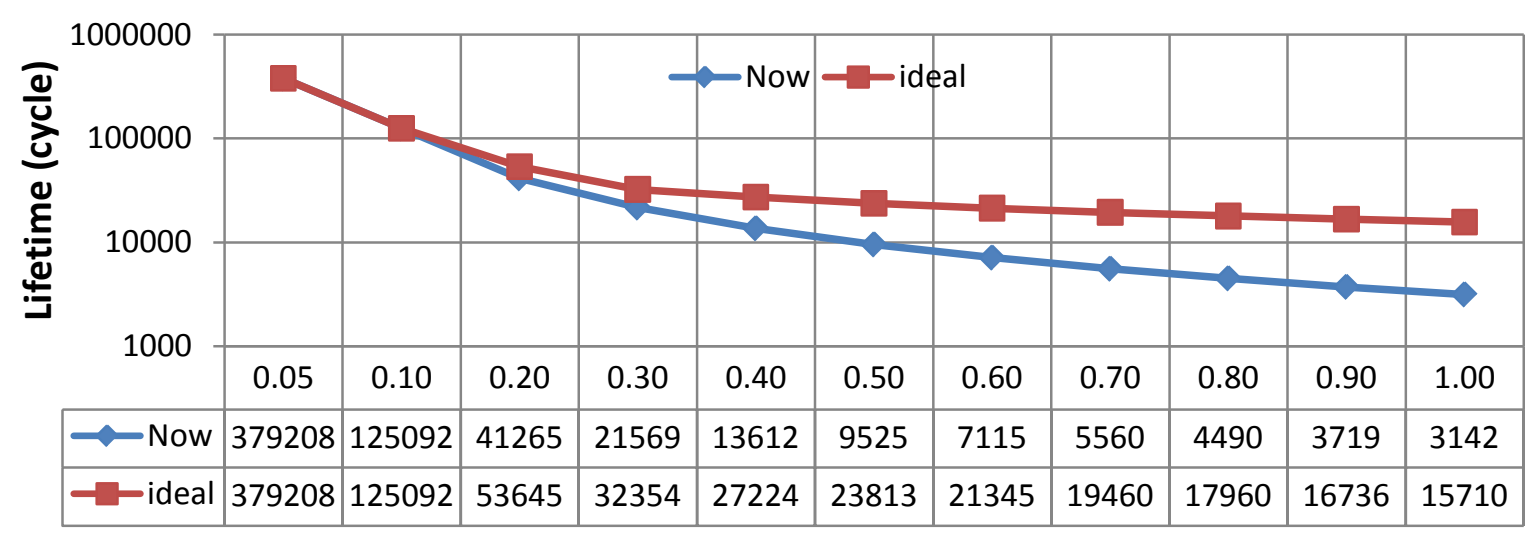

Depth of Discharge

Figure 36: The battery lifetime with respect to the depth of discharge

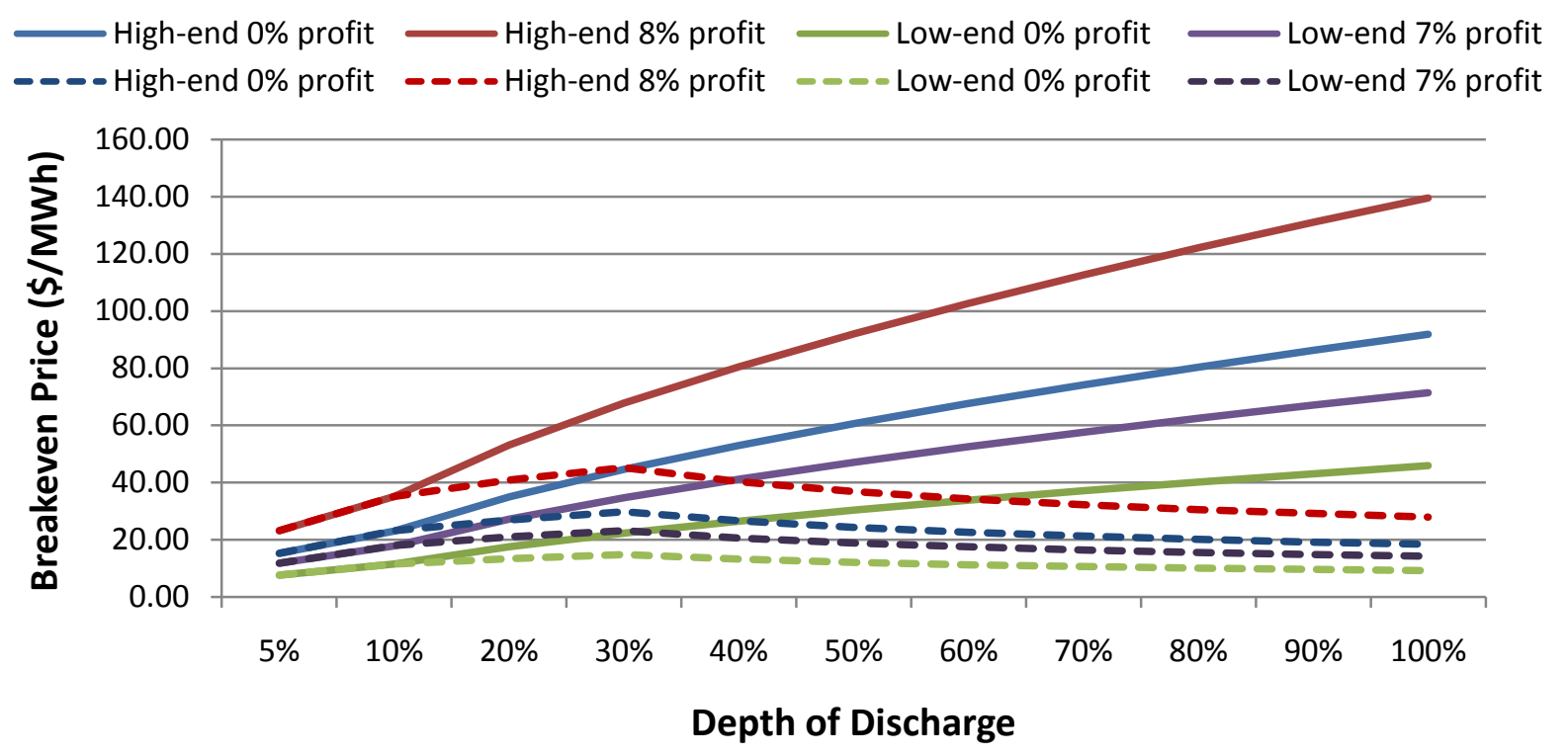

Figure 37: A comparison of high-end and low-end breakeven prices of the improved battery lifecycle case (dashed lines) and the base case (solid lines) 
- Under the pay-by-energy scheme for regulation and real-time dispatch services breakeven prices are above $\$ 100 / \mathrm{MWh}$, making the op eration not e conomical in the $\mathrm{C}$ alifornia market, for a 4 MW, 28 MWh NaS battery (see Table 22).

Table 22: The breakeven prices, utilization rates, and battery lifetimes (Pay-by-energy)

\begin{tabular}{|c|c|c|c|c|c|c|c|c|c|c|c|c|c|c|c|c|}
\hline \multicolumn{7}{|c|}{ Breakeven Price (8\% Profit) (\$MWh) } & \multirow{2}{*}{\multicolumn{5}{|c|}{$\begin{array}{c}\text { Utilization Rate }\left(P_{\text {ave }} / P_{\text {rated }}\right) \\
\text { DOD }\end{array}$}} & \multicolumn{5}{|c|}{ Adjusted Life Time (Year) } \\
\hline & \multirow{2}{*}{$\begin{array}{l}P_{\text {rated }} \\
\text { (MW) }\end{array}$} & \multicolumn{5}{|c|}{ DOD } & & & & & & \multicolumn{5}{|c|}{ DOD } \\
\hline & & 1 & 0.8 & 0.6 & 0.4 & 0.2 & 1 & 0.8 & 0.6 & 0.4 & 0.2 & 1 & 0.8 & 0.6 & 0.4 & 0.2 \\
\hline \multirow[t]{5}{*}{ Regulation } & 4 & 197 & 206 & 204 & 198 & 238 & 0.18 & 0.17 & 0.17 & 0.18 & 0.15 & 20 & 20 & 20 & 20 & 20 \\
\hline & 8 & 112 & 106 & 103 & 119 & 124 & 0.18 & 0.18 & 0.17 & 0.15 & 0.14 & 14 & 16 & 20 & 20 & 20 \\
\hline & 12 & 89 & 89 & 86 & 80 & 87 & 0.18 & 0.16 & 0.15 & 0.15 & 0.13 & 10 & 12 & 15 & 20 & 20 \\
\hline & 16 & 84 & 79 & 73 & 67 & 68 & 0.15 & 0.15 & 0.15 & 0.14 & 0.13 & 8 & 10 & 12 & 15 & 20 \\
\hline & 20 & 77 & 71 & 65 & 60 & 57 & 0.15 & 0.15 & 0.15 & 0.14 & 0.12 & 7 & 8 & 9 & 13 & 20 \\
\hline \multirow{2}{*}{$\begin{array}{l}\text { Real-time } \\
\text { Dispatch }\end{array}$} & 4 & 164 & 169 & 183 & 203 & 270 & 0.15 & 0.15 & \begin{tabular}{|l|}
0.14 \\
\end{tabular} & 0.12 & 0.09 & 20 & 20 & 20 & 20 & 20 \\
\hline & 8 & 97 & 101 & 114 & 135 & 189 & 0.13 & 0.12 & 0.11 & 0.09 & 0.07 & 19 & 20 & 20 & 20 & 20 \\
\hline \multirow{3}{*}{$\begin{array}{c}20 \% \\
\text { Renew ables }\end{array}$} & 12 & 82 & 83 & 90 & 108 & 148 & 0.11 & 0.10 & \begin{tabular}{|l|}
0.09 \\
\end{tabular} & 0.08 & 0.06 & 15 & 19 & 20 & 20 & 20 \\
\hline & 16 & 74 & 73 & 77 & 95 & 125 & 0.10 & 0.09 & \begin{tabular}{|l|}
0.08 \\
\end{tabular} & 0.07 & 0.05 & 13 & 16 & 20 & 20 & 20 \\
\hline & 20 & 68 & 68 & 70 & 83 & 110 & 0.09 & 0.08 & 0.07 & 0.06 & 0.05 & 11 & 14 & 19 & 20 & 20 \\
\hline \multirow{5}{*}{$\begin{array}{l}\text { Regulation } \\
\text { No-wind }\end{array}$} & 4 & 135 & 137 & 137 & 135 & 144 & 0.18 & 0.18 & 0.18 & 0.18 & 0.17 & 20 & 20 & 20 & 20 & 20 \\
\hline & 8 & 77 & 73 & 71 & 72 & 79 & 0.18 & 0.18 & 0.18 & 0.17 & 0.16 & 14 & 16 & 19 & 20 & 20 \\
\hline & 12 & 63 & 60 & 55 & 52 & 55 & 0.18 & 0.17 & 0.17 & 0.16 & 0.15 & 9 & 11 & 13 & 18 & 20 \\
\hline & 16 & 56 & 52 & 48 & 45 & 43 & 0.17 & 0.17 & 0.17 & 0.16 & 0.14 & 7 & 8 & 10 & 14 & 20 \\
\hline & 20 & 52 & 48 & 44 & 40 & 37 & \begin{tabular}{l|l|}
0.17 \\
\end{tabular} & 0.17 & 0.16 & 0.16 & 0.14 & 6 & 7 & 8 & 11 & 19 \\
\hline \multirow{5}{*}{$\begin{array}{l}\text { Real-time } \\
\text { Dispatch } \\
\text { No-wind }\end{array}$} & 4 & 177 & 179 & 201 & 229 & 303 & 0.14 & 0.14 & 0.12 & 0.11 & 0.08 & 20 & 20 & 20 & 20 & 20 \\
\hline & 8 & 108 & 115 & 128 & 151 & 219 & 0.12 & 0.11 & 0.10 & 0.08 & 0.06 & 20 & 20 & 20 & 20 & 20 \\
\hline & 12 & 86 & 90 & 101 & 121 & 172 & 0.10 & 0.09 & 0.08 & 0.07 & 0.05 & 16 & 20 & 20 & 20 & 20 \\
\hline & 16 & 77 & 79 & 87 & 109 & 147 & 0.09 & 0.08 & 0.07 & 0.06 & 0.04 & 14 & 17 & 20 & 20 & 20 \\
\hline & 20 & 72 & 74 & 78 & 96 & 129 & 0.08 & 0.07 & 0.06 & 0.05 & 0.04 & 12 & 16 & 20 & 20 & 20 \\
\hline
\end{tabular}


- Under the pay-by-capacity scheme for r egulation services, the battery has a 1 onger 1 ife and a lower cost when it runs at lower DODs (see Table 23). With current technology, the battery's rated power output is $4 \mathrm{M} \mathrm{W}$. T he $\mathrm{r}$ esults i ndicate that i $\mathrm{ft}$ he $4 \mathrm{MW}$ battery provides on edirectional regulation service, the high-end cost will be $\$ 26 / \mathrm{MW}$ and the low-end cost will be $\$ 16 / \mathrm{MW}$. In the California market, this means the NaS battery may become marginally profitable.

Table 23: The breakeven price comparison between pay-by-energy and pay-by-capacity

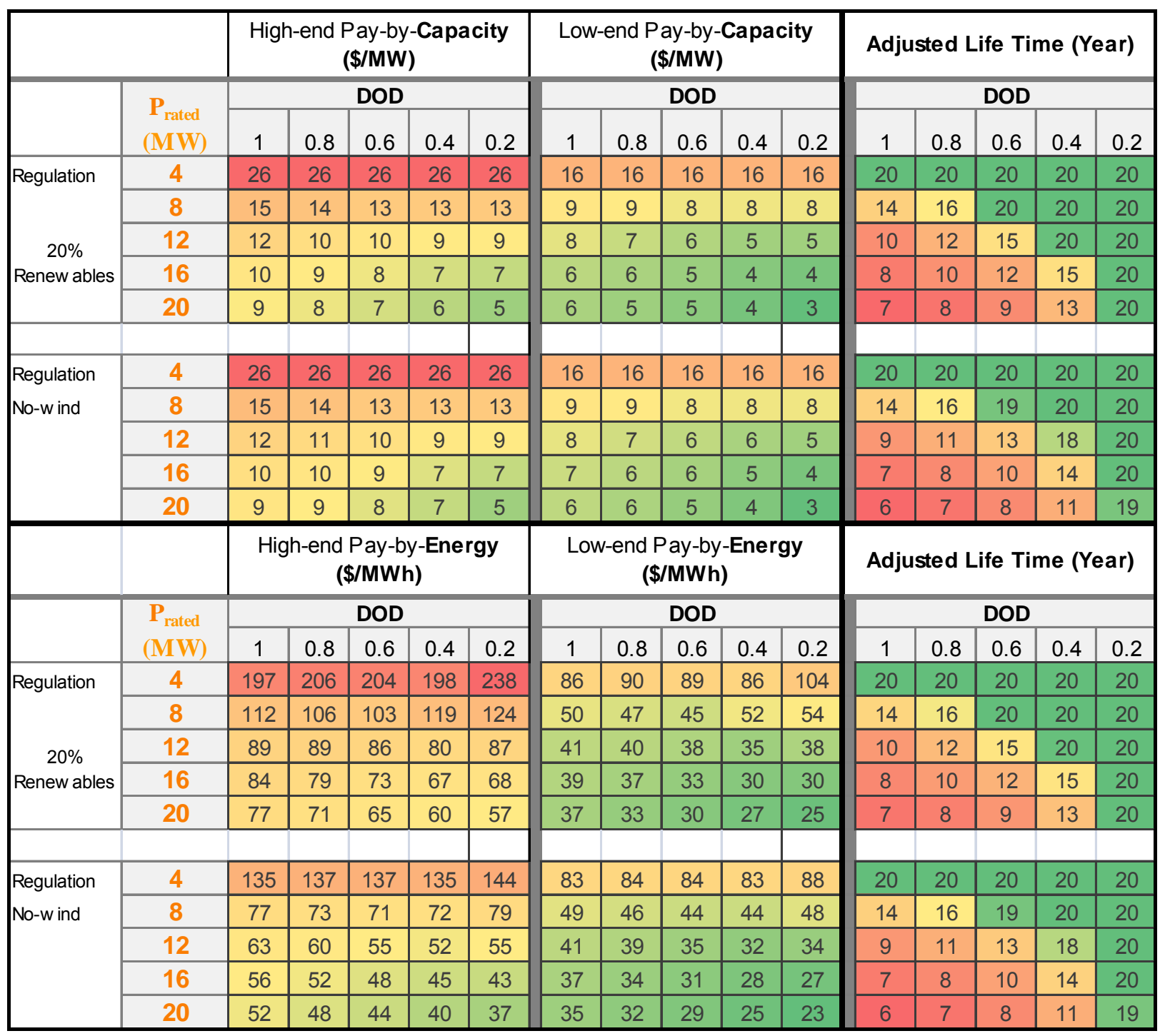


- The breakeven price will drop significantly if the battery's rated-power output can be increased (Table 22, Table 23 and Figure 38) b ecause the ba ttery is ab le to handle a b roader $r$ ange of signals. H owever, above $12 \mathrm{M} \mathrm{W}$, the p rice de cline is not significant, $\mathrm{b}$ ut the ba ttery life is shortened dramatically. Therefore, if ba ttery m anufacturers i ncrease the ba ttery's $r$ ated-power output up to 8 or $12 \mathrm{MW}$ breakeven price could decline $1 / 2$ to $2 / 3$ based on the current lifecycleDOD curve.

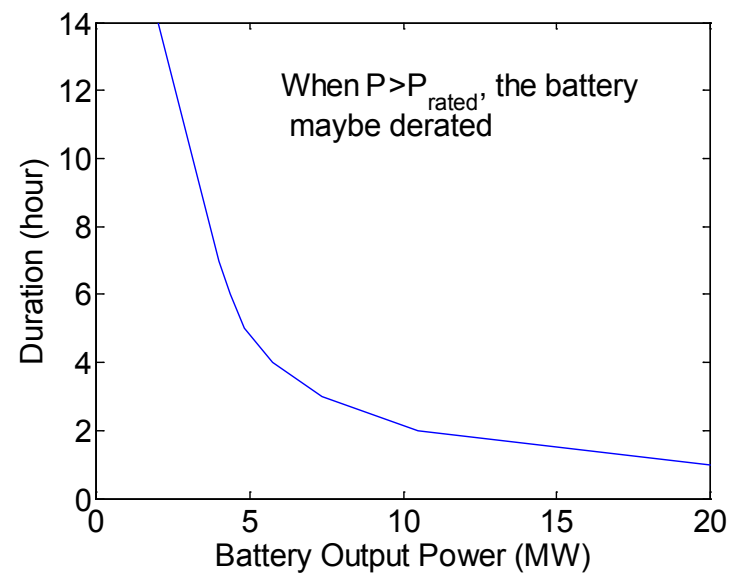

Figure 38: The $28 \mathrm{MWh}$ NaS battery capacity to power ratio

- At higher-rated power, there is a tradeoff between the depth of discharge (DOD) and battery life (see Table 22 and Table 23 ). At $4 \mathrm{M} \mathrm{W}$, the DOD does not result in a shortened ba ttery 1 ife because the $28 \mathrm{MWh}$ battery is underused when providing the regulation. At $20 \mathrm{MW}$, however, the battery lives are significantly shorter at higher DODs.

- The NaS battery provides almost the same amount of regulation or real-time dispatch services for the "with $20 \%$ renewables" and "without wind" cases. Thus, the breakeven prices were similar. More batteries contribute greater ancillary service capacity and therefore, allow more intermittent generation resources to connect to the power grid. However, the amount of regulation and realtime dispatch services that an individual battery provides depends mainly on its power rating. For the "with $20 \%$ r enewables" and "without wind" cas es, signals sent to the NaS battery ar e all within its rated power output $\pm 4 \mathrm{MW}$. For example, although $193 \mathrm{MW}$ are needed for regulation without wind, and $248 \mathrm{MW}$ are needed for regulation with $20 \%$ renewable, for the $4 \mathrm{M} \mathrm{W} \mathrm{NaS}$ battery, it provides services within $\pm 4 \mathrm{MW}$ in bo th cases; therefore, the a mounts of e nergy provided in both cases are similar.

- The regulation and real-time dispatch signals sent to the $\mathrm{NaS}$ battery are scaled total regulation and real-time dispatch signals, so that the signals are within the battery rated power output, for example, $\pm 4 \mathrm{MW}$. As shown in Figure 39, for the case in which $50 \%$ of the time, the normalized signal is out side $\pm 4 \mathrm{MW}$, the battery a verage pow er out put is much higher than that of the $5 \%$ case, resulting in more economical services (see Table 24). For the $50 \%$ of signals ou tside the battery's ca pability, the r egulation and real-time s ignals $\mathrm{c}$ an be provided $\mathrm{m}$ ore e fficiently by storage devices that ha ve high power ou tputs but l ess ene rgy st orage capa cities, for ex ample, flywheels. 


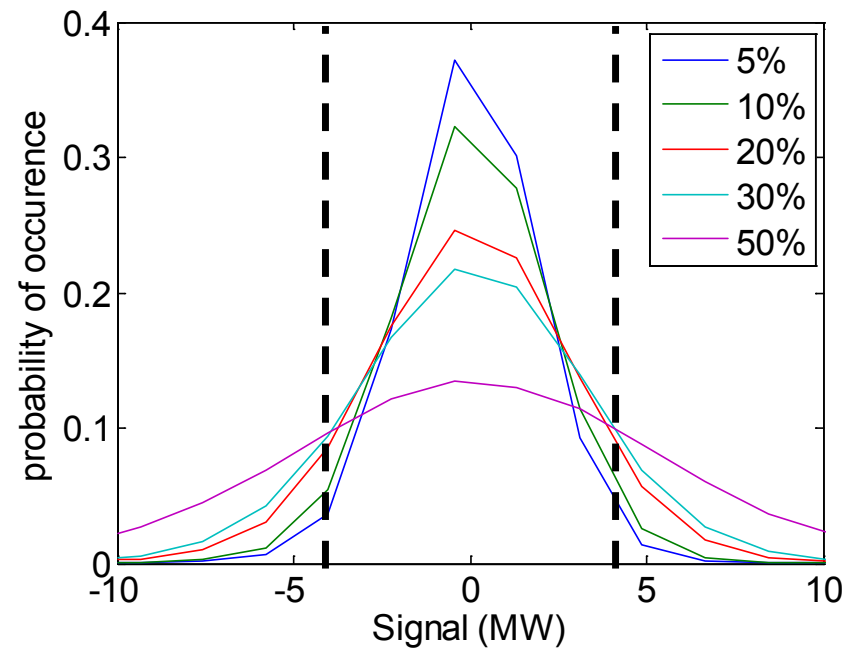

Figure 39: The probability distribution functions of the regulation signals

Table 24: A comparison of breakeven prices for different normalized signals

\begin{tabular}{|c|c|c|c|c|c|c|c|c|c|c|c|}
\hline \multicolumn{7}{|c|}{ Breakeven Price (High End) } & \multicolumn{5}{|c|}{ Breakeven Price (Low End) } \\
\hline & \multirow{2}{*}{$\begin{array}{c}\text { Signal } \\
\text { Outliers }\end{array}$} & \multicolumn{5}{|c|}{ DOD } & \multicolumn{5}{|c|}{ DOD } \\
\hline & & 1 & 0.8 & 0.6 & 0.4 & 0.2 & 1 & 0.8 & 0.6 & 0.4 & 0.2 \\
\hline \multirow[t]{2}{*}{ Regulation } & $5 \%$ & 197 & 206 & 204 & 198 & 238 & 101 & 105 & 104 & 101 & 122 \\
\hline & $10 \%$ & 175 & 177 & 176 & 171 & 203 & 90 & 90 & 90 & 87 & 104 \\
\hline \multirow{3}{*}{$\begin{array}{c}20 \% \\
\text { Renewables }\end{array}$} & $20 \%$ & 138 & 140 & 135 & 148 & 160 & 71 & 72 & 69 & 76 & 82 \\
\hline & $30 \%$ & 131 & 129 & 127 & 143 & 146 & 67 & 66 & 65 & 73 & 75 \\
\hline & $50 \%$ & 112 & 105 & 101 & 112 & 116 & 59 & 55 & 52 & 57 & 60 \\
\hline & & & & & & & & & & & \\
\hline \multirow{3}{*}{$\begin{array}{l}\text { Realtime } \\
\text { Dispatch }\end{array}$} & $5 \%$ & 231 & 238 & 257 & 285 & 381 & 118 & 122 & 132 & 146 & 195 \\
\hline & $10 \%$ & 205 & 217 & 228 & 270 & 355 & 105 & 111 & 117 & 138 & 182 \\
\hline & $20 \%$ & 174 & 181 & 195 & 231 & 308 & 89 & 93 & 100 & 118 & 158 \\
\hline \multirow{2}{*}{$\begin{array}{c}20 \% \\
\text { Renewables }\end{array}$} & $30 \%$ & 151 & 159 & 177 & 204 & 278 & 77 & 82 & 91 & 104 & 142 \\
\hline & $50 \%$ & 135 & 142 & 155 & 180 & 239 & 70 & 73 & 79 & 92 & 123 \\
\hline \multirow{5}{*}{$\begin{array}{l}\text { Regulation } \\
\text { No-wind }\end{array}$} & 10 & 191 & 193 & 193 & 190 & 202 & 98 & 99 & 99 & 97 & 104 \\
\hline & $10 \%$ & 175 & 172 & 175 & 172 & 185 & 90 & 88 & 89 & 88 & 95 \\
\hline & $20 \%$ & 144 & 144 & 143 & 149 & 156 & 74 & 74 & 73 & 76 & 80 \\
\hline & $30 \%$ & 132 & 131 & 129 & 140 & 144 & 68 & 67 & 66 & 72 & 74 \\
\hline & $50 \%$ & 117 & 112 & 108 & 113 & 119 & 61 & 58 & 55 & 58 & 61 \\
\hline & & & & & & & & & & & \\
\hline \multirow{5}{*}{$\begin{array}{l}\text { Realtime } \\
\text { Dispatch } \\
\text { No-wind }\end{array}$} & $5 \%$ & 249 & 251 & 283 & 322 & 426 & 128 & 129 & 145 & 165 & 218 \\
\hline & $10 \%$ & 217 & 226 & 254 & 285 & 387 & 111 & 116 & 130 & 146 & 198 \\
\hline & $20 \%$ & 183 & 201 & 219 & 250 & 339 & 94 & 103 & 112 & 128 & 174 \\
\hline & $30 \%$ & 167 & 183 & 193 & 224 & 312 & 86 & 94 & 99 & 115 & 160 \\
\hline & $50 \%$ & 143 & 147 & 161 & 192 & 267 & 73 & 75 & 82 & 98 & 137 \\
\hline
\end{tabular}


Future research should focus on the economics of the combined services of batteries. By bidding into the e nergy, r egulation, r eal-time di spatch, and reserve $m$ arkets, the ba ttery ow ner $\mathrm{c}$ an collect revenue from different markets, likely resulting in a more economical operation than bidding in a single market. However, providing multiple services requires an optimization on the battery's commitment schedule. To address these optimal op eration strategies, a battery commitment problem needs to be well defined and solved. 


\subsection{References}

[1] J. Waters. 2001. News Release: AEP Tests Sodium Sulfur Battery's Electric Storage Capabilities. American Electric Power Co, Inc: 22 March, 2001. Columbus, Ohio. Available online: http://www.aep.com/newsroom/newsreleases/?id=790

[2] P. Davidson. 2007. "New battery packs powerful punch.” USA TODAY. Available online: http://www.usatoday.com/money/industries/energy/2007-07-04-sodium-battery N.htm

[3] Wikipedia, 2009. "Net present value." Available online: http://en.wikipedia.org/wiki/Net_present_value.

[4] C.T. Horngren, G.L. Sundem, W.O. Stratton. 2002. "Introduction to Management Accounting." Prentice Hall.

[5] Y.V. Makarov, C. Loutan, J. Ma, and P. de Mello. 2009. "Operational impacts of wind generation in California power system.” IEEE Transactions on Power Systems. 24(2): 1039-1050.

[6] Y.V. Makarov, P. Nyeng, B. Yang, J. Ma, J.G. DeSteese, D.J. Hammerstrom, S. Lu, V.V. Viswanathan, and C.H. Miller. 2008. Wide-Area Energy Storage and Management System to Balance Intermittent Resources in the Bonneville Power Administration and California ISO Control Areas. PNNL-17574. Pacific Northwest National Laboratory, Richland, WA.

[7] Viswanathan V.V. October 2007. "Cycle life DOD.xls.” Pacific Northwest National Laboratory. Available on request.

[8] R. Walawalkar and J Apt. 2008. Market Analysis of Emerging Electric Storage Systems. DOE/NETL2008/1330. U.S. Department of Energy, National Energy Technology Laboratory, Morgantown WV.

[9] Office and Management and Budget. October 1992. "Guidelines and Discount Rates for Benefit-Cost Analysis of Federal Programs.” Circular A-94. Washington, D.C.

[10] Office of Management and Budget. December 2008. "Appendix C - Discount Rates for CostEffectiveness, Lease Purchase, and Related Analyses, OMB Circular No. A-94.” Washington, D.C.

[11] California Independent System Operator Renewables Workgroup. 2007. "Methodology to Evaluate the Impacts of Wind Generation on California ISO's Regulation and Load Following Requirements Under MRTU," in Integration of Renewable Resources Report - Transmission and Operating Issues and Recommendations for Integrating Renewable Resources on the California ISO-Controlled Grid, California Independent System Operator (CAISO) Report. Available online:

http://www.caiso.com/1ca5/1ca5a7a026270.pdf. 